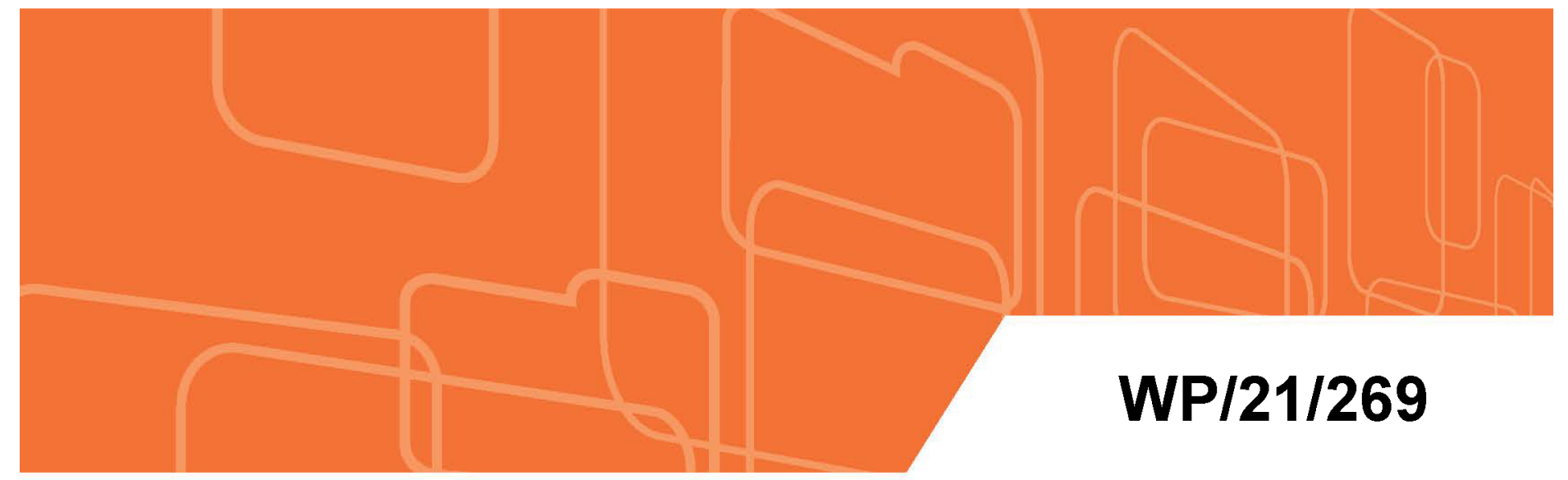

\title{
Gender Budgeting in G20 Countries
}

by Virginia Alonso-Albarran, Teresa Curristine, Gemma Preston, Alberto Soler, Nino Tchelishvili, and Sureni Weerathunga

IMF Working Papers describe research in progress by the author(s) and are published to elicit comments and to encourage debate. The views expressed in IMF Working Papers are those of the author(s) and do not necessarily represent the views of the IMF, its Executive Board, or IMF management.

$$
\text { I N T E R N A T I O N A L }
$$




\title{
IMF Working Paper
}

\author{
Fiscal Affairs Department
}

\section{Gender Budgeting in $\mathbf{6 2 0}$ Countries}

\author{
Prepared By Virginia Alonso-Albarran, Teresa Curristine, Gemma Preston, Alberto Soler, \\ Nino Tchelishvili, and Sureni Weerathunga \\ Authorized for distribution by Katherine Baer
}

November 2021

IMF Working Papers describe research in progress by the author(s) and are published to elicit comments and to encourage debate. The views expressed in IMF Working Papers are those of the author(s) and do not necessarily represent the views of the IMF, its Executive Board, or IMF management.

\begin{abstract}
Achieving gender equality remains a significant challenge, that has only deepened with the on-set of the COVID-19 pandemic. Gender budgeting (GB) can help promote gender equality by applying a gender perspective to fiscal policies and the budget process. This paper takes stock of GB practices in G20 countries and benchmarks country performance using a GB index and data gathered from an IMF survey. All G20 countries have enacted gender focused fiscal policies but the public financial management (PFM) tools to operationalize these policies are far less established. We find that notwithstanding heterogeneity across countries, the average G20 level of GB practice is relatively low. More progress has been made establishing GB frameworks and budget preparation tools than with budget execution, monitoring and auditing. Too few countries assess the upfront impact of policies on gender and/or evaluate ex-post the effectiveness of policies and programs. Where GB features are in place, they tend to operate as an 'add-on', rather than a strategic and integral part of resource allocation decisions. Progress with GB does not appear to be dependent on the level of country development. Key to future efforts will be harnessing opportunities for integrating GB tools into existing PFM systems and more closely linking GB initiatives with PFM reforms.
\end{abstract}

JEL Classification Numbers: E60, H11, H5, H61, H83, J16, J38

Keywords: G20, Gender Equality, Gender Budgeting, Public Financial Management Author's E-Mail Address: valonsoalbarran@imf.org; tcurristine@imf.org; gpreston@imf.org; asoler@imf.org; ntchelishvili@imf.org, and sweerathunga@imf.org. 
ABSTRACT

\section{TRENDS IN GENDER EQUALITY AND GENDER RESPONSIVE FISCAL POLICIES IN G20} COUNTRIES

III. TRENDS AND APPROACHES IN GENDER BUDGETING

A. The Evolution of Gender Budgeting

B. The IMF Gender Budgeting Approach and Framework $\underline{12}$

IV. STATUS OF GENDER BUDGETING IN G20 COUNTRIES $\frac{13}{13}$

A. Overview of GB practices in the G20 Countries- Gender Budgeting Index $\frac{13}{16}$

B. Detailed Analysis of GB Practices in G20 Countries

\section{BEYOND THE G20 - COMPARING G20 GB PUBLIC FINANCIAL MANAGEMENT PRACTICES WITH OTHER COUNTRIES

VI. IMPLEMENTATION OF GENDER BUDGETING - CHALLENGES AND SUCCESS FACTORS $\underline{\mathbf{2 5}}$

A. Major challenges encountered by countries in GB implementing __________

B. Important Success Factors to Implementing Gender Budgeting ___________ 27

VII. IMPLEMENTATION OF GENDER BUDGETING-THE WAY FORWARD _________ 29

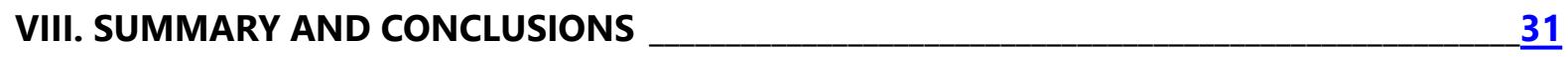

REFERENCES _____________________________________________________________

\section{BOXES}

1. The IMF Survey of National GB practices

2. Summary of Advanced GB PFM Practices and Tools in G20 Countries

\section{FIGURES}

1. Women's Labor Force Participation Rate

2. Proportion of Time Spent on Unpaid Work

3. Gender Pay Gap

4. Women's managerial leadership

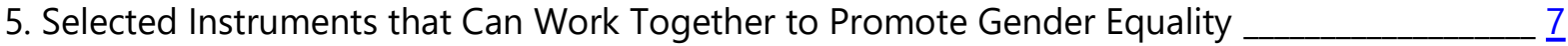

6. A Holistic Approach to GB throughout the Budget Cycle

7. G20 Gender Budgeting Index (GBI) Scores by Countries_________________

8.1. PFM Tools Used to Support GB

8.2. Relative Strengths and Weaknesses of GB Tools Comparing G20 to Other Countries ___ 24

9. PFM Tools to Support Gender Budgeting GBI Scores by Income Group and Region _____

10. Major Challenges Encountered in Successfully Implementing Gender Budgeting ______

11. Most Important Factors that Explain the Successful Implementation of GB ______

12. Impact of Gender Budgeting on Gender Equality 
13. Proposed Sequencing of GB Implementation

\section{TABLES}

1. Gender-Related Fiscal Policies Implemented by G20 Countries

2. Average $\mathrm{GBI}$ Indexes for the $\mathrm{G} 20+$ and by Income Group

3. Heat Map: Level of GB Practices in G20 Countries across the GB Cycle

\section{APPENDICES}

1. Stylized Data on Gender Equality Gaps in G20 Countries $\frac{36}{37}$

2. Gender Budgeting PFM Tools embedded within the Budget Cycle 37

3. Illustrative Example of Specific Gender Budgeting PFM Tools in Action $-\frac{38}{39}$

4. Questionnaire Used to Assess Gender Budgeting in G20 Countries and Gender Index $-\frac{39}{43}$

5. Table of Correlations Between GBI Components

6. Methodology for the Gender Budgeting Index 44

7. A possible Sequencing of GB Reforms 45

8. Q9: Legal provision for Gender Budgeting in G20 Countries 47

9. Gender Budgeting Practices in G20 and Selected Countries 48 


\section{INTRODUCTION ${ }^{1}$}

Achieving gender equality remains a major challenge and important gaps persist - which the COVID-19 pandemic has only exacerbated. Governments have adopted a combination of policies and instruments to help tackle gender inequalities. ${ }^{2}$ The COVID-19 pandemic's impact on women has ignited calls for governments to tailor pandemic and recovery policies to address the augmented challenges women face. Beyond legal and regulatory changes to promote equality in the public and private sector, these include fiscal policies to improve access and opportunities particularly in health and education and to enhance labor market participation.

\section{Gender budgeting (GB) recognizes that government budgets impact men and women}

differently. Policy decisions made by governments can serve to either promote gender equality or reinforce existing inequalities. GB uses fiscal policies and public financial management (PFM) tools to promote gender equality (Stotsky 2016). It incorporates a gender lens into the budget process to ensure that governments are acutely aware of the impact of their choices on gender outcomes. GB is not just about funding explicit gender equality initiatives. It also entails analyzing fiscal policies and budgetary decisions to understand their impact - intended and unintended - on gender equality and using this information to design and implement more effective gender policies.

\section{International recognition for GB as an instrument to enhance gender equality continues to} grow. The United Nation's 1995 Beijing Platform for Action called for integrating a gender perspective into government budget processes. More recently, the UN's 2015 Sustainable Development Goals (SDGs) called for adequate resources and tools to track budget allocations for gender equality (SDG indicator 5.c.1). The 2015 Addis Ababa Action Agenda for Development recognized the importance of tracking resource allocations for gender equality and strengthening capacity for GB. In 2020, G20-Women, an official engagement group to the G20, called for greater investment in GB to ensure that fiscal policies advance gender equality in the short and long-term recovery from the COVID-19 crisis. $^{3}$

\section{This paper examines the status of GB in G20 countries using data obtained from an IMF} survey. The remainder of this paper is divided into the following sections. Section II discusses trends in gender equality and highlights G20 countries' gender responsive fiscal policies. Section III provides a brief history of the GB approaches and presents the holistic IMF GB framework. Section IV

\footnotetext{
${ }^{1}$ The authors would like to thank Johann Seiwald, Jessie Nabulambo Kilembe and Ozlem Aydin for their contributions and comments to earlier versions of the paper and G20 country authorities for their participation in the GB survey.

${ }^{2}$ This reflects an increased understanding of the impact of gender inequalities on society, women's rights and economic growth. For details on how gender inequalities impact economic growth see Elborgh-Woytek and Newiak et al 2013, Kalpana and Jain-Chandra et al 2017, Sahay and Čihák 2018, and Ostry, Alvarez and Espinoza et al 2018.

${ }^{3}$ See also IMF 2021 which calls for countries to deploy gender-responsive policies and budgeting, to help mitigate the impact of COVID-19 on gender equality and to address longer term structural issues.
} 
examines G20 countries GB PFM practices and benchmarks them using a Gender Budget Index (GBI). Section V compares G20 countries' GB practices with those of other countries. Section VI discusses challenges and key success factors with implementing GB. Section VII examines opportunities to improve GB implementation. The final section provides some conclusions.

\section{TRENDS IN GENDER EqUALITY AND GENDER RESPONSIVE FISCAL POLICIES IN G20 COUNTRIES}

Since the Beijing Declaration called for the empowerment of women, progress has been made on many fronts. There has been progress on economic participation, political opportunity, health and education including significant improvements in the enrollment of girls in primary education, enhancement of women's legal rights and reductions in maternal mortality ratios.

Figure 1. Women's labor participation rate remains below men's

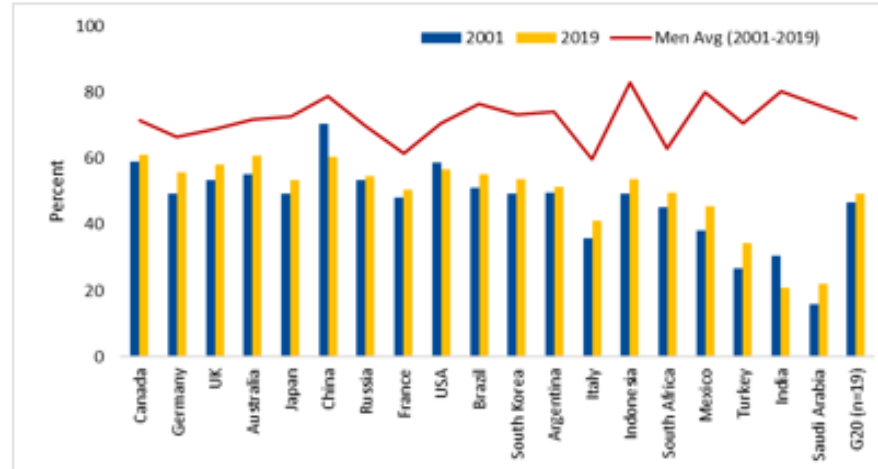

Source: World Bank

Figure 3. The gender pay gap is substantial

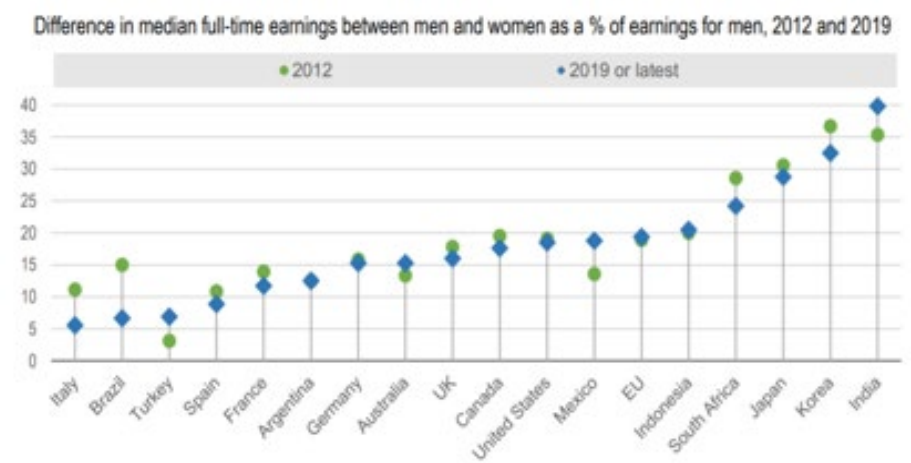

Figure 2. and the burden of unpaid work falls on women

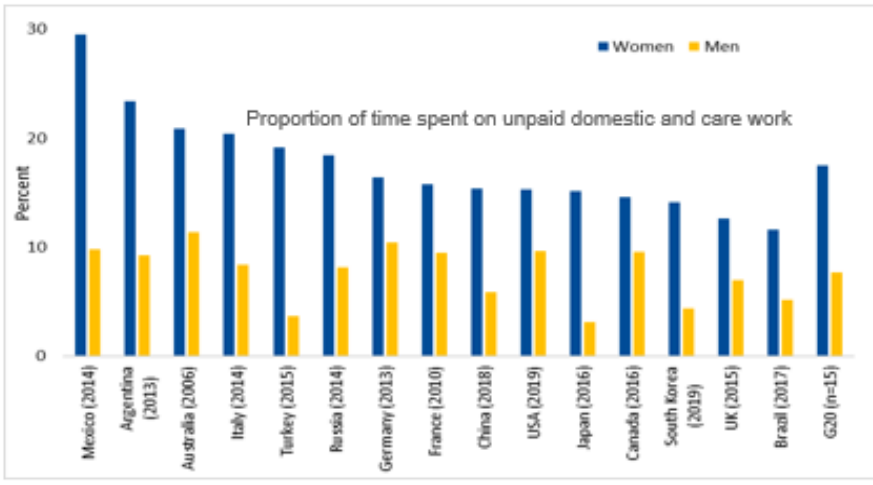

Source: UN Glabal SDG Database

Figure 4. and women's managerial leadership remains below $\mathbf{5 0 \%}$

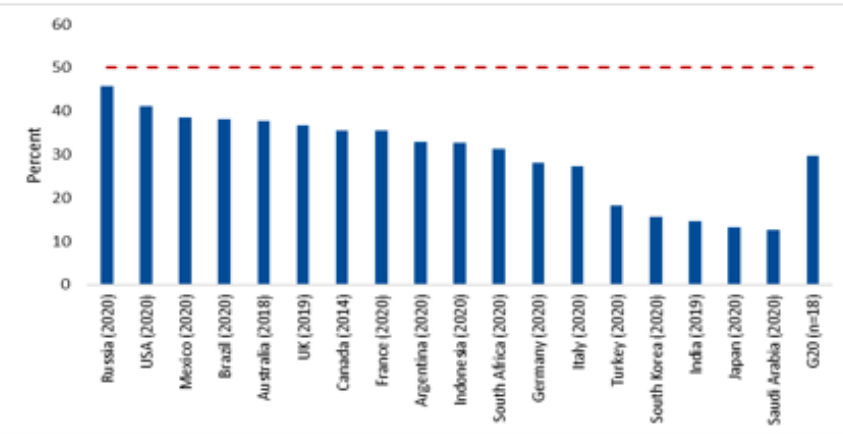

Source: ILO

Source: OECD,2020

However, substantial gender gaps persist and much remains to be done - with COVID-19 only serving to widening these gaps. Despite progress in most $\mathrm{G} 20$ countries $^{4}$ in the last fifteen years, women's participation rate in the workforce on average still remains below that of men (Figure 1).

\footnotetext{
${ }^{4}$ For more details on China see (Brussevich, Dabla-Norris, and Li, 2021).
} 
Women are significantly over-represented in the total number of hours spent on unpaid work (Figure 2). The average gender pay gap has narrowed but remains substantial (Figure 3) and women's managerial leadership remains below 50 percent in all G20 countries (see Figure 4). Appendix 1 provides more information on other gender gaps in G20 countries. The 2021 World Economic Forum Gender Gap report highlighted that at the present pace it will take another 267 years to close the gender gap for economic empowerment.

Closing gender gaps is complex and government policies play an important role - but achieving gender equality also requires progressively shifting cultural and societal norms. Governments can change legislation to improve gender equality and help to end discrimination, introduce public employment practices to encourage the hiring and promotion of women and change government machinery including budget processes. But government action alone cannot succeed in achieving gender equality, especially if countries have strong cultural and social barriers which reinforce inequality. Shifting cultural views and perceptions of women's role in society, can be as influential as government actions in either promoting or blocking gender equality (Fabrizio et al 2020, UNDP 2020). Formal and informal mechanisms are interconnected and can work together to promote gender equality (figure 5). Addressing these barriers is key to achieving successful and sustained change.

Figure 5. Selected Instruments that Can Work Together to Promote Gender Equality

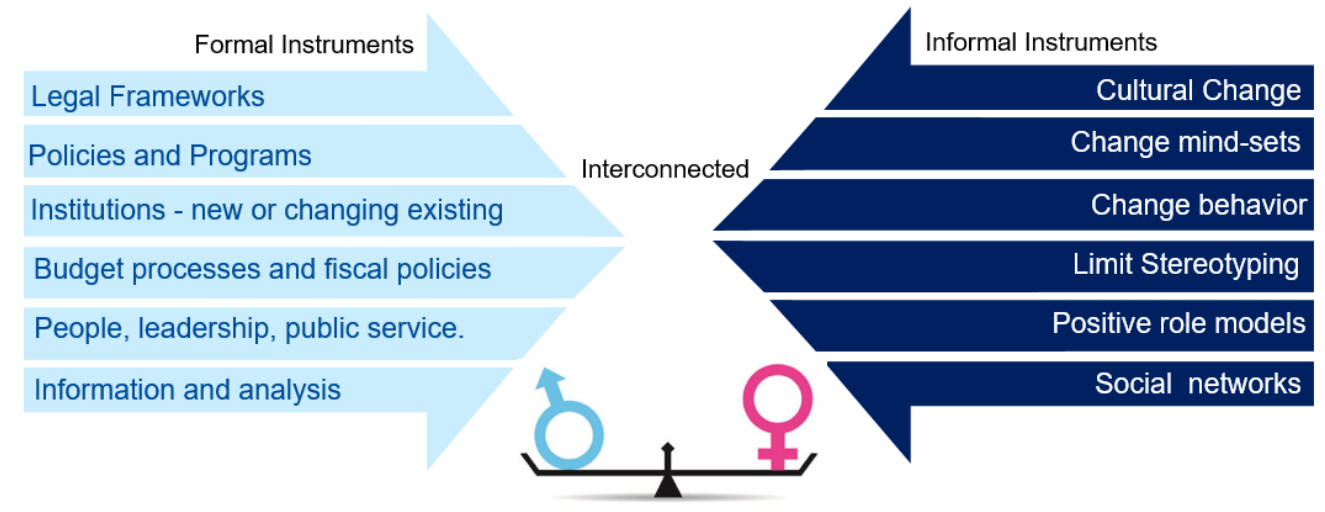

Source: IMF staff.

GB is an important instrument that governments have at their disposal to help promote gender equality and close gender gaps. GB helps to operationalize fiscal policies that promote gender equality. GB can help examine the impact of government policies on gender - and drive more informed decisions. The success of government policies and therefore the impact that GB can have is influenced by many factors including political support for gender equality, the consistency of GB reforms as well as the country's cultural attitudes and social norms.

Targeted fiscal policies are a key mechanism through which governments seek to achieve their gender equality goals and address the gender gaps discussed above. GB can help to 
operationalize these policies. Table 1 summarizes the most common gender responsive fiscal policies in $\mathrm{G} 20$ countries on the expenditure and revenue sides. ${ }^{5}$

Expenditure policies aimed at improving women's labor participation and health and educational outcomes are common among $\mathbf{G 2 0}$ countries. To support the development of women, almost all G20 countries have policies designed to improve women's health needs, provide protection against domestic violence and promote women's educational attainment. Moreover, a majority of countries encourage women to specialize in technical areas which were historically dominated by men, such as science, technology and mathematics. Most countries also provide financial support to help low-income women who face economic difficulties including labor market barriers and single-parent households. Most G20 countries have also made changes to pension systems to make some allowance for contribution gaps as a result of workplace absence due to childcare responsibilities.

For emerging market $\mathbf{6 2 0}$ countries, policies related to secondary and university education, infrastructure and transportation investments have helped more women to enter into paid employment (Fabrizio, Fruttero and Gurara et al 2020). In addition, all G20 donors, except for one, have incorporated gender equality considerations into their foreign cooperation and aid programs.

Tax policies are widely used by $\mathbf{G 2 0}$ countries to help encourage labor market participation. The majority of G20 countries have individual taxation or tax incentives to correct for labor supply distortions stemming from joint family taxation arrangements that disincentivize the second earners' labor participation within households (Bick and Fuchs-Schündeln 2017). Tax relief for single parents has been adopted by around half of countries. However, gender-targeted in-work credits or incentives are only reported by a few countries. For example, in Spain there is a tax deduction for working mothers with children less than 3 years old.

While the majority of G20 countries have policies actively seeking to increase women's participation in the labor market, only a few have policies to promote women into leadership positions. A vast majority of countries promote part-time work, childcare support and paid parental leave for both parents. Promoting childcare is even more important for low-skilled workers, taking into account the higher weight of this cost in their incomes. In the US, families in the bottom quartile of income distribution spend 17.4 percent of their income on childcare compared to 7.8 percent for the top quartile (Herbst 2015). In terms of remuneration, most countries have passed equal pay legislation. Only nine countries, however, have set quotas for women's inclusion in public sector managerial and board positions and only six have quotas for the inclusion of women on private sector boards.

\footnotetext{
${ }^{5}$ This is based on a list of common fiscal policies that intend to promote gender equality and it is not intended to be an exhaustive list. The data in this table is gathered from the IMF survey (See Box 2 for more details).
} 
Table 1. Gender-Related Fiscal Policies Introduced by G20 Countries

\begin{tabular}{|c|c|}
\hline 1. Tax Policies & 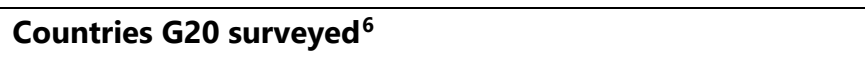 \\
\hline $\begin{array}{l}\text { Tax based on individuals or incentives for the second } \\
\text { earner (as opposed to tax based on family or joint } \\
\text { taxation) }\end{array}$ & $\begin{array}{l}\text { Argentina, Australia, Canada, China, Germany, Italy, Japan, } \\
\text { Russian Federation, S. Korea, Turkey, UK, Austria, Spain. }\end{array}$ \\
\hline Tax relief for single parents or other family situations & $\begin{array}{l}\text { Australia, Canada, France, Germany, Italy, Japan, Russian } \\
\text { Federation, Saudi Arabia, S. Korea, USA, Austria, Spain. }\end{array}$ \\
\hline Gender targeted in-work tax credits or benefits & Saudi Arabia, Turkey, Spain. \\
\hline \multicolumn{2}{|l|}{ 2. Expenditure and regulatory policies } \\
\hline $\begin{array}{l}\text { Public sector gender quotas in managerial/board } \\
\text { positions }\end{array}$ & $\begin{array}{l}\text { Australia, France, Germany, Indonesia, Mexico, South Korea, } \\
\text { Saudi Arabia, South Africa, Austria. }\end{array}$ \\
\hline $\begin{array}{l}\text { Private sector gender quotas in managerial/board } \\
\text { positions }\end{array}$ & France, Germany, Italy, Saudi Arabia, South Africa, Austria. \\
\hline Equal pay legislation & $\begin{array}{l}\text { Australia, Brazil, Canada, France, Germany, Indonesia, Italy, } \\
\text { Japan, Russian Federation, Saudi Arabia, South Africa, S. } \\
\text { Korea, Turkey, UK, Austria. }\end{array}$ \\
\hline Policies to encourage female labor participation & All G20 survey \\
\hline Policies to promote part-time work (women and men) & $\begin{array}{l}\text { Australia, Brazil, Canada, China, Germany, France, Italy, Japan, } \\
\text { Mexico, Russian Federation, Saudi Arabia, South Korea, } \\
\text { Turkey, United Kingdom, United States, Spain. }\end{array}$ \\
\hline \multicolumn{2}{|l|}{ 2. Expenditure and regulatory policies } \\
\hline $\begin{array}{l}\text { Policies to provide financial support for low-income } \\
\text { women }\end{array}$ & $\begin{array}{l}\text { Argentina, Australia, Brazil, Canada, France, Germany, India, } \\
\text { Indonesia, Japan, Mexico, Russian Federation, Saudi Arabia, } \\
\text { South Africa, Turkey, United Kingdom, United States. }\end{array}$ \\
\hline Policies to promote women's education & $\begin{array}{l}\text { Argentina, Australia, Canada, France, Germany, India, } \\
\text { Indonesia, Japan, Mexico, Russian Federation, Saudi Arabia, } \\
\text { South Africa, Turkey, United Kingdom, United States, Austria }\end{array}$ \\
\hline $\begin{array}{l}\text { Policies against stereotypes (i.e. STEM (Science, } \\
\text { Technology, Engineering, Mathematics; managerial } \\
\text { positions) }\end{array}$ & $\begin{array}{l}\text { Argentina, Australia, Brazil, Canada, France, Germany, India, } \\
\text { Italy, Japan, Saudi Arabia, Turkey, United Kingdom, United } \\
\text { States, Spain, Austria }\end{array}$ \\
\hline Policies to promote women's specific health needs & All G20 survey \\
\hline Childcare support & All G20 survey, except US and China (not answered) \\
\hline Paid parental leave (mother) & All G20 survey, except US (not answered) \\
\hline Paid parental leave (father) & All G20 survey, except India, Indonesia, US (not answered) \\
\hline $\begin{array}{l}\text { Gender-related pension reforms (e.g. pensions } \\
\text { incorporating non-contributed periods) }\end{array}$ & $\begin{array}{l}\text { Argentina, Australia, Brazil, France, Germany, Italy, Japan, } \\
\text { Mexico, Russian Federation, Saudi Arabia, South Korea, } \\
\text { Turkey, United States, Spain, Austria }\end{array}$ \\
\hline Policies to counter domestic violence & All G20 survey (China not answered) \\
\hline Gender-responsive foreign aid and cooperation & $\begin{array}{l}\text { Argentina, Australia, Brazil, Canada, France, India, Indonesia, } \\
\text { Italy, Japan, Saudi Arabia, South Korea, United States, Austria, } \\
\text { others through EU cooperation. }\end{array}$ \\
\hline
\end{tabular}

Sources: IMF Staff and IMF Survey 2017 and 2019.

\footnotetext{
${ }^{6}$ Argentina, Australia, Brazil, Canada, China, France, Germany, India, Indonesia, Italy, Japan, Mexico, Russian Federation, Saudi Arabia, South Africa, South Korea, Turkey, United Kingdom, United States, Spain and Austria.
} 


\section{TRendS AND APPROACHES IN Gender BUdgeting}

\section{A. The Evolution of Gender Budgeting}

\section{Countries' interest in GB has grown over time as GB practices have been endorsed in} international fora. It was first introduced in the 1980s by the Australian Government and was subsequently adopted in Canada and South Africa and other Commonwealth countries with the help of the Commonwealth Secretariat. The impetus for GB increased with the 1995 Beijing Platform for Action and in the late 1990s and 2000s the application of GB grew, especially in emerging and developing countries with the support of donors and UN Women. In 2002, at least 40 countries had some form of GB (Budlender 2002) and by 2017 this number doubled to 80, albeit with diverse approaches and varying levels of scope, depth and commitment. GB has also been applied extensively at the state and local levels (e.g. Germany, India, Uganda, Spain and Sweden). The number of OECD countries implementing GB has increased from 12 in 2016 to 17 in 2018.

Since its initial development in the 1980s, the concept of GB has evolved. It has moved from focusing mostly on allocations to "women's issues" or women's programs, towards a broader approach that stresses the importance of bringing a gender perspective and awareness to all government policy, planning and budgeting (Hofbauer 2003; Budlender et al 2002). While there are several definitions in the literature, GB is now widely seen as focusing more on understanding the impacts of public expenditure and revenue policies on women and girls, compared to men and boys and addressing whether they reduce, increase or leave unchanged gender equality. For example, does a pension reform impact women and men differently? If so, how can policies reduce the gender bias? More broadly, GB is about analyzing the gender effects of all public programs and policies and how to improve them.

GB is not about the radical reform of existing budgetary procedures, nor is it about creating a new or parallel budgeting system (OECD 2014 and Sarraf 2003). Rather, it involves integrating additional tools into the existing budget system to analyze the differential impact of governments' budget on women and men, thereby translating the government's commitments on gender equality into budgetary commitments (Budlender Sharp and Allen 1998). In sum, GB is simply good budgeting which can improve outcomes and impact in terms of the efficiency and gender equity of the overall budget process.

Countries have adopted different approaches to GB, there is no single model. Countries have employed a wide variety of GB approaches. These initiatives usually vary in their origin, scope, objectives, institutional arrangements, entry points to the budget process, legal basis, analytical tools and players involved (Kolovich 2018). Some countries have formally adopted GB initiatives into their legal framework, while others have directly incorporated GB tools and processes into the budget for example by improving budget classification.

\section{GB practices and frameworks continue to evolve, highlighting emerging perspectives on its} application over time. GB continues to evolve with experiences from country case studies, research and technical assistance undertaken by a range of donors, non-governmental organizations, academia, and multilateral organizations. Some emerging views are discussed below: 
- The application of GB waxes and wanes over time and progress is not necessarily linear. Even in some early reformers (Australia and South Africa), GB has faded or is no longer applied systemically. Other PFM reforms such as performance budgeting have experienced similar fates in some countries. Several factors can contribute to this including poor implementation strategies, lack of capacity and data, resistance from key stakeholders (Polzer, Nolte and Seiwald 2021), difficultly in assigning responsibility for GB reform to any specific ministry and in obtaining coordination between ministries. In addition, GB requires a good understanding and quantification of gender equality needs and the best PFM tools to address these elements are those that are most often lacking. The vacillating fortunes of GB highlights the importance of promoting wide societal and political support for $\mathrm{GB}$ and formalizing requirements in legislation to ensure reforms endure changes in governments.

- The application of GB appears not to be related to a country's level of development. This reflects several factors, including different starting points for gender equality, strong donor and international organization support for GB implementation and GB's contribution to achieving the gender aspects of the millennium goals and SDGs. GB is part of a wider development agenda supporting women's empowerment which is seen as key to reducing poverty and achieving development goals. International organizations, like UN Women, have played a key role in promoting the integration of a gender lens into the budget process particularly in developing countries and emerging economies.

- There is a recognition of the important role of the ministry of finance (MOF) in the successful application of GB. Historically, GB has been confined to ministries of women or similar institutions. With ministries of women having little direct spending responsibilities and little power to influence or direct other ministries without central support, this has often resulted in its marginalization from central budgetary decision making. It has been a constant struggle to convince MOFs of GB's importance and of their role in the driver's seat in its successful implementation. There is now growing awareness, within wider government and among MOFs themselves, of their key role in successfully executing GB.

- There is more awareness of GB's importance in increasing transparency on the design and monitoring of government's gender equality policies and budget allocations. By improving reporting on budget allocations and impact assessments, GB provides a platform for citizen engagement in gender policies. In this regard, the involvement of parliamentary commissions and civil society helps to draw attend to gender equality issues and gaps and more recent GB initiatives (e.g., Mexico, Argentina) have helped to promote better transparency and public discussions.

- There is a growing consensus on the need for an integrated GB approach which incorporates a gender perspective into the whole budget cycle. The IMF, the OECD and the PEFA Secretariat's approaches to GB emphasize the inclusion of GB tools across the whole budget cycle. Some countries apply GB tools on an ad-hoc basis or just to one part of the budget cycle. For example, including gender in the budget circular but not incorporating GB 
tools in the budget execution and reporting phases. While this may allow countries to fund gender programs, it does not provide any information on how a program's money is spent, if gender objectives are achieved or how programs could be improved. An integrated approach to GB also calls for linking planning to budgeting. Many countries include gender equality goals in national or sectoral plans, but they are not costed or translated into the budget.

\section{B. The IMF Gender Budgeting Approach and Framework}

The IMF approach to GB encourages the holistic integration of a gender perspective across each phase of the budget cycle through gender-responsive fiscal policies and gender-specific PFM practices. This holistic approach builds on the conceptual framework articulated in the assessment of GB practices in G7 countries (IMF 2017). Figure 6 shows its four main pillars and highlights the gender specific PFM tools that can be used in each phase of the budget cycle.

Figure 6. A Holistic Approach to GB Throughout the Budget Cycle

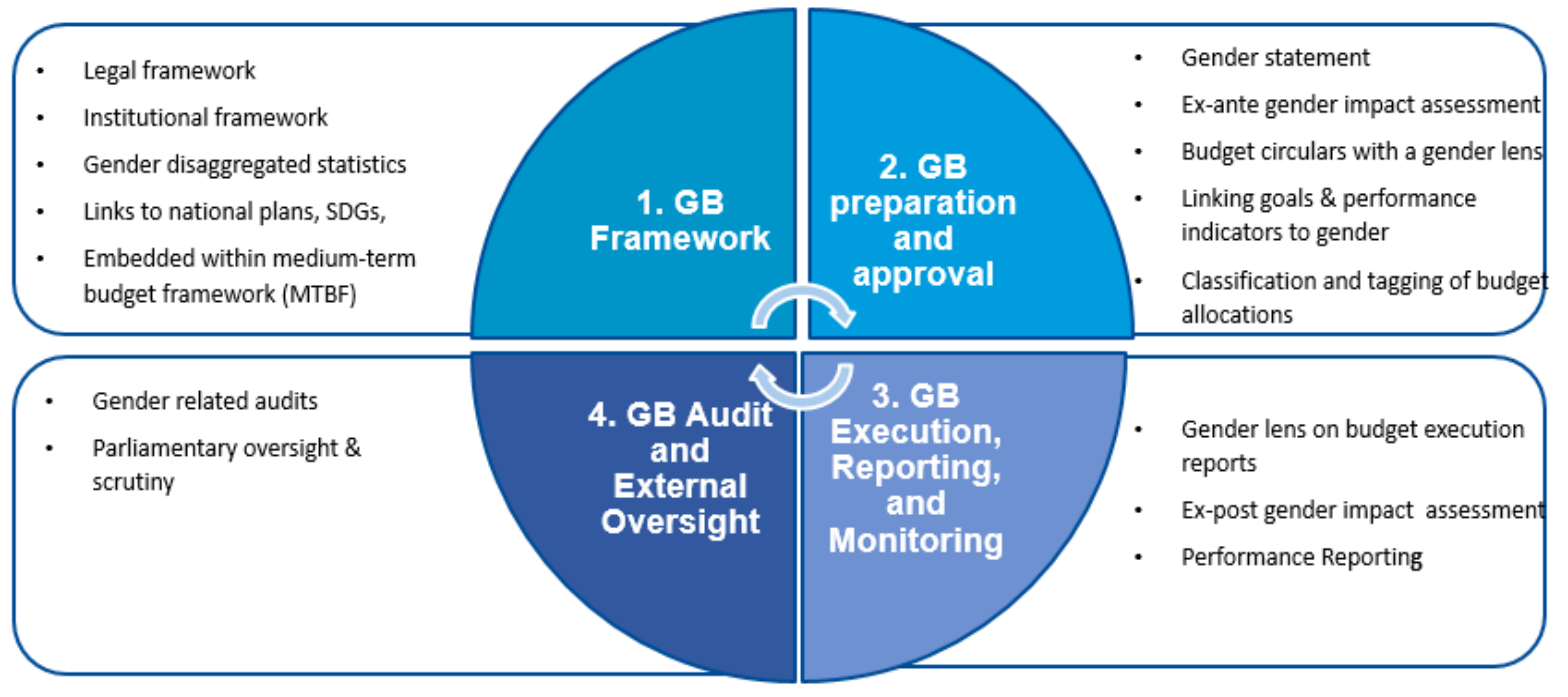

Source: IMF staff.

The design of these tools involves applying a gender lens throughout the policy making, budget preparation, execution, monitoring, and evaluation process. It is also important that lessons learned from the evaluation and assessment of programs/policies feed into a new cycle of policy design. The key features of gender-specific PFM tools that are relevant to each phase of the budget cycle are explained in more detail in Appendix 2 and Appendix 3 provides an example of how to apply GB tools throughout the budget cycle. The IMF approach focuses on the integration of GB PFM tools and practices across all phases of the budget cycle to get the most benefit from the implementation of GB reforms. However, a sequenced approach that helps to appropriately prioritize reform actions should be taken. Further guidance on appropriate sequencing, based on country experience is discussed in later sections and Appendix 7. 
Based on this framework the IMF developed a survey to capture governments' GB practices. ${ }^{7}$ The survey covers gender-related fiscal policies, the implementation of PFM practices across the four GB pillars mentioned above and a section on GB benefits and implementation challenges. The survey captures not only the existence of the most relevant PFM tools but also tries to capture aspects of the quality of their application. Government officials in all G20 countries plus Spain (permanent G20 guest) and Austria (G20 guest) completed this online multiple-choice survey. Beyond the G20, the survey gathers data on GB practices from 72 other countries around the world. More details of this survey are provided in Box 2 and Appendix 6.

\section{Box 1. The IMF Survey of National GB practices}

The survey aims to capture countries' progress in the implementation of policies and PFM institutions that support the gender-responsiveness of the budget. It comprises 38 questions structured in 5 blocks (1. Gender policies and fiscal policies, 2. Legal and institutional framework, 3. Budget preparation, 4. Budget execution minoring and audit and 5. Benefits, challenges and impact). The survey asks questions around the four pillars of the IMF GB Framework, and about gender equality policies, and GB benefits, implementation challenges and facilitating factors. The questions not only aim to reflect whether GB tools are in place and actively used, but also tries to capture their most relevant characteristics and how they are used (to the extent possible). For some responses, countries are asked to provide links to relevant documents, which have been verified, and where information is available answers have been scrutinized to detect and remove inconsistencies as much as possible. Appendices 4 and 6 provide further details on the survey.

Building on the responses to the survey, FAD has set up a database of GB practices, which currently includes 93 countries from all income levels and world regions. Most of this information reflects national practices during 2019, and in a few cases in 2020. This database has not only provided an analytical basis for this paper, but it also constitutes a valuable tool for the IMF's capacity development (CD) activities on $\mathrm{GB}$, as it maps countries' main potential weaknesses and helps benchmark them against regional or income comparators. For the purpose of this paper, the 19 G20 countries, plus Spain (permanent G20 guest) and Austria (guest) have been studied. The European Union is also a member of the G20.

Source: IMF staff.

\section{Status of Gender Budgeting in G20 Countries}

This section benchmarks GB practices in G20 countries against the holistic approach to GB described above using the results of the IMF survey. This section is divided into two parts. The first provides an overview of GB practices in G20 countries using a gender budgeting index (GBI) which compares countries relative performance and analyzes overall $\mathrm{G} 20$ countries practices. The second, examines in detail the performance of G20 countries against each of the four pillars in the GB framework and uses a heat map to convey performance.

\section{A. Overview of GB practices in the G20 Countries- Gender Budgeting Index}

Using the data collected from the IMF survey, this paper constructs a gender budgeting index (GBI) to benchmark country GB practices against the IMF GB framework. The GBI is calculated

\footnotetext{
${ }^{7}$ The IMF approach is also consistent with the evolving approaches advocated by the OECD, World Bank, PEFA Secretariat and others.
} 
by assigning a score (from zero to three) to 23 key questions within the survey. These questions relate to 12 PFM instruments throughout the budget cycle. The unweighted average of the 23 questions is equal to the overall country GBI. ${ }^{8}$ Appendix 6 summarizes the GBI methodology. In Figure 7, individual country indexes have been ranked at three levels of practice according to their average $\mathrm{GBI}$, high (between 1.47 and 2.25), medium (0.75 and 1.46) and low (0.03 and 0.74). ${ }^{9}$ From this perspective, the cluster of countries characterized by the highest score in relative terms comprises Canada, Austria, Mexico, France, Spain, South Korea and Japan. Note that the highest country average GBI score is 2.24 and the lowest is 0.03 for this group of countries, while the GBI can have values from 0 to 3 according to the level of practice for each GB tool (see Heatmap Table 3). ${ }^{10}$

Figure 7. G20 Gender Budgeting Index (GBI) Scores by Countries ${ }^{11}$

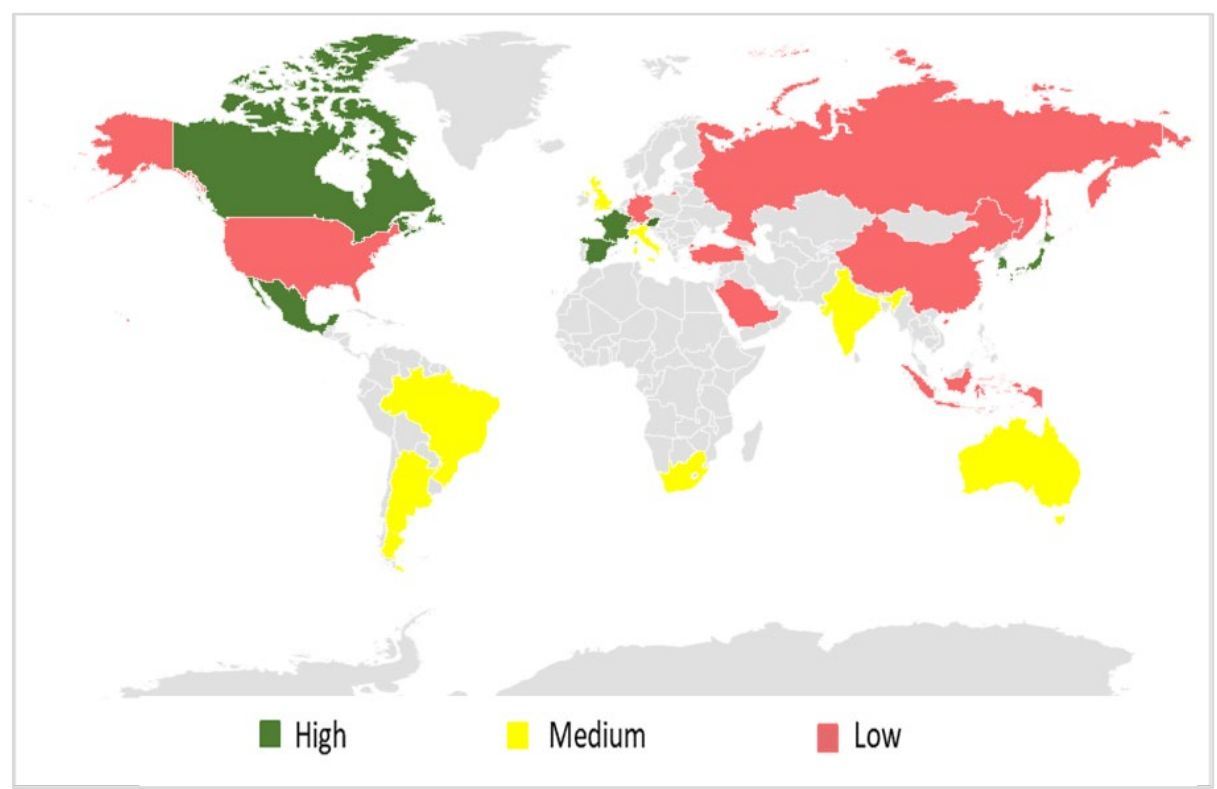

Source: IMF Survey and IMF Staff. Note: The boundaries, colors, denominations, and any other information shown on the maps do not imply, on the part of the IMF, any judgment on the legal status of any territory or any endorsement or acceptance of such boundaries.

\footnotetext{
${ }^{8}$ Unweighted questions in the GBI reflect a holistic approach to the PFM tools applied throughout the budget cycle, whereby all its phases are a priori equally important and their interrelations potentially relevant. From an empirical perspective, assigning weights through statistical techniques typically used in the construction of synthetic indicators, such as correlations between the components of the index and outcome variables, cannot be applied given the length of the index series (one single period).

${ }^{9}$ The GBI is a broad-based indicator and shows a country's status of GB implementation only at a point in time. Complementing indicators, country-specific context and application of judgement based on experience remain important elements to interpreting country results.

${ }^{10}$ In practically all the scored questions, there are one or more countries that receive the highest scores. This indicates that the benchmarks used do not represent too high standards and can be read as the distance to the best performers.

${ }^{11}$ For federal states (Germany and United States), the GBI does not capture GB policies at a lower level of public administration.
} 
Overall across G20 countries, GB practices are significantly better for developing a GB institutional framework and integrating a gender perspective into budget preparation than in budget execution and auditing. The highest scores within the two first pillars can be observed in the institutional framework and the use of performance indicators. In budget execution, both execution reports and ex-post gender impact assessments (GIAs) have low scores, and in audit and external oversight it is mainly the first one which lowers the average.

The average for advanced economies in the G20 (AEs) is higher than for emerging markets (EMEs) in the overall index, however there are significant intra-group differences. The largest differences are found in ex-ante GIA and statistics where AEs perform higher, but EMEs are stronger in performance indicators and budget classification. In terms of intra-group differences, Canada, France, Austria and Spain exhibit significantly better averages than other advanced economies. Likewise, the distance between Mexico and other emerging countries is also noticeable.

Table 2. Average GBI Indexes for the G20+ and by Income Group (Rank 0-3)

\begin{tabular}{|c|c|c|c|}
\hline & \multicolumn{3}{|c|}{ Averages } \\
\hline & $\begin{array}{c}\text { G20 + } \\
\text { Austria + } \\
\text { Spain }\end{array}$ & $\begin{array}{l}\text { Advanced } \\
\text { G20 }\end{array}$ & $\begin{array}{l}\text { Emerging } \\
\quad \text { G20 }\end{array}$ \\
\hline 1. GB Framework & 1.52 & 1.88 & 1.13 \\
\hline Legal Framework on GRB & 1.05 & 1.27 & 0.80 \\
\hline Institutional framework & 1.87 & 2.06 & 1.67 \\
\hline Fiscal data disaggregated by gender & 1.65 & 2.30 & 0.93 \\
\hline 2. GB Preparation Approval & 1.32 & 1.53 & 1.08 \\
\hline Gender statements & 1.14 & 1.64 & 0.60 \\
\hline $\begin{array}{l}\text { Ex-ante gender impact assessment to assess the impact of } \\
\text { proposed policies on gender equality }\end{array}$ & 0.89 & 1.64 & 0.07 \\
\hline Budget circular containing specific guidelines on gender objectives & 1.52 & 1.64 & 1.40 \\
\hline Linking gender goals to programs and performance indicators & 1.87 & 1.76 & 2.00 \\
\hline Budget classification incorporates a gender perspective & 1.17 & 1.00 & 1.35 \\
\hline 3. GB Execution, Reporting \& Monitoring & 0.48 & 0.66 & 0.28 \\
\hline Budget execution reports incorporate gender perspective & 0.31 & 0.36 & 0.25 \\
\hline $\begin{array}{l}\text { Ex-post gender impact assessments to assess the impact of } \\
\text { policies on gender goals }\end{array}$ & 0.64 & 0.95 & 0.30 \\
\hline 4. GB Audits \& External Oversight & 0.98 & 1.14 & 0.80 \\
\hline Gender related audits & 0.43 & 0.45 & 0.40 \\
\hline Parliamentary oversight & 1.52 & 1.82 & 1.20 \\
\hline Total GBI & 1.17 & 1.41 & 0.91 \\
\hline
\end{tabular}

Source: IMF survey and IMF staff.

Countries are at different stages of adopting GB and have a range of approaches suggesting there is no linear path for implementation. Some have a relatively advanced level of practice and have formally integrated GB into their legal and institutional settings and throughout almost all facets of their budget cycle. In others, key instruments have been adopted and implementation plans are ongoing, reflecting relatively good or substantial levels of practice even though a comprehensive GB framework is not yet in place. In another group of countries, the adoption of GB tools in the budget cycle has been ad-hoc and more limited. GB initiatives in the US, Germany and 
China are implemented at the subnational level, which is beyond the scope of the survey, whereby GBI scores only capture the federal level. Furthermore, convergence towards best performers has proved to be a gradual process, which involves mobilizing key stakeholders, adapting existing budget tools and developing new ones.

The analysis of correlations between the GBI elements sheds further light on the possible inter-linkages of GB tools and enablers. Appendix 5 shows the correlation coefficient between the GBI components for the whole set of 21 countries, with correlations higher than 0.4 highlighted. The main findings from this analysis are as follows.

- The legal and institutional framework seems a probable enabler. ${ }^{12}$ This is valid for upstream GB (budget call circulars and gender statements), but also for incorporation of gender goals into the budget classification and development of linkages between gender goals and performance indicators.

- Some upstream budget activities (budget preparation) appear significantly correlated. This is the case of gender budget statements, budget circulars and ex-ante GIAs. This may be partly explained by the complementarities between these tools.

- The availability of gender-disaggregated statistics can foster gender impact assessments (GIAs). As could be expected, this is also positively correlated with parliamentary oversight, perhaps because the former provides a quantitative basis for discussion and performance monitoring. Interestingly too, the existence of these statistics does not appear to bear any clear relation with ex-post GIAs, which may be more related to the feasibility of tracking gender-sensitive expenditure.

- The overall correlation of budget execution and auditing tools with other components of the GBI tends to be weak. This could be due to the fact that the use of downstream tools may be constrained by factors not captured by the GBI, such as the inability to track gender expenditure through information systems or quality issues in performance indicators design or overall weakness with the budget execution system.

\section{B. Detailed Analysis of GB Practices in G20 Countries}

This section examines in detail the GB practices of G20 countries across all four pillars of the IMF PFM framework. The results are summarized by country in the heatmap in Table 3 and discussed in detail below.

\footnotetext{
12 In general, causation cannot be directly inferred from a high correlation between variables $X$ and $Y$. This happens because without further statistical tests it may be difficult to know whether $X$ causes $Y$ or the other way around, or both are caused by a third variable $Z$. As regards the interpretation of these specific correlation coefficients, some potential directions of causality seem implausible (e.g. from the existence of gender budget statements to legislation), although both could be favored by a third common factor, such as political commitment or good institutional coordination.
} 
Table 3. Heat Map: Level of GB Practices in G20 Countries Across the GB Cycle

\begin{tabular}{|c|c|c|c|c|c|c|c|c|c|c|c|c|c|c|c|c|c|c|c|c|c|}
\hline & \multicolumn{19}{|c|}{ G20 } & \multicolumn{2}{|c|}{ Non G20 } \\
\hline & Canada & Mexico & France & $\begin{array}{l}\text { South } \\
\text { Korea }\end{array}$ & Japan & Italy & Argentina & \begin{tabular}{|l|} 
South \\
Africa \\
\end{tabular} & India & UK & Brazil & Australia & Turkey & Indonesia & \begin{tabular}{|c|} 
Russian \\
Federation \\
\end{tabular} & \begin{tabular}{|c|} 
Saudi \\
Arabia \\
\end{tabular} & Germany & USA & China & Austria & Spain \\
\hline \multicolumn{22}{|c|}{ Legal and Institutional Framework } \\
\hline \multicolumn{22}{|l|}{ Legal Framework on GRB } \\
\hline \multicolumn{22}{|l|}{ Institutional framework } \\
\hline \multicolumn{22}{|c|}{ Fiscal data disaggregated by gender } \\
\hline \multicolumn{22}{|l|}{ Budget Preparation } \\
\hline \multicolumn{22}{|l|}{ Gender statements } \\
\hline \multicolumn{22}{|c|}{ Ex-ante gender impact assessment to assess the impact of proposed policies on gender equality } \\
\hline \multicolumn{22}{|c|}{ Budget circular containing specific guidelines on gender objectives } \\
\hline \multicolumn{22}{|c|}{ Linking gender goals to programs and performance indicators } \\
\hline \multicolumn{22}{|c|}{ Budget classification incorporates a gender perspective } \\
\hline \multicolumn{22}{|c|}{ Budget Execution and Monitoring } \\
\hline \multicolumn{22}{|c|}{ Budget execution reports incorporate gender perspective } \\
\hline \multicolumn{22}{|c|}{ Ex-post gender impact assessments to assess the impact of policies on gender goals } \\
\hline \multicolumn{22}{|c|}{ Audit and Parliamentary oversight } \\
\hline \multicolumn{22}{|l|}{ Gender related audits } \\
\hline Parliamentary oversight & & & & & & & & & & & & & & & & & & & & & \\
\hline
\end{tabular}

Source: IMF staff. Note: The information has been drawn from the IMF survey.

\begin{tabular}{|l|c|c|c|c|}
\hline \multirow{3}{*}{ LEGEND } & \multicolumn{4}{|c|}{ Level of Practice by GB tool } \\
\cline { 2 - 5 } & No practice & Limited practice & Good practice & Advanced practice \\
\cline { 2 - 5 } & $\mathrm{GBI}=0$ & $\mathrm{GBI}=0.1-1$ & $\mathrm{GBI}=1.1-2.4$ & $\mathrm{GBI}=2.5-3$ \\
\hline
\end{tabular}




\section{Pillar 1: Gender Budgeting Framework: Legal and Institutional Framework}

Over half of G20 countries have formalized GB requirements within a comprehensive framework ${ }^{13}$, providing a firm foundation for integrating a gender perspective into the budget process. These frameworks can include laws that enshrine the incorporation of a gender perspective into the budget process, but also lower-ranking regulations, directives and methodologies, that deliver detailed instructions and technical guidance on GB implementation. In a majority of countries integrating GB requirements into the legal and technical framework has been a relatively recent phenomena, occurring over the last decade. This is the case even where GB practices have existed for some time. For example, in Canada, some of the GB tools which had been introduced in mid 1990s were only enacted in legislation in the 2018 Gender Budgeting Act.

Less than half of $\mathbf{G 2 0}$ countries have GB requirements enshrined in the constitution or highranking laws despite this being cited as a key success factor. ${ }^{14}$ Only Austria has a GB requirement in their constitution which is advanced practice. Eight other countries use high-ranking laws, that cannot be easily modified and so remain stable over time. Other countries just use annual budget laws or other regulation to ensure that policy design embeds gender aspects, but their adhoc character renders them less effective than other laws with permanent status and overarching nature (Appendix 8).

Institutional responsibility for leading GB reforms involves the Prime Minister's Office or the MOF in the majority of countries. ${ }^{15}$ In addition, to comprehensive legislative frameworks, advanced GB practice is reinforced by assigning institutional responsibility for implementing GB reform to powerful central agencies. The involvement of the President's/Prime Minister's Office and the MOF elevates the importance and priority of the reform. In 40 percent of countries, the MOF is responsible for ensuring the integration of GB practices into PFM legislation and processes. Coordination by MOFs facilitates a richer technical and financial discussion of gender policies, when setting budget policy proposals and expenditure envelope, as is the case in Canada.

\section{The collection of gender-disaggregated statistics has become widespread among G20} countries, but in general they are not fully integrated into the budget processes. ${ }^{16} \mathrm{Gender}$ disaggregated statistics can enhance the soundness of GIAs (both ex-ante and ex-post) and help with the construction of credible performance indicators. Practically all countries which compile gender-disaggregated statistics, also publish them, however a key challenge is to integrate them into decision making. In terms of the frequency of the use of gender statistics, Australia reported using them very frequently to inform budget decisions and gender analysis and Canada also reported using them frequently in decision making.

\footnotetext{
13 Question 7 of the survey.

${ }^{14}$ Question 9 of the survey.

15 Question 10 of the survey.

${ }^{16}$ Question 25a, 25b and 25c of the survey.
} 


\section{Pillar 2: Gender Budgeting: Budget Preparation}

Nearly all countries have gender equality goals which are most often incorporated into medium-term strategic plans. ${ }^{17}$ When gender goals are embedded in national and/or sectoral plans and incorporated into the budget and medium-term frameworks, they have a better chance of being funded and therefore actually being delivered. Similarly, international commitments for example to support the SDGs for gender equality require integration into sectoral objectives and holding political leaders accountable for results.

\section{Linking gender goals to program objectives and assessing the fiscal impact of proposals within a medium-term budget framework is an advanced practice, however it is not} frequently applied. ${ }^{18}$ Framing spending proposals within a multi-year fiscal constraint helps to refine and prioritize priorities within sector strategies through cost-benefit analysis. Nonetheless, only three countries (Saudi Arabia, South Africa and Turkey) reported to apply this approach. In another six countries (Argentina, Brazil, France, Indonesia, Japan and Mexico) gender equality goals are also linked to programs, and costings are done on an annual basis. Without adequate costings of proposals prioritization within allocated expenditure ceilings can be compromised, even if gender goals are linked to programs. In eight G20 countries plus Austria, gender goals exist but are not linked to programs or costed.

More than half of governments have performance measures in place to monitor their progress in achieving gender goals. ${ }^{19}$ Setting gender-related performance targets against government programs is an advanced practice that allows program performance to be assessed at government-wide level however only six countries are performing at this level. Targets can be quantitative or more qualitative in nature. Argentina, Germany, Italy and UK report on the performance of gender policies, but no targets are set during budget preparation, and in Indonesia only a few ministries have performance targets. ${ }^{20}$ In the US, some agencies or program offices set their own gender targets.

\section{Only one third of G20 countries produce and publish an annual gender budget statement to} raise awareness of the differential impacts of budget policies on women and men. ${ }^{21} \mathrm{Gender}$ budget statements help governments better understand their gender priorities, their financial implications and the estimated impact of policies on gender outcomes. They also enhance transparency for citizens on the government's gender policy priorities, commitments and plans for delivery. Eight of the respondents reported producing and publishing a gender statement (Canada, France, India, Japan, Mexico, South Korea, as well as Austria and Spain). Most of these statements flesh out government's gender policies, how they relate to gender objectives and gender gaps and some provide details on the content and costing of flagship initiatives and their expected impact on

\footnotetext{
17 Question 2 of the survey.

${ }^{18}$ Question 14 of the survey.

19 Question 19 of the survey.

20 In Russian Federation, performance monitoring is conducted outside the budget process. The National Strategy for Action on Women 2017-2022 mandates monitoring results of measures implemented by line ministries.

${ }^{21}$ Question 15 of the survey.
} 
gender equality. Further, these statements are included in budget documentation and posted on the websites of the respective governments or ministries of finance.

\section{Only half of G20 governments have guidelines in budget circulars to help ensure a} comprehensive and coordinated approach to GB during budget preparation. ${ }^{22}$ Incorporating GB guidance for agencies into MOF budget circulars helps to set clear operational procedures for effective coordination and GB implementation. This approach is taken in ten countries where instructions usually deal with the identification of gender-sensitive programs or policies (e.g. by means of classifiers), requirements and/or templates for the presentation of GIAs (Canada and South Korea), or the inclusion of gender objectives in existing programs. ${ }^{23}$ In India and South Africa, budget circulars instruct on how to allocate resources to specific gender initiatives. In Italy, there is a specific gender circular. Almost half of G20 countries have no budget circulars in place to guide GB implementation.

Forward looking tools such as ex-ante GIAs are only actively deployed in five countries. Exante $\mathrm{GIAs}^{24}$ are highly beneficial to effectively understand the potential impact of new policies on gender and improve their design. Only Canada, France, and UK plus Austria and Spain conduct exante GIA for all or most new policy initiatives, while Australia, Japan and South Korea do so for some proposals. Ex-ante GIA may also analyze the multi-dimensional effects of gender policies, like the Canadian GBA+ methodology.

Relatively few G20 countries have an agreed and consistent GIA methodology. ${ }^{25}$ Developing a common methodological basis for GIAs is an advanced practice that enhances comparability across ministries and allows for quality checks. Nonetheless, a common methodology is only in place in five countries (Austria, Canada, France, South Korea and Spain). Quality assurance over assessments are conducted by MOFs, ministries of Women or both. In some countries (Canada, France and Spain) gender-specialized units in line ministries carry out a first validation of the quality of GIAs. However, the capacity of these units within line ministries could be uneven and quality assurance checks should also be performed by MOFs to ensure consistency across government.

Given the importance of tracking gender policies over the budget cycle, a majority of G20 countries have integrated them into their budget program structures. ${ }^{26}$ Tracking genderrelated expenditure can enhance medium-term planning, improve prioritization in budget requests and facilitate the monitoring of the performance of gender policies. One pre-condition for tracking is that gender activities can be traced in the programmatic structure of the budget, where this is in place, or as line items. A third of countries follow an advanced practice where gender is incorporated into program classification both in stand-alone gender programs and within other programs. Nine countries lack a programmatic structure in the budget.

\footnotetext{
22 Question 16a of the survey.

23 Budget call circulars do not contain any methodology for conducting GIA in any G20 country.

${ }^{24}$ Questions 17a and 17b of the survey.

${ }^{25}$ Questions $17 \mathrm{c}$ and $17 \mathrm{e}$ of the survey.

${ }^{26}$ Question 21b of the survey.
} 
However, specific gender classifiers and markers to identify gender-relevant programs and activities are used in eight countries. Attaching codes or labels to gender-sensitive programs in budget documentation can help to more easily identify them. This is especially useful when genderrelated activities coexist with others within programs or sub-programs. For instance, in Canada programs are tagged to the pillars of the Gender Results Framework, when relevant for gender equality objectives. Italy has coded public expenditure using three digits, 0,1 and 2, where 0 denotes gender-neutrality, 1 implies gender-sensitivity (i.e expenditures which have different impact on men and women) and 2 is used for those expenditures whose goal is reducing gender inequality. Argentina tags gender-sensitive programs with the acronym PPG, denoting an intended gender impact. Some countries have incorporated other tracking methodologies with similar functionalities to classifiers, in order to identify gender-relevant initiatives during budget preparation.

\section{Pillar 3: Gender Budgeting: Budget Execution, Reporting and Monitoring}

Gender information is rarely included in in-year execution reports or in the government's annual financial reports. ${ }^{27}$ Monitoring of gender programs needs to be underpinned by information on their financial and non-financial performance. In-year budget execution reports that monitor progress against gender goals are produced only by two counties - Italy and Mexico. Only Canada, Mexico and South Korea report annual performance against gender goals. Other countries table their reports in their Parliaments and publish annual reports on gender policy actions by sector or clusters of objectives. These reports provide information on the financial impact of gender policies and, for some of them, their non-financial performance against observable indicators. For example, the Italian Gender Budget Report.

Ex-post GIAs are performed in a handful of cases but are rarely used to improve gender policy design. ${ }^{28}$ Ex-post GIA goes beyond monitoring non-financial performance indicators, as it provides a multi-dimensional view of the effects of revenue and expenditure initiatives on gender equality, as well as the factors explaining these results. However, only seven countries (Brazil, France, Germany, Italy, Mexico and South Korea, plus Austria) reported to conduct ex-post GIA. When it comes to the use of ex-post GIAs only in France is it used frequently, and there it is used for gender gap analysis and occasionally as an input into the design of new gender goals and policy or for making amendments on existing policies. ${ }^{29}$ This is a lost opportunity to harness a powerful tool that can assess the effectiveness of current policy and use these finds to shape future policy interventions.

\section{Pillar 4: Gender Budgeting: Audit and Oversight}

Oversight of gender equality objectives by legislative bodies is present in half of the G20 countries but several still have deficits in this area. ${ }^{30}$ Greater involvement of the legislature reinforces accountability on gender policies and reforms. Legislatures most common roles include publishing reports on gender equality issues, reviewing information on gender equality goals and

\footnotetext{
${ }^{27}$ Questions 26 and 27 of the survey.

${ }^{28}$ Questions 28 and 29 of the survey.

${ }^{29}$ Perhaps representatively, South Korea acknowledges that, although ex-post GIA is intended to provide a sound basis to develop performance indicators for gender programs or activities, it is seldom used for this purpose.

30 Question 31 of the survey.
} 
performance targets, and conducting hearings on gender equality issues. Although Gender Committees are not widespread yet, they are already active in nine countries (e.g. in Canada, where the House of Commons Standing Committee on the Status of Women has issued Calls for Action in numerous gender-related areas). In Austria several committees oversee gender topics. In some countries, such as Argentina, parliamentarians have received training to better assess the gender perspective in legislative and budgetary discussions. In other countries like Australia, the legislature, can ask the Parliamentary Budget Office to produce a costing that reveals the gender impact of particular government policies.

\section{Box 2. Summary of Advanced GB PFM Practices and Tools in G20 Countries}

In Austria the constitution requires that all levels of government undertake GB. New or amended laws and regulations, and major investment or procurement contracts, must include a mandatory ex-ante impact assessment on gender equality. GB guidelines are complemented by an annual budget circular with details and instructions. The government publishes a gender statement and reports achievements against gender equality outcomes. The Austrian Court of Audit analyzes the impact of budget programs and tax and sectoral policies on gender.

Canada has integrated forward-looking GB PFM tools into the budget preparation stage. The ex-ante GIA $(G B A+)$ is applied to assess the potential impact of policies based on gender and other identity factors to develop more inclusive budget measures. The Gender Statement accompanying the Budget reflects the government's efforts to understand the differential outcomes of policy choices, outlines the main gender gaps and provides an overview of the progress made towards achieving the government's equality objectives.

In France the Gender Budget Statement assesses fiscal policies and the budget from a gender perspective and presents the programs that contribute to gender equality with their budgets and contains some performance indicators. The 2020 budget circular instructs all ministries to integrate a gender dimension when defining or revising the performance indicators that are annexed to the Budget Law, setting a basis for monitoring progress in the annual performance reports.

In Japan the Council for Gender Equality in the Cabinet Office, headed by the Prime Minister, leads and promotes the gender equality agenda. Since 2015, each year, the Japanese government prepares the Intensive Policy to Accelerate the Empowerment of Women, which aims to incorporate a gender perspective into the annual budget requests of ministries and agencies.

In South Korea the Gender Impact Analysis Assessment' (GIAA) law requires a GIA assessment for policies which influence the rights, interests and social participation of women. Ministries are required to prepare and submit to the National Assembly a gender budget statement and balance sheet showing information on budget allocation, execution, performance evaluation and management. The Ministry of Strategy and Finance issues budget guidelines which require every ministry to report gender equality goals that will be considered in budget allocations discussions.

In Mexico by law the National Development Plan must be formulated with a cross-cutting gender perspective. The Federal Budget and the Financial Responsibility Law provide guidelines on how gender-oriented considerations should be incorporated into the budget, stipulating that resources assigned to budget programs and investments earmarked for addressing equality between women and men cannot be removed or diminished. A gender perspective has been incorporated into the program structure, and gender-related indicators into the performance evaluation system with in-year and end-year reporting.

In Spain the Law on Equality for Men and Women requires that the government prepares a gender budget statement and a gender impact assessment for each new policy proposal, together with an assessment of the policy's economic and budgetary impact. In Parliament, both the Congress and the Senate have established a Commission on Equality.

Source: IMF staff. 
Supreme audit institutions still play a very limited role in assessing the performance of gender programs and activities. ${ }^{31}$ External scrutiny of gender activities is critical for detecting design and implementation gaps, that can be used to strengthen policy design in future proposals. In many countries, this role is assigned to Supreme Audit Institutions. Austria is the country with the longest experience and the most advanced practices, the Supreme Audit Institution published 55 audit reports in the last three years on tax and sectoral expenditure policies, as well as individual programs. In Mexico, UK and India the scope of audits is somewhat narrower and focuses on the expenditure side of the budget. ${ }^{32}$ Box 2 provides a summary of selected advanced GB practices in G20 countries. More details on individual G20 countries GB practices are provided in Appendix 9.

\section{Beyond the G20 - Comparing G20 GB Public Financial Management Practices With Other COUNTRIES}

Globally countries are experimenting with a range of GB PFM tools, but deployment is uneven and average levels of practice are relatively low. Beyond the G20, Spain and Austria, the survey gathered data on GB PFM practices from 72 other countries around the world. ${ }^{33}$ Using this broader IMF survey data we place the GB practices of G20 countries in a wider context. What we find is that the average GBI scores of countries outside of the $\mathrm{G} 20$ is also relatively low $(0.88)$, with no country yet reaching an overall advanced level of practice (average GBI score higher than 2.5) though some individual tools rank at the advanced level. Figure 8.1 compares the average level of GB PFM practices across the budget cycle of other countries surveyed, with that of G20 countries.

The trends in strengths and weaknesses of GB PFM practices observed in G20 countries are also true for those surveyed outside of the $\mathbf{G 2 0}$. Although overall GBI scores are lower, average GBI scores for non-G20 countries for each PFM practice, broadly mirror trends observed for G20 countries, with few exceptions (Figure 8.1). Consistent with the analysis for the G20 countries, areas of strengths for countries outside of the G20 are within the GB supporting framework (institutional and gender disaggregated data), select elements of budget preparation (budget circulars, linking goals to programs and indicators) and parliamentary oversight. Typical weaknesses are in budget execution reports, gender audits and ex-post and ex-ante GIA. This shows that the application of some GB tools presents challenges across all countries.

\footnotetext{
31 Question 32 of the survey.

${ }^{32}$ Audit activities have been initiated more recently in these other countries. For instance, UK National Audit Office produced for the first time in 2018 a report on the gender pay gap.

33 The survey is composed of 93 countries, of which 19 are G20 plus Spain and Austria. The total survey includes 12 advanced economies, 47 emerging market economies and 34 Low Income Developing Countries.
} 
Figure 8.1. PFM Tools Used to Support GB - Comparison of G20 Countries with Other Countries Surveyed
Figure 8.2. Relative Strengths and Weaknesses of GB Tools Comparing G20 to other Countries ${ }^{1}$

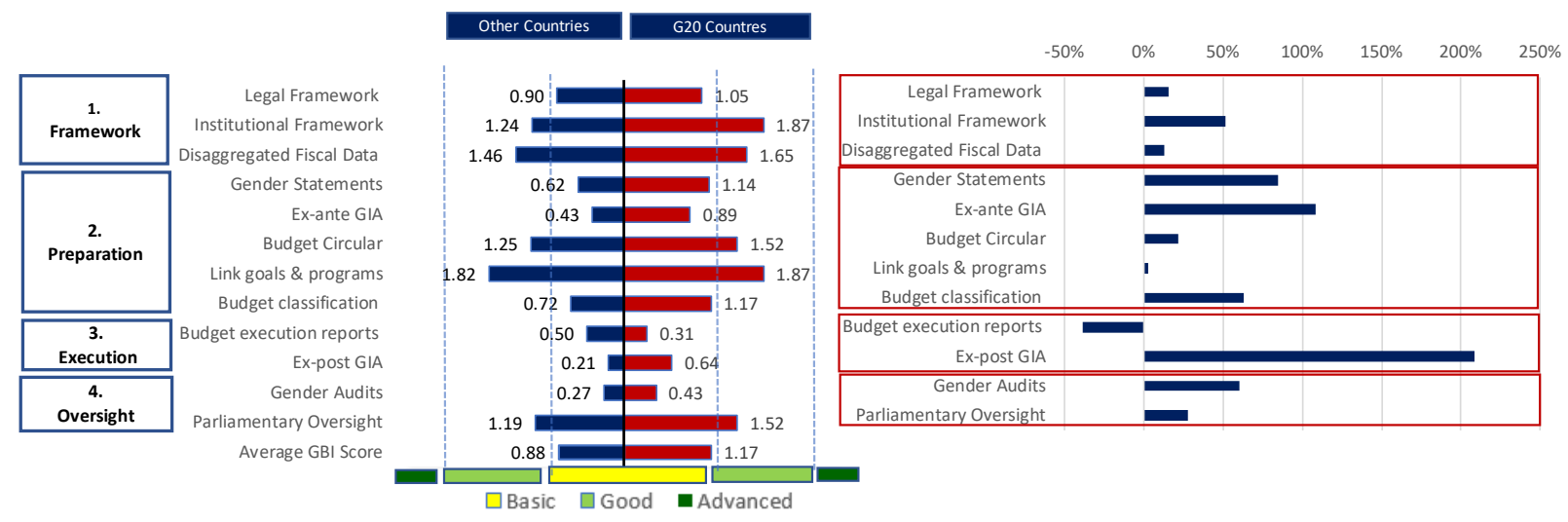

Source IMF Staff.

Note: Differentials are calculated by looking at the difference in GBI scores between the G20 and other countries.

Scores of non-G20 countries are most significantly lower than $\mathbf{G 2 0}$ countries in the areas of ex-post and ex-ante GIA and gender budget statements (Figure 8.2). G20 countries on average score at least more than double that of other countries in these GB PFM practices. Surprisingly, integration of gender into budget execution reports is one area where countries outside of the G20 score on average higher than G20 countries but still at basic practice level.

Strong performance in the GB implementation does not appear to be heavily dependent on income level or development of the country. Consistent with the literature, the survey data shows that the contribution of donors towards supporting GB initiatives is particularly noticeable. This is especially the case in low income countries (LICS), with a spike in utilization of certain tools in these countries. This is related to some LICs facing severe challenges in gender inequality and provision of support by international organizations and donors to improve capacities and to help achieve the millennium goals and SDGs. In this regard, as shown in Figure 9, LICs outscore emerging market economies surveyed across all GB PFM practices, with one exception (parliamentary oversight). In addition, LICs are on par, or even outscore, advanced economies in a few areas including in linking gender goals to programs and performance indicators and budget execution reports. This adds further weight to the finding that progress can be made in implementing GB PFM tools irrespective of income level. 
Figure 9. PFM Tools to Support Gender Budgeting GBI Scores by Income Group and Region
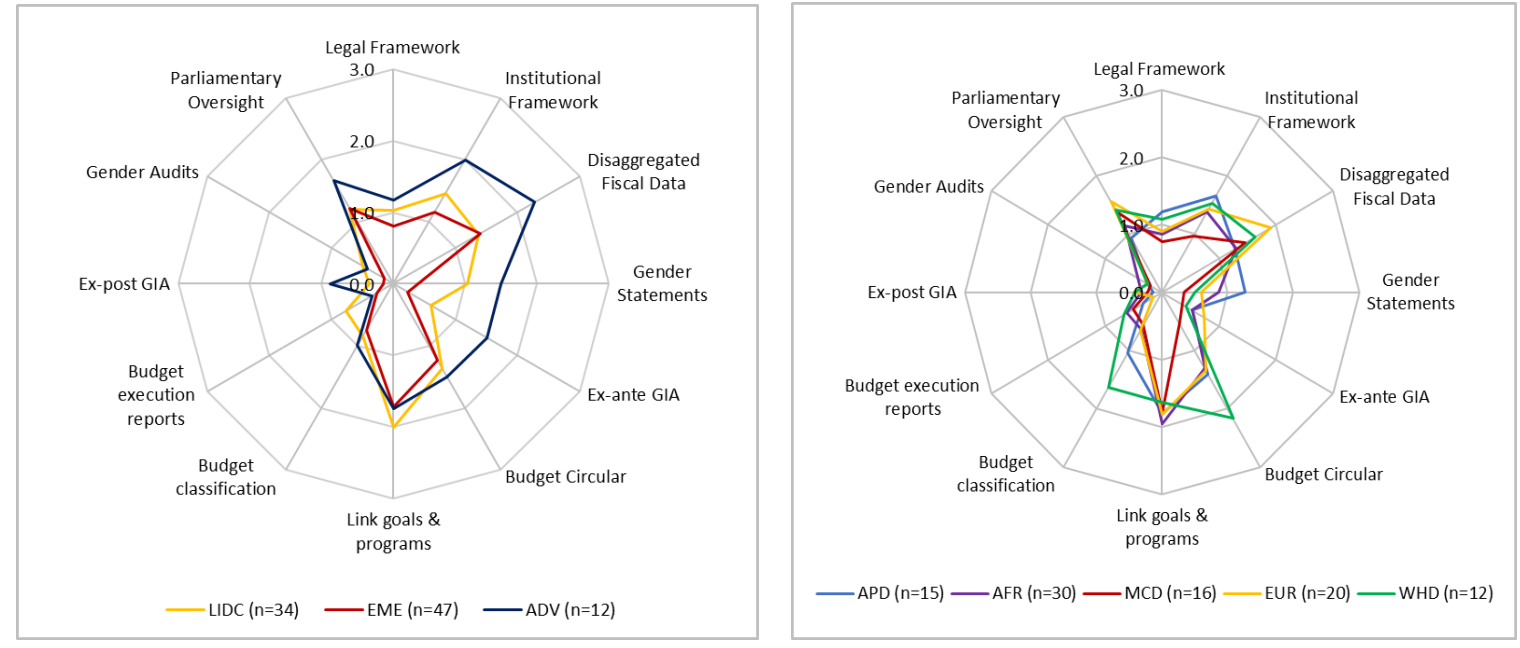

Source: IMF Survey and IMF Staff.

\section{Implementation of Gender Budgeting - Challenges and Success Factors}

\section{A. Major challenges Encountered by Countries in GB implementing}

Technical challenges are highlighted as the key hurdle to implementing GB. Survey responses ${ }^{34}$ show that key challenges to effectively implementing GB are shared across both $G 20$ and non-G20 countries, and broadly include lack of guidance, coordination and expertise, insufficiently disaggregated data and low quality of GIAs. Figure 10 highlights these findings. These challenges, which are largely technical in nature, are reported to weigh much more heavily on a country's ability to implement GB than lack of political support, suggesting that there is considerable opportunity to strengthen $G B$ practices through increased technical guidance and assistance. While political support for gender equality is not one of the major impediments to the technical implementation of GB practices, it is overwhelmingly viewed as one of the most critical factors when it comes to the success of GB in influencing decisions and policy outcomes.

While challenges are broadly shared among countries, G20 countries are more acutely concerned about the poor quality of GIAs and the lack of clear guidance in the budget process. Nearly 60 percent of G20 countries are concerned about the quality of GIAs, which may reflect the concerns about data and specialized staff. This could also explain the relatively small reliance on GIAs as an input to decision making. Nearly 50 percent of G20 countries, identify the lack of clear instructions on how to incorporate gender considerations into the annual budget as one of the most important challenges to successful GB implementation.

This is relatively unsurprising when put together with the finding that more than half of $\mathbf{G 2 0}$ countries indicate that guidelines for GB do not currently exist. ${ }^{35}$ Where circulars do exist, they may need to be more granular and be accompanied by guidelines for methodologies for analyzing

\footnotetext{
${ }^{34}$ Survey question 38. Responses are for all countries that completed this question.

35 Survey question 16.
} 
the gender impact of proposals. The failure of key ministries to coordinate and provide clear guidance may be symptomatic of a need for clearer lines of accountability and leadership on GB issues. Further, 40 percent of other countries surveyed and a quarter of G20 countries indicate that there is no specific entity that coordinates gender issues during budget preparation.

Figure 10. Major Challenges Encountered in Successfully Implementing Gender Budgeting

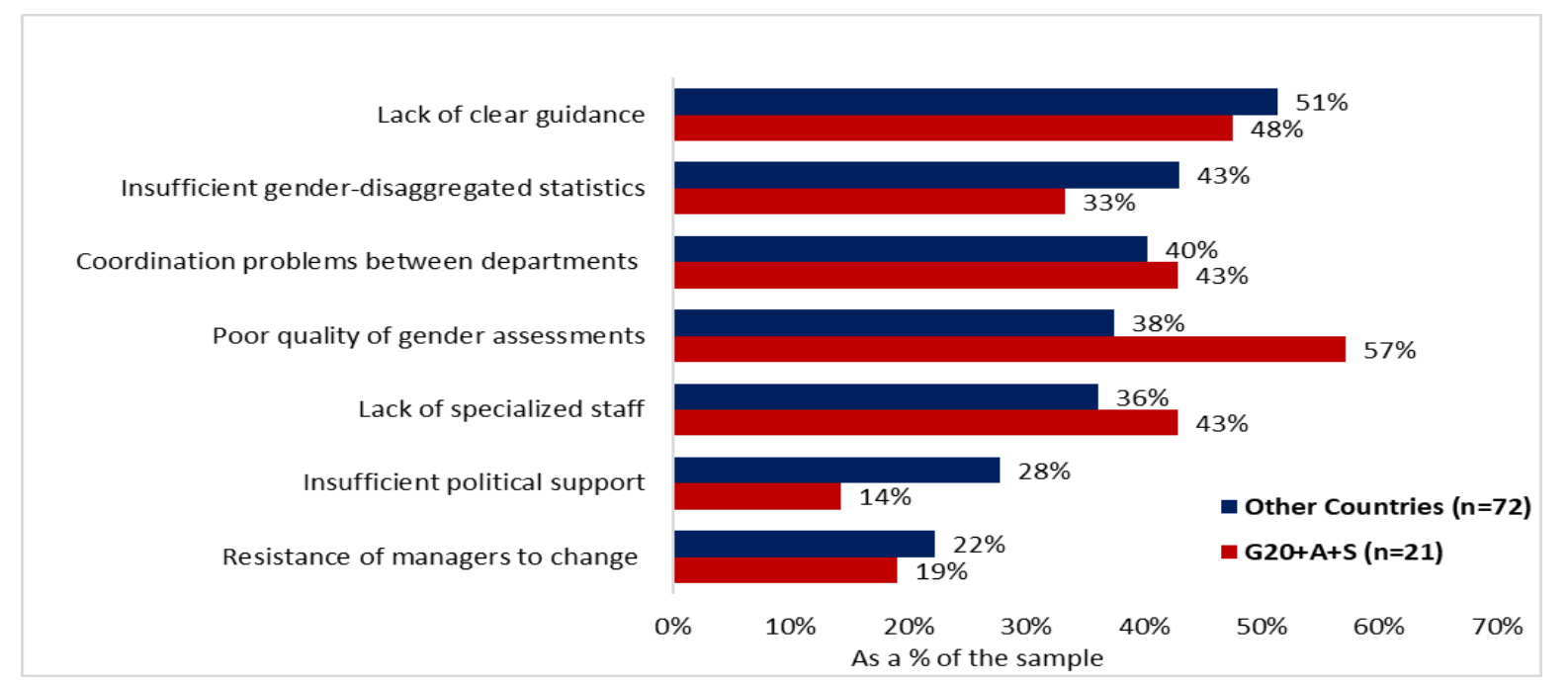

Source: IMF Survey and IMF Staff.

In addition to survey results, IMF capacity development activities have revealed two main types of challenges faced by countries in GB implementation. These are:

- Difficulties related to specific institutional and technical requirements of GB. Line ministries often lack the expertise necessary to undertake a full diagnostic of gender gaps, design adequate policy measures and assess the financing needs to close these gaps. This complicates the development of meaningful targets and performance indicators. Relatedly, countries often point out to their inability to track gender-sensitive policies over their implementation cycle, due to lack of budget classifications or failure to incorporate gender classifiers in the financial management information systems (FMIS). On the institutional side, when MOFs are not fully involved in GB implementation, this results in lack of coordination, lack of GB instructions and weak accountability on budget formulation and execution of genderrelated policies.

- Difficulties related to shortcomings in PFM. The absence of key PFM tools hinders GB. One frequent example is the lack of an operational medium-term budget framework (MTBF), which facilitates the strategic deployment of gender policies within a common resource envelope. Others are a poor definition of annual budget priorities and/or their deficient transmission to line ministries during budget preparation, low capacity to cost policies and monitor their execution, or the lack of a performance-based framework. On the contrary, good PFM practices may contribute to enhance GB, and synergies have been reaped between PFM reforms and GB mainstreaming, as evidenced in Austria. 


\section{B. Important Success Factors to Implementing Gender Budgeting}

The survey finds that political support, binding legislative requirements and active support of MOFs are universally identified as key drivers of GB success. This is clearly illustrated in Figure 11. In addition, gender policies are more likely to succeed when governments adopt a comprehensive approach to integrating the gender perspective into the budget process. There are two factors that G20 countries consider to be much more important success factors than other countries - having clear gender equality goals that are linked to programs and securing the support and engagement of line ministries. These factors may reflect the tendency for G20 countries to have experimented more with performance budgeting and with devolved budgetary procedures leading to stronger coordination needs vis-à-vis line ministries. By the same token, G20 countries do not see that support from the international community or increased funding playing a particularly big role in the success of gender budgeting, while other countries do see these factors as important in GB success.

Figure 11. Most Important Factors that Explain the Successful Implementation of GB

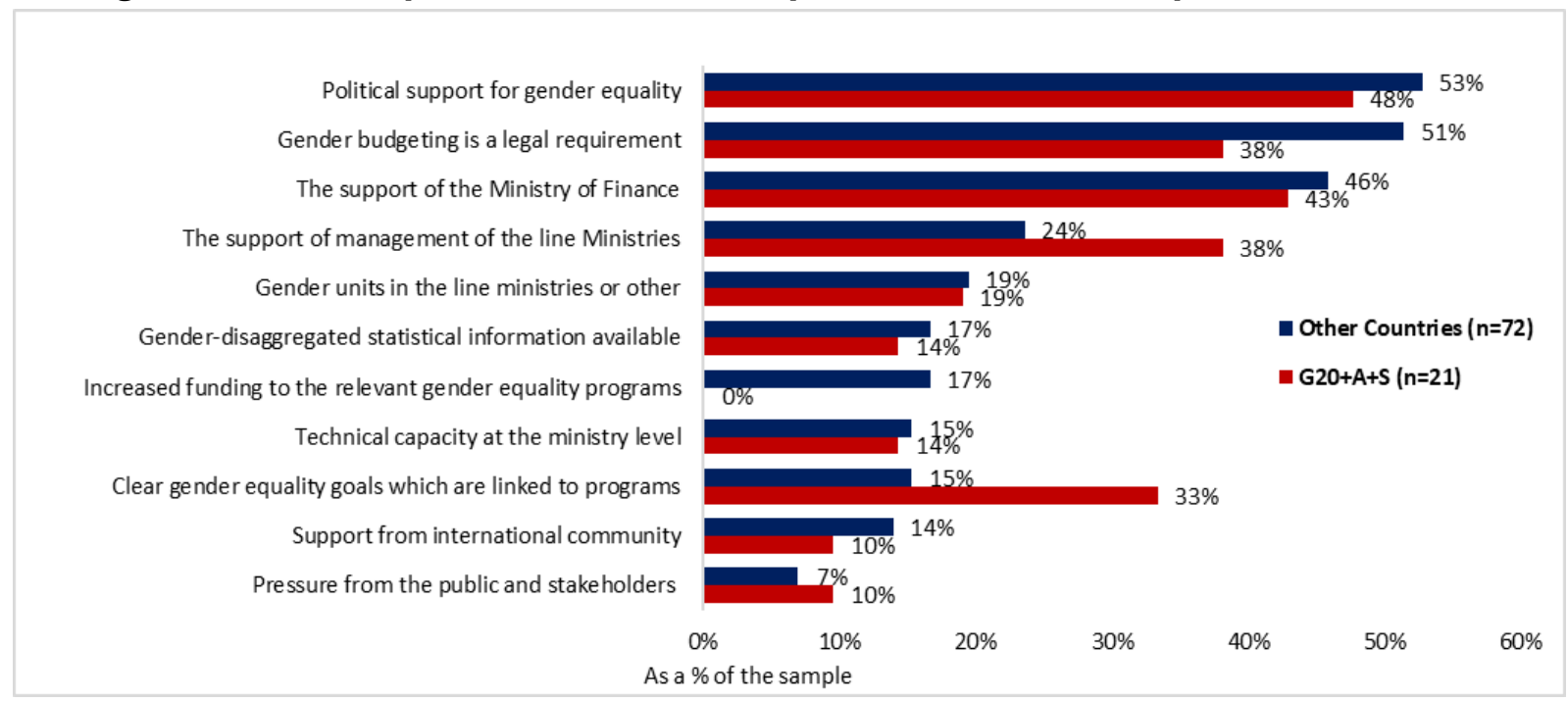

Source: IMF Survey and IMF Staff.

Political support for gender equality is identified as the most important factor in successfully implementing GB. Survey responses present a unified picture about the importance of political support for improving gender equality, across practically all countries, with more than 50 percent of all responses identifying this as a key success factor. This is consistent with the literature that highlevel political commitment for gender equality and strong leadership is a requirement for successful GB (OECD 2020) and for progressing reforms to improve gender equality outcomes.

Legal requirements are needed for sustaining $\mathbf{G B}$ efforts over time. Having binding legislative requirements to implement GB comes in as a close second behind having strong political support. EMEs and LICs view political support and a legal requirement of almost equal importance. The importance of a binding legal requirement for implementing GB is also well documented in the literature (Kolovich 2018). A legal framework, which provides a consistent and articulated basis to 
develop and prioritize gender policies, helps to progress the discussion of gender-related policies in a systematic way rather than an ad-hoc fashion and ensures continuity over political administrations.

The engagement of MOFs is a key factor to successful GB. This is evident across all country groups although very significantly in low-income countries. More broadly, support from the MOF scores much more highly than the support of other ministries, for example the ministry for women. This likely reflects the traditional stewardship that MOF have over budget processes, while relevant line ministries (in this case for women) can in some countries have limited control and authority over the budget process. Significantly in 40 percent of G20 countries and more than half of non-G20 countries, the MOF is the institution with primary responsibility for GB reform.

GB has increased the awareness of the impact of policies on gender equality and sharpened the focus on attaining gender equality goals. Both $G 20$ and non-G20 countries reported having received important benefits from the implementation of GB including a better understanding of the intended and unintended impact of the budget on gender equality (see figure 12). This leads to better informed policy choices, meaning policy makers are more aware of the potential impact of decisions on gender. Countries have also reported a greater focus on the achievement of gender equality goals. In addition, more than a quarter of G20 countries have reportedly altered rules and regulations, and more than a third of advanced countries have increased their analysis of gender issues, as a result of GB implementation.

Figure 12. Impact of Gender Budgeting on Gender Equality

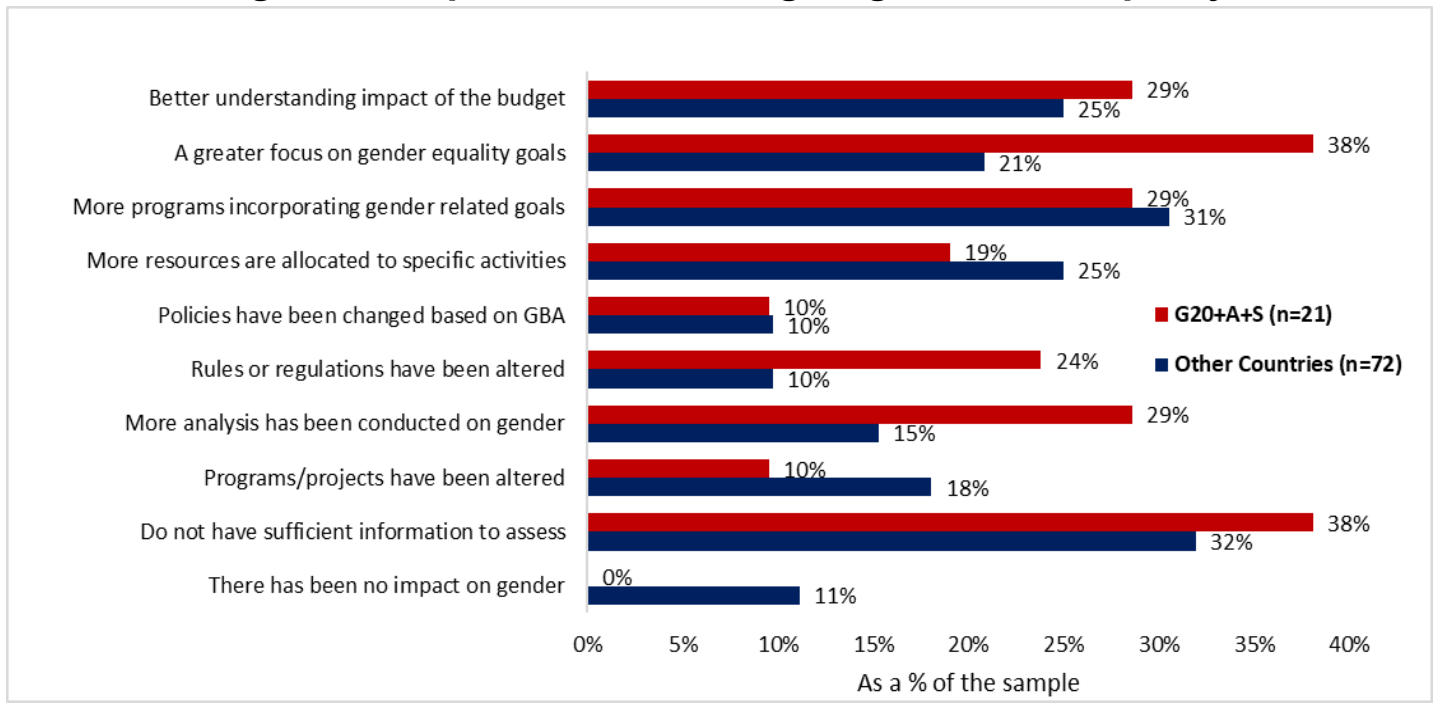

Source: IMF Survey and IMF Staff.

Gender equality is ultimately about changing societies, which entails changes in not just government policy and actions, but also in the private sector and in the behavior of citizens. Evidence connecting GB tools to measurable changes in gender equality outcomes is scarce. This reflects a wider issue with linking government policies and activities to wider societal outcomes, which goes beyond GB. Directly attributing progress made towards gender equality to the implementation of $G B$ is challenging because there are many other factors that impact the achievement of gender equality, including most importantly, societal attitudes and behaviors. However, it is clear from the 
survey that GB practices can make a difference in the way governments consider policy in respect to gender and lead to more conscious and better-informed decision making.

\begin{abstract}
A recent review of $G B$ literature highlights the need for countries to evaluate more the outcomes of GB reforms in a timely manner (Polzer, Nolte and Seiwald 2021). This is consistent with the survey results which confirm some countries need for more information on GB outcomes. This gap needs to be addressed to gain a more in-depth understanding of GB's impact on gender equality and to adjust GB reforms as needed to improve outcomes.
\end{abstract}

\title{
VII. IMPLEMENTATION OF GENDER BUDGETING- THE WAY FORWARD
}

Opportunities exist to enhance the way that GB PFM tools are used to better design and operationalize gender responsive fiscal policies. Based on the analysis of the IMF survey results, country experiences and GB practices as documented in the literature, considerable opportunities exist to improve the implementation of GB PFM. This paper identifies five important opportunities that could be leveraged to improve GB implementation:

1. Focus fiscal policies on areas where gender gaps persist. A number of GB PFM tools can support efforts to not only design, but re-design fiscal policies, adjusting resources to better address persistent gender gaps. For instance, GIAs help to better understand the gender impact of current and alternative policies; tracking and reporting spending and performance helps to evaluate their effectiveness; and ex-post GIA is used in redesigning policy interventions. Further strengthening of gender disaggregated statistical products and tools will also help to underpin improvements in GIAs. Understanding where gaps exist encourages a forward-looking approach to designing and adjusting policies, ultimately providing better alignment between the gender impact of a particular policy and the government's gender goals.

2. Reinforce PFM foundations to support GB practices. Strong PFM systems are needed for the effective implementation of GB PFM tools. Gaps in GB PFM tools are highly correlated to areas where there are gaps in PFM foundations. Evidence from the IMF survey shows that without guidelines or a common methodology for impact assessments it is difficult for line ministries to implement a common approach to GB analysis. Similarly, countries that cannot produce timely budget execution or performance reports cannot get a good grasp of the impact that spending is having on gender. Strengthening PFM tools can enhance the prioritization, design and impact of gender policies.

3. Synchronize GB reforms with PFM reforms to leverage progress. Fundamental improvements to PFM institutions will help to improve GB PFM tools and systems and can act as a catalyst for progressing GB reforms. As GB is concerned with integrating gender tools into existing PFM systems, addressing gaps in PFM offers an opportunity to more closely linking PFM reforms with GB initiatives. This is happening in countries transitioning to program and performance budgeting, where GB is gaining traction as PFM pillars are built.

4. More deeply integrate GB PFM into the budget preparation processes. While survey results present a picture of relatively stronger GB PFM practices in the budget preparation phase, there 
are still a number of areas where integration can be improved. In particular, a stronger connection between gender needs analyses, gender strategies and available resources can help to ensure that fiscal policies designed to improve gender outcomes can be prioritized and delivered within an overall expenditure envelope. Clear priorities will help coordination between ministries (especially Finance and Women ministries) on the implementation of GB tools.

5. Improve GB practices in budget execution, monitoring and ex-post evaluation, including by enhancing program and performance-based budgeting. Evaluating the effectiveness of gender policies in delivering gender outcomes is not widespread and is usually related to the implementation of program and performance-based budgeting. There are three specific elements that can help to improve GB practices: i) Ensuring that gender-sensitive programs and/or line items can be identified and spending can be tracked in the FMIS or using other markers, both if the gender impact is complete or partial; ii) Improving and developing the use of performance indicators to track and monitor program performance against specific outcomes; iii) Developing granular ex-post analysis which requires strong analytical capacity and resources. This practice is crucial to allow for better transparency and monitoring of the effectiveness of policies to inform changes in future decisions.

Solutions must be tailored to individual country circumstances depending on the stage of implementation, level of practice and available resources. A sequenced approach can be especially advantageous where no previous GB practices exist, stakeholders are not yet sufficiently engaged, technical capacity is still developing, or there are PFM limitations. Although some countries, like Austria, have succeeded at introducing GB through a "big-bang" strategy, a gradual approach is more common. In these cases, sequencing should be based on a credible timeline, be structured around monitorable milestones and be underpinned by clear legal norms and methodological principles. Based on our learning from the status of country efforts generated from the survey and IMF involvement with CD activities, a possible approach to the sequencing of GB reform implementation is highlighted in Figure 13 and discussed in detail at Appendix 7.

Figure 13. Proposed Sequencing of GB Implementation

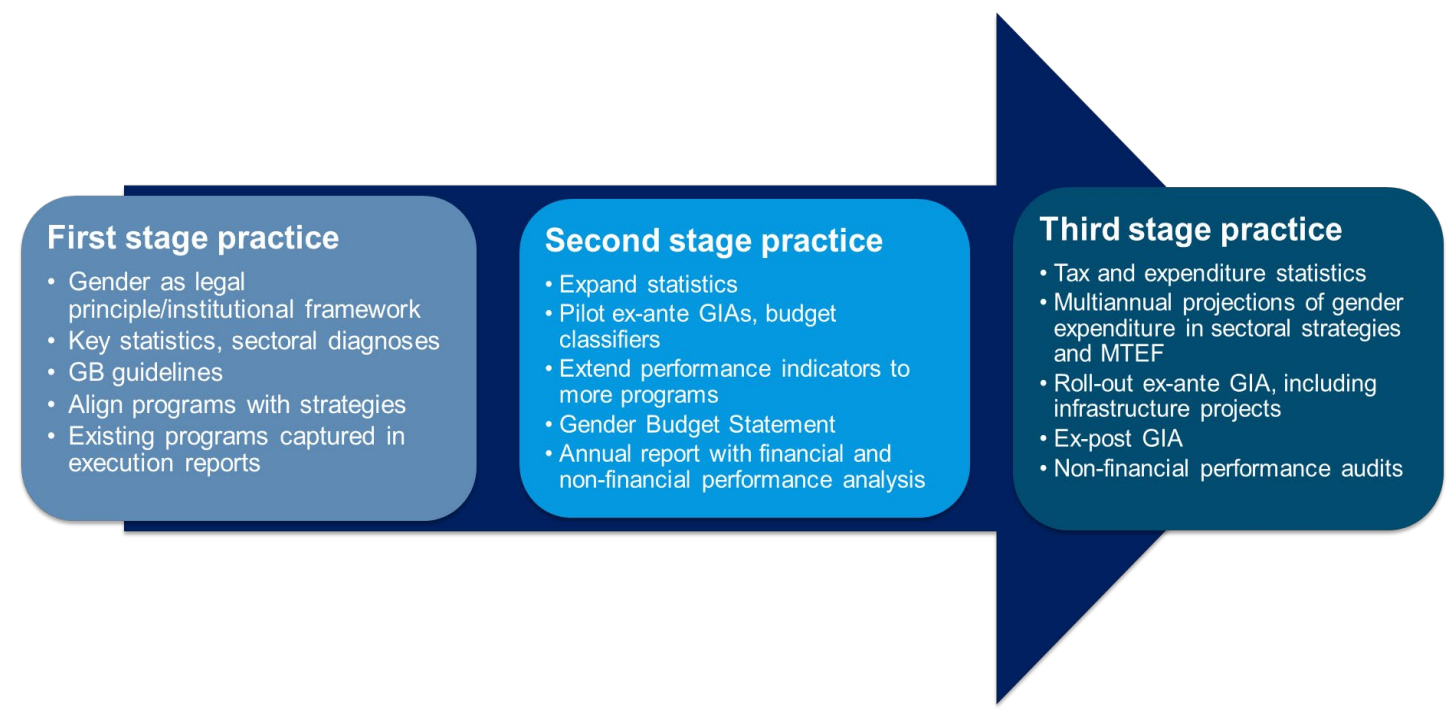

Source: IMF staff. 


\section{SUMmary AND CONCLUSIONS}

Despite progress in most $\mathbf{G 2 0}$ countries in the last fifteen years, achieving gender equality remains a significant challenge that has been only exacerbated by the COVID-19 pandemic Women's participation rate in the workforce on average still remains below that of men, the average gender pay gap remains substantial, women's leadership remains below 50 percent and women are significantly over-represented in the number of hours spent on unpaid work.

GB is an important instrument for tackling gender inequality and closing these gaps - yet the overall average level of GB practices in $\mathbf{G 2 0}$ countries is low. Policy decisions made by governments can serve to either promote gender equality or reinforce existing inequalities. And while progress towards gender equality depends on many factors, such as changes in societal attitudes and behaviors, GB can play an important role to identify gaps in fiscal policies and provide the tools needed to address them.

All G20 countries have enacted gender focused fiscal policies but the PFM tools to operationalize these policies are far less established. While there is significant variation across individual country GB practices, there is no country that achieves an overall average level of advanced practice. Across the budget cycle, clear strengths and weaknesses in GB practices emerge. GB practices are significantly stronger within institutional frameworks and budget preparation processes, than for budget execution and auditing practices - but opportunities for improvement exist in all areas. The trends in strengths and weaknesses of GB practices observed in G20 countries are also true for those surveyed outside of the G20.

Where GB features are in place, GB PFM tends to operate more as an 'add-on', rather than as an integral part of strategic and resource allocation decisions. Countries are at various stages of adopting GB and have a range of approaches, suggesting there is no single model and no linear path for implementation. Future efforts should focus on where policy gaps exist and strengthening the implementation of GB tools that can make a difference to addressing these gaps. PFM foundations should be reinforced to support GB implementation and future GB efforts should be synchronized with PFM reforms to catalyze progress.

All countries can do more to integrate a gender perspective throughout the budget cycle to get the biggest 'bang-for-their-buck' in terms of GB reform efforts. For example, including gender in the budget circular but not incorporating GB tools in the budget execution and reporting phases, may allow countries to fund gender programs - but does not provide any information on how a program's money is spent, if gender objectives are achieved or how programs could be improved.

A more integrated approach to GB also requires better deployment of GB tools in the planning phases of the budget cycle to improve the sustainability of gender policies. Sectoral gender strategies are often highly imprecise, unevenly costed and disconnected from medium-term budget envelopes. Success is promoted by a medium-term strategy, appropriately sequenced and synchronized with envisaged PFM reforms. In most countries gender strategies need to be better linked to medium-term budget frameworks and the financial implications of different initiatives 
within these strategies need to be better assessed and prioritized. Many countries include gender equality goals in national or sectoral plans, but they are not costed or translated into the budget and therefore lack realism about their implementation.

Globally, support for GB is broadening and there are considerable opportunities for countries to do more to improve - regardless of a country's level of development or income. Strong performance in GB implementation does not appear to be heavily dependent on the level of development or income group of a country.

Powerful GB tools are being underutilized and countries are missing out on valuable opportunities to drive policy change and fight gender inequality. Too few countries assess the upfront impact of policies on gender and/or evaluate ex-post the effectiveness of policies and programs. This analysis helps to raise awareness of where the gender gaps are and how policies and programs influence gender equality. However, this analysis needs to be integrated into budget decision making if it is to result in better targeted policy. Policy makers need to be made aware of the impact of their choices on gender upfront - to make better informed decisions. And as policies are implemented, future decisions should be informed by a policy's track-record of impact. Further efforts to improve GB budget execution practices, and ex-post evaluations are necessary, including by enhancing program and performance-based budgeting efforts.

Strong political backing for improving gender outcomes, a MOF who is firmly in the 'driver's seat' and binding legislative requirements are key to successful GB reforms. The vacillating fortunes of GB highlights the importance of promoting wide societal and political support for GB and formalizing requirements to ensure reforms endure changes in governments. Empowering the MOF to develop common methodological guidelines, including gender considerations in budget circulars and strengthening quality checks would help improve GB analysis and help to overcome major implementation challenges.

GB has helped to shape and influence societal views by providing transparent information on government gender policies, or lack thereof. Countries report that implementation of GB has translated into an increased focus on gender equality goals in budget allocations and awareness of the impact of fiscal policies on gender. This provides a platform for raising awareness about the costs of inaction where civil society is called to play a stronger role. More research is needed on the direct effectiveness of GB tools in terms of their contribution to improving gender equality outcomes and the levers by which this is achieved.

Effectively responding to the pandemic means transitioning to GB practices that are more influential in shaping and changing policy decisions. The COVID-19 pandemic has highlighted how the failure to consider gender aspects in the design and implementation of policies can have an unintended impact. It is important that GB PFM tools help disentangle the gender impact of policies during the design and budgeting phases, help to track expenditure effectiveness and improve accountability. Making the impact of policies on equality more visible through better analysis and reporting will help to promote implementation and improve results. The COVID-19 pandemic presents new challenges for the implementation of $\mathrm{GB}$, while underscoring the urgency and importance of progress in this area. 


\section{REFERENCES}

Addis Ababa Action for development. 2015. Addis Ababa Action Agenda of the Third International Conference on Financing for Development. United Nations, New York.

Balmori, Helena Hofbauer. 2003. Gender and Budgets: Overview Report. United Kingdom: BRIDGE (development - gender), Institute of Development Studies, University of Sussex.

Bick, Alexander, and Nicola Fuchs-Schündeln. 2017. "Quantifying the Disincentive Effects of Joint Taxation on Married Women's Labor Supply." American Economic Review 107 (5): 100-104.

Brussevich, Mariya, Era Dabla-Norris, Christine Kamunge, Pooja Karnane, Salma Khalid, and Kalpana Kochhar. 2018. "Gender, Technology, and the Future of Work." IMF Staff Discussion Note 18/07, IMF, Washington, DC.

Brussevich, Mariya, Era Dabla-Norris, and Bin Grace Li, 2021 "China's Rebalancing and Gender Inequality", IMF Working Paper

Budlender, Debbie. 2015. Budget Call Circulars and Gender Budget Statements in the Asia Pacific: REVIEW. UN Women.

Budlender, Debbie. 2002. "Gender budgets: What's in it for NGOs?" Gender and Development (Taylor \& Francis, Ltd.).

Budlender, Debbie, Rhonda Sharp, and Kerri Allen. 1998. How to Do a Gender-Sensitive Budget Analysis: Contemporary Research and Practice. Australian Agency for International Development, Canberra and the Commonwealth Secretariat, London.

Budlender, Debbie, Diane Elson, Guy Hewitt, and Tanni Mukhopadhyay. 2002. Gender Budgets Make Cents: Understanding gender responsive budgets. London, United Kingdom: Gender Affairs Department, Commonwealth Secretariat.

Chakraborty, Lekha. 2016. "Asia: A Survey of Gender Budgeting Efforts." IMF Working Paper: WP/16/150.

Clements, Benedict, Ruud de Mooij, Sanjeev Gupta, and Michael Keen, . 2015. Inequality and Fiscal Policy. International Monetary Fund.

Crossley, Thomas F., and Sung-Hee Jeon. 2007. "Joint Taxation and the Labour Supply of Married Women: Evidence from the Canadian Tax Reform of 1988*." Fiscal Studies 28: 343-265.

Downes, Ronnie, and Scherie Nicol. 2019. "Designing and Implementing Gender Budgeting: A path to action." Organisation for Economic Co-operation and Development (OECD).

Downes, Ronnie, Lisa von Trapp, and Scherie Nicol. 2017. "Gender budgeting in OECD countries." OECD Journal on Budgeting (OECD) 16/3.

Duflo, Esther. 2012. "Women Empowerment and Economic Development." Journal of Economic Literature 50: 1051-1079.

Elborgh-Woytek, Katrin, Monique Newiak, Kalpana Kochhar, Stefania Fabrizio, Kangni Kpodar, Philippe Wingender, Benedict Clements, and Gerd Schwartz. 2013. "Women, Work, and the Economy: Macroeconomic Gains from Gender Equity." IMF Staff Discussion Note; SDN/13/10

Elson, Diane. 1991. "'Male bias in macroeconomics: The case of structural adjustment'." in Elson, D., (ed) Male bias in the development process (Manchester University Press, Manchester and New York).

Elson, Diane. 2006. Budgeting for Women's Rights: Monitoring Government Budgets for Compliance with CEDAW. United Nations Development Fund for Women (UNIFEM). 
European Commission. 2018. The 2018 Ageing Report: country fiches. European CommissionEconomic and Financial Affairs.

Frey R. (2016) Interlinking Gender Responsiveness and Participation in Public Budgeting Processes. In: Ng C. (eds) Gender Responsive and Participatory Budgeting. SpringerBriefs in Environment, Security, Development and Peace, vol 22. Springer, Cham.

Fabrizio, Stefania, Anna Fruttero, Daniel Gurara, Lisa Kolovich, Vivian Malta, Marina M Tavares, and Nino Tchelishvili. 2020. "Women in the Labor Force: The Role of Fiscal Policies." IMF Staff Discussion Note: SDN/20/03. International Monetary Fund, Washington DC.

Herbst, Chris M. 2015. "The Rising Cost of Child Care in the United States: A Reassessment of the Evidence." IZA Discussion Papers, No. 9072.

Lavan K. (2006) Discussion Paper: Towards Gender-Sensitive Participatory Budgeting.

ILO. 2018. "Global Wage Report 2018/19: What lies behind gender pay gaps." Geneva: International Labour Office.

ILO. 2018. World Employment and Social Outlook: Trends for Women 2018 - Global snapshot. Geneva: International Labour Office.

ILO, and OECD. 2019. "Women at Work in G20 countries: Progress and policy action, Paper prepared under Japan's G20 Presidency (2019)." G20 2019 Japan.

IMF. 2017. "Gender Budgeting in G7 Countries." (International Monetary Fund (IMF).

IMF 2021 "Gender Equality and COVID-19: Policies and Institutions for Mitigating the Crisis', Special Series on COVID-19, Washington, DC.

Kochhar, Kalpana, Sonali Jain-Chandra, and Monique Newiak, eds. 2017. Women, Work, and Economic Growth. Washington, DC: International Monetary Fund.

Kolovich, Lisa, ed. 2018. Fiscal Policies and Gender Equality. International Monetary Fund (IMF).

McKinsey Global Institute. 2020. COVID-19 and gender equality: Countering the regressive effects. McKinsey Global Institute.

OECD. 2019. Budgeting and Public Expenditures in OECD Countries 2019. Paris: OECD Publishing.

OECD. 2014. Budgeting Practices and Procedures in OECD Countries. Paris: OECD Publishing.

OECD. 2012. Closing the Gender Gap: Act Now. Paris: OECD Publishing.

OECD. 2019. Government at a Glance 2019. Paris: OECD Publishing.

OECD. 2012. OECD Employment Outlook 2012. Paris: OECD Publishing.

OECD. 2017. OECD Employment Outlook 2017. Paris: OECD Publishing.

OECD. 2019. SIGI 2019 Global Report: Transforming Challenges into Opportunities, Social Institutions and Gender Index. Paris: OECD Publishing.

OECD. 2017. The Pursuit of Gender Equality: An Uphill Battle. 2017: OECD Publishing.

OECD. 2020. "Women at the core of the fight against COVID-19 crisis." OECD Policy Responses to Coronavirus (COVID-19). Paris: OECD Publishing.

Quinn, Sheila. 2016. "Europe: A Survey of Gender Budgeting Efforts." IMF Working Paper (WP/16/155) International Monetary Fund (IMF).

Ostry, Jonathan D., Jorge Alvarez, Raphael Espinoza, and Chris Papageorgiou. 2018. "Economic Gains from Gender Inclusion: New Mechanisms, New Evidence." IMF Staff Discussion Note 18/06, International Monetary Fund, Washington, DC.

CInternational Monetary Fund. Not for Redistribution 
Polzer, Tobias, Isabella M. Nolte and Johann Seiwald. 2021 "Gender budgeting in public financial management: a literature review and research agenda" International Review of Administrative Sciences.

Raquel Fernández, Asel Isakova, Francesco Luna, and Barbara Rambousek. 2021 "Gender Equality and Inclusive Growth", IMF Working Paper (International Monetary Fund (IMF).

Sahay, Ratna, and Martin Čihák. 2018. "Women in Finance: A Case for Closing Gaps." IMF Staff Discussion Note 18/05, International Monetary Fund, Washington, DC.

Sarraf, Feridoun. 2003. "Gender Responsive Government Budgeting." IMF Working Paper: WP/03/83 (International Monetary Fund, Washington DC).

Sharp, Rhonda. 2003. "Budgeting for Equity: Gender Budget Initiatives Within a Framework of Performance Oriented Budgeting." (United Nations Development Fund for Women (UNIFEM)).

Sharp, Rhonda. 2007. Gender Responsive Budgets (GRB's) Have a Place in Financing Gender Equality and Women's Empowerment. United Nations- Division for the Advancement of Women.

Stotsky, Janet G. 2006. "Gender Budgeting." IMF Working Paper: WP/06/232.

Stotsky, Janet G. 2016. "Gender Budgeting: Fiscal Context and Current Outcomes." IMF Working Paper Series, WP/16/149 (International Monetary Fund, Washington DC).

Thomas, Alastair, and Pierce O'Reilly. 2016. "The Impact of Tax and Benefit Systems on the Workforce Participation Incentives of Women." OECD Taxation Working Papers No. 29 (OECD, Paris).

UN General Assembly. 2015. Transforming our world : the 2030 Agenda for Sustainable Development. UN General Assembly.

UN Women. 2015. Budgets with a Gender Perspective at Federal and State Levels in Mexico. United Nations Entity for Gender Equality and the Empowerment of Women (UN Women).

UN Women. 2015. Conceptual References for Gender-Responsive Budgeting. United Nations Entity for Gender Equality and the Empowerment of Women (UN Women).

UN Women. 2015. International Experiences in Elaborating Public Budgets with a Gender Perspective. United Nations Entity for Gender Equality and the Empowerment of Women (UN Women).

UN Women. 2010. Introduction to Gender-Responsive Budgeting and Aid Effectiveness. United Nations Entity for Gender Equality and the Empowerment of Women (UN Women).

UNDP. 2020. "Tackling Social Norms: A game changer for gender inequalities." 2020 Human Development Perspectives. United Nations Development Programme.

United Development Fund for Women (UNIFEM). 2010. Gender-Responsive Budgeting in South Eastern Europe. United Nations Development Fund for Women (UNIFEM).

Unterhofer, Ulrike, and Katharina Wrohlich. 2017. "Fathers, Parental Leave and Gender Norms." IZA Discussion Paper No. 10712.

World Bank. 2012. World Development Report 2012 : Gender Equality and Development. Washington DC: World Bank.

World Economic Forum. 2021. Global Gender Gap Report 2021. Geneva: World Economic Forum. 


\section{Appendix 1. Stylized Data on Gender Equality Gaps in G20 Countries}

\section{Decision Making:}

- Globally, as of 2019, women represent less than one-third (on average 25\%) of members of parliaments in G20 countries.

- Almost half of the G20 countries have established quotas, incentives for political parties to include women on candidate lists, or other special measures at the national level to promote women's political participation and representation.

\section{Labor Inclusion:}

- Globally, in 2019 the gender pay gap persists. In 18 of the G20 countries, women earn $15 \%$ less than men.

- Less than half of the economies analyzed in the latest World Bank report "Women, Business and the Law" have legislation mandating equal remuneration for work of equal value.

- Globally, only $55 \%$ of women (aged 15-64) are engaged in the labor market as opposed to $78 \%$ of men.

\section{Financial Inclusion:}

- The legal framework of all G20 countries provides women with the same rights as men to open a bank account at a formal financial institution and guarantees women's equal access to credit.

- Despite this framework, on average, $22 \%$ of women in the G20 countries lack access to formal bank accounts

Source: W20 - Women's official engagement group of the G20. - About W20 - Women20. 


\section{Appendix 2. Gender Budgeting PFM Tools embedded within the Budget Cycle}

\section{Pillar 1 - Gender Budgeting Framework - Legal and Institutional}

Legal and institutional gender responsive budgeting framework: This includes strong legal frameworks or institutional settings that outline and reinforce the requirement to implement gender budgeting.

Gender disaggregated statistics: In key areas, statistics are collected disaggregated by gender. For example, the number of women and men that receive a given government service, macroeconomic, labor market and sociodemographic statistics. These are used in gender related analysis and impact assessments.

\section{Pillar 2 - Gender Budgeting - Preparation and Approval}

Gender budget statement: A gender budget statement is a gender-specific policy and accountability document produced by a government to show how the annual budget aims to improve gender equality. It can be produced before the outset of budget preparation (Pre-Budget Statement) or be a part of the annual budget documentation. These statements are traditionally tabled in the legislature.

Ex-ante gender impact assessment (GIA): An ex-ante GIA provides an assessment of the potential impact (direct or indirect) of a policy proposal on gender to inform decision makers of the potential impact of their next policy decisions on gender outcomes before the decisions are taken. The assessment can be quantitative or qualitative.

Gender budget circulars: They are part of the budget guidelines or rules circulated by the ministry of finance at the beginning of the annual or multiannual budget process to help the spending ministries to operationalize a gender perspective into their budget proposal. This usually includes instructions on how to classify and track spending on gender, guidelines for gender impact assessments (usually ex ante) and templates to be used in the budget submissions.

Linking gender goals to program and performance: Program and performance-based budgeting helps to introduce gender budgeting from the budget preparation phase of the budget cycle by linking gender related policy goals to specific programs and to performance indicators. This also facilitates monitoring during execution.

Gender budget classification and tagging: a budget program or line item can be tagged or marked according to its gender impact. This helps to identify expenditure proposals according to their gender impact during budget preparation (such as OECD or UNICEF markers) and also facilitates monitoring of budget execution. Budget classifiers can also incorporate gender codes to identify the allocations with gender impact, usually embedded in the finance management information system.

\section{Pillar 3 - Gender Budgeting - Execution, Reporting and Monitoring}

Gender budget execution reports incorporate a gender perspective: in-year and end-year execution reports produced by the ministry of finance that identify the year-to-date gender related spending against gender programs. The report may also cover non-financial performance information.

Ex-post gender impact assessments (GIAs): They assess the impact of policies after a program has been delivered to evaluate whether the policy was effective in achieving the desired policy outcomes, including examining how the policy impacted both men and women. It could also usefully be compared with the ex-ante GIAs, to improve the quality of future ex-ante policy assessments.

\section{Pillar 4 - Gender Budgeting Audit and External Oversight}

Gender related audits: Generally conducted by the supreme audit institution, these are independent, external, usually performance audits that examine how gender objectives are mainstreamed into public policies and budgetary processes, and how the use of public funds in selected programs and/or sectors has impacted gender equality.

Parliamentary oversight: This involves oversight by the legislature of how effectively public resources have been used on gender-related policies to deliver gender outcomes. Oversight mechanisms include annual reports that are tabled and discussed, as well as parliamentary committees, hearings and research or costings by parliamentary budget offices commissioned by members of the legislature. 


\section{Appendix 3. Illustrative Example of Specific Gender Budgeting PFM Tools in Action Throughout the Budget Cycle}
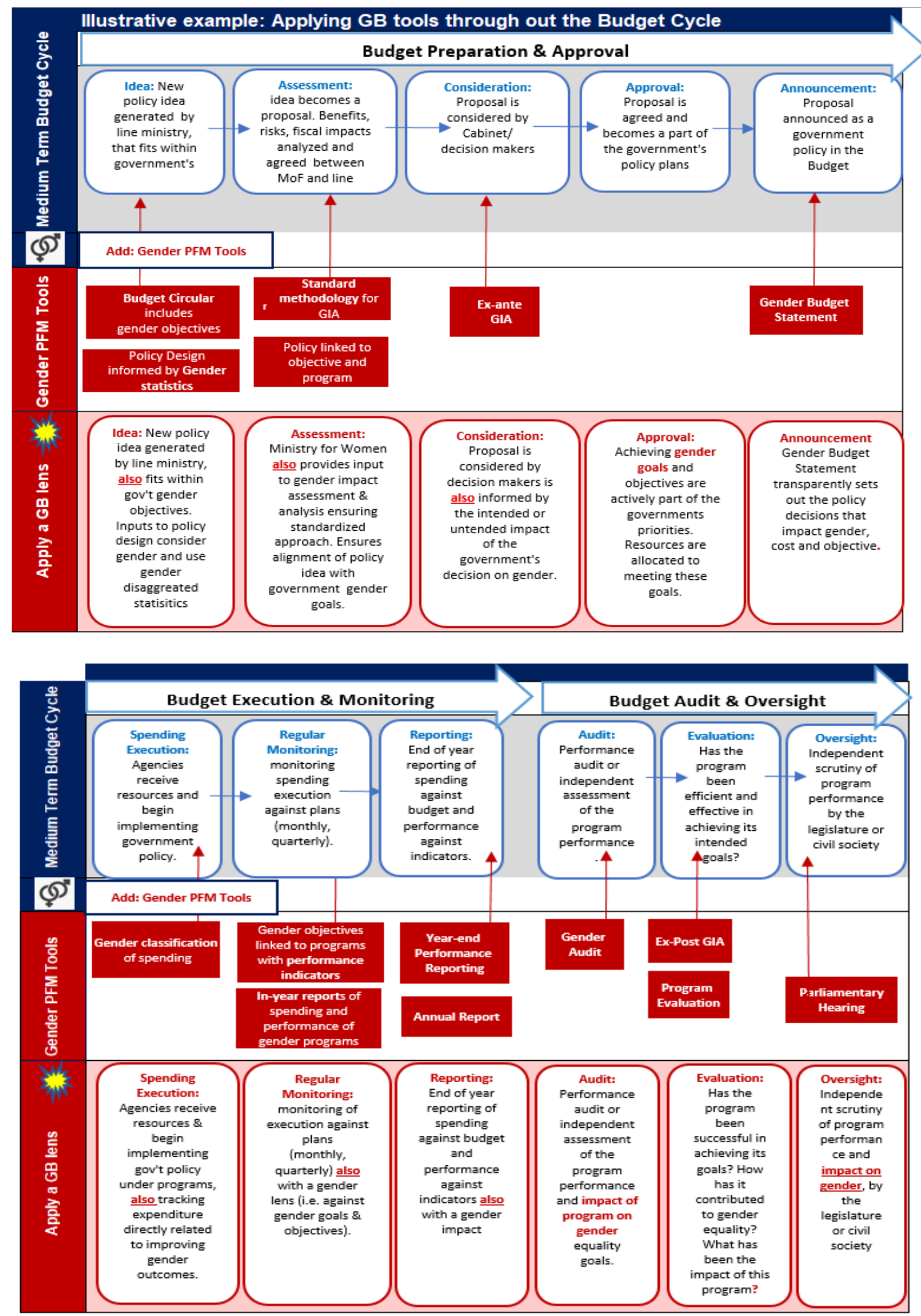


\section{Appendix 4. Questionnaire Used to Assess Gender Budgeting in G20 Countries}

\begin{tabular}{|c|c|c|}
\hline Indicators & Questions & Applicable responses \\
\hline Legal Framework on GRB & $\begin{array}{l}\text { 9. Is there a legal provision for gender budgeting? } \\
\text { (Check all that apply) }\end{array}$ & $\begin{array}{l}\text { - Yes, in the constitution } \\
-\quad \text { Yes, in an organic law } \\
\text { - Yes, in a public finance law } \\
-\quad \text { Yes, in an annual budget law } \\
-\quad \text { Yes, in a planning law } \\
-\quad \text { Yes, in regulations only } \\
-\quad \text { Yes, in other laws, please specify } \\
-\quad \text { No }\end{array}$ \\
\hline \multirow[t]{3}{*}{ Institutional framework } & $\begin{array}{l}\text { 7. Does the government have a gender budgeting } \\
\text { framework? }\end{array}$ & $\begin{array}{l}- \text { Yes } \\
- \text { No }\end{array}$ \\
\hline & $\begin{array}{l}\text { 10. Is there a specific institution with primary } \\
\text { responsibility for gender budgeting reform? } \\
\text { (Select a maximum of two) }\end{array}$ & $\begin{array}{l}\text { - Yes, the president/prime minister's/ Cabinet office } \\
\text { - Yes, the ministry of finance } \\
\text { - Yes, the ministry/agency for women } \\
\text { - Yes, the ministry/ agency of social affairs } \\
\text { - Yes, units within spending/ line ministry/ department and agencies } \\
-\quad \text { Yes, the legislature } \\
-\quad \text { Yes, an independent agency } \\
-\quad \text { Other, please specify } \\
-\quad \text { No }\end{array}$ \\
\hline & $\begin{array}{l}\text { 13. Is there a specific organization that coordinates } \\
\text { discussions on gender issues during budget } \\
\text { preparation? } \\
\text { (Check all that apply) }\end{array}$ & $\begin{array}{l}\text { - Yes, the president/prime minister's office } \\
\text { - Yes, the cabinet office } \\
\text { - Yes, the ministry of finance } \\
-\quad \text { Yes, there is an inter-ministerial committee on gender } \\
-\quad \text { Yes, the ministry/agency for gender } \\
-\quad \text { Other, please specify } \\
-\quad \text { No }\end{array}$ \\
\hline Gender statements & $\begin{array}{l}\text { 15. Does the government produce and publish a gender } \\
\text { budgeting statement? }\end{array}$ & $\begin{array}{l}\text { - The government produces a gender budgeting statement (YES/ NO) } \\
\text { - The government produces and publishes a gender budgeting statement (YES/ NO) } \\
\text { - Other, please specify: }\end{array}$ \\
\hline \multirow[t]{2}{*}{$\begin{array}{l}\text { Ex-ante gender impact } \\
\text { assessment to assess the impact } \\
\text { of proposed policies on gender } \\
\text { equality }\end{array}$} & $\begin{array}{l}\text { 17a. Does the government conduct ex ante gender } \\
\text { impact assessments on new government policy } \\
\text { initiatives? }\end{array}$ & $\begin{array}{l}\text { - Yes, for all new proposals } \\
-\quad \text { Yes, for most new proposals } \\
-\quad \text { Yes, for some new proposals } \\
-\quad \text { Yes for a few new proposals } \\
-\quad \text { No }\end{array}$ \\
\hline & $\begin{array}{l}\text { 17c. Is there a common methodology for ex ante gender } \\
\text { impact assessments? }\end{array}$ & $\begin{array}{l}\text { - Yes, there is a government wide methodology } \\
\text { - } \quad \text { Yes, individual ministries develop a common sectorial methodology } \\
\text { - } \\
\text { - }\end{array}$ \\
\hline
\end{tabular}




\begin{tabular}{|c|c|c|}
\hline Indicators & Questions & Applicable responses \\
\hline & $\begin{array}{l}17 \mathrm{~d} \text {. How are gender impact assessments used in the } \\
\text { budget preparation? }\end{array}$ & $\begin{array}{ll}- & \text { It is used to identify the budget lines with gender impact (quantitative or qualitative) } \\
- & \text { It is used in an overall report on budget gender impact assessment } \\
- & \text { It is used to feed into budget decisions } \\
- & \text { It is not used in practice }\end{array}$ \\
\hline $\begin{array}{l}\text { Budget circular containing specific } \\
\text { guidelines on gender objectives }\end{array}$ & $\begin{array}{l}\text { 16a. Does the budget circular or guidelines include details } \\
\text { on the application of gender budgeting? } \\
\text { (Check all that apply) }\end{array}$ & $\begin{array}{l}\text { - Yes, in guidelines from the ministry of finance to spending ministries } \\
\text { - Yes, in guidelines from individual spending ministries to subordinated departments and } \\
\text { agencies } \\
\text { - No, there are no guidelines on gender budgeting }\end{array}$ \\
\hline \multirow[t]{3}{*}{$\begin{array}{l}\text { Linking gender goals to programs } \\
\text { and performance indicators }\end{array}$} & $\begin{array}{l}\text { 2. Does the government have policies to promote gender } \\
\text { equality? } \\
\text { (Check all that apply) }\end{array}$ & $\begin{array}{l}\text { - Yes, gender equality policies are part of the national development /strategic Plan } \\
-\quad \text { Yes, gender equality policies are part of sectorial/ministerial plans } \\
-\quad \text { Yes, there is a separate strategic plan for gender equality } \\
\text { - } \quad \text { Yes, the government has explicit gender equality goals } \\
-\quad \text { Yes, the government developed gender equality policies to achieve the United } \\
\quad \text { Nation's Sustainable Development Gender Equality goal. } \\
\text { - Other, please specify } \\
\text { - } \quad \text { No }\end{array}$ \\
\hline & $\begin{array}{l}\text { 14. If gender equality goals are set are, they linked to } \\
\text { programs? }\end{array}$ & $\begin{array}{l}\text { - } \quad \text { Yes, they are linked to programs and costed on an annual basis. } \\
\text { - } \quad \text { Yes, they are linked to programs and costed on a medium-term basis. } \\
\text { - } \quad \text { They are not linked to programs but the cost can be identified in the budget through } \\
\text { a classifier. } \\
\text { - } \quad \text { They are linked to programs but not costed. } \\
\text { - } \quad \text { They are not linked to programs nor costed. }\end{array}$ \\
\hline & $\begin{array}{l}\text { 19. Are there performance targets related to gender } \\
\text { equality? }\end{array}$ & $\begin{array}{ll}- & \text { Yes, there are government wide gender equality performance targets } \\
- & \text { Yes, most ministries have gender related performance targets } \\
- & \text { Yes, in some ministries have gender related performance targets } \\
- & \text { Yes, in a few ministries have gender related performance targets } \\
- & \text { There are performance measures for gender equality but no targets } \\
- & \text { There are no performance measures or targets for gender equality } \\
- & \text { Other, please specify }\end{array}$ \\
\hline $\begin{array}{l}\text { Budget classification incorporates } \\
\text { a gender perspective }\end{array}$ & $\begin{array}{l}21 \mathrm{~b} \text {. If the budget classified according to programs, how } \\
\text { is gender incorporated into the program classification? }\end{array}$ & $\begin{array}{ll}- & \text { There are stand-alone gender programs } \\
- & \text { Gender is embedded in other individual programs } \\
- & \text { There are both stand-alone programs and gender is also embedded in individual } \\
& \text { programs } \\
- & \text { Other please specify }\end{array}$ \\
\hline
\end{tabular}




\begin{tabular}{|c|c|c|}
\hline Indicators & Questions & Applicable responses \\
\hline & $\begin{array}{l}\text { 22. Are budgetary allocations tagged with any type of } \\
\text { budget classifiers to identify their linkage to gender } \\
\text { objectives? }\end{array}$ & $\begin{array}{ll}- & \text { Yes } \\
- & \text { No }\end{array}$ \\
\hline \multirow[t]{3}{*}{$\begin{array}{l}\text { Fiscal data disaggregated by } \\
\text { gender }\end{array}$} & $\begin{array}{l}\text { 25a. Does the government collect data disaggregated by } \\
\text { gender? }\end{array}$ & $\begin{array}{ll}- & \text { Yes, in all sectors } \\
- & \text { Yes, in most sectors } \\
- & \text { Yes, in some sectors } \\
- & \text { Yes, in a few sectors } \\
- & \text { No } \\
\end{array}$ \\
\hline & 25b. Is this data published? & \begin{tabular}{ll|}
- & Yes \\
- & No \\
\end{tabular} \\
\hline & $\begin{array}{l}\text { 25c. Is this data used in decision making? } \\
\text { (Very Frequently, Frequently, Occasionally, Rarely, } \\
\text { Never) }\end{array}$ & \begin{tabular}{|ll}
- & Yes, to inform budget decision making \\
- & Yes, to inform decision making on policies \\
- & Yes, to inform decision making on new legislation \\
- & Yes, they are used to develop performance indicators and targets \\
- & Yes, to inform new analysis on gender issues
\end{tabular} \\
\hline \multirow[t]{2}{*}{$\begin{array}{l}\text { Budget execution reports } \\
\text { incorporate gender perspective }\end{array}$} & $\begin{array}{l}\text { 26. Do budget execution reports issued by the } \\
\text { government in-year include information on gender } \\
\text { related expenditures? }\end{array}$ & $\begin{array}{ll}- & \text { Yes } \\
- & \text { No }\end{array}$ \\
\hline & $\begin{array}{l}\text { 27. Does the government's end of year annual financial } \\
\text { statement include information on the following? } \\
\text { (YES/ NO) }\end{array}$ & $\begin{array}{|ll|}- & \text { Gender related expenditure } \\
- & \text { Gender related tax policies } \\
- & \text { Compares approved budget for gender related expenditure to actual budget spent } \\
- & \text { Other, please specify } \\
\end{array}$ \\
\hline \multirow{2}{*}{$\begin{array}{l}\text { Ex-post gender impact } \\
\text { assessments to assess the impact } \\
\text { of policies on gender goals }\end{array}$} & $\begin{array}{l}\text { 28. Does the government conduct ex post gender } \\
\text { impact assessments of budget expenditures? }\end{array}$ & $\begin{array}{ll}- & \text { Yes } \\
- & \text { No } \\
\end{array}$ \\
\hline & $\begin{array}{l}\text { 29. Have gender impact assessments (ex-ante and ex } \\
\text { post) influenced decision making in the following } \\
\text { areas? } \\
\text { (Very Frequently, Frequently, Occasionally, Rarely, } \\
\text { Never) }\end{array}$ & \begin{tabular}{|ll}
- & Informed annual budget decision making \\
- & Informed medium-term budget decision making \\
- & Informed decision making on new policies \\
- & Informed decision making on amendments to existing policies \\
- & Informed analysis on gender issues \\
- & Informed the agenda and goals for gender equality \\
\end{tabular} \\
\hline Gender related audits & $\begin{array}{l}\text { 32. Has the National/Supreme audit institution in the } \\
\text { past three years, produced audit reports with? } \\
\text { (YES/ NO) }\end{array}$ & \begin{tabular}{|ll}
- & With ex-post analysis on the impact of the budget on gender equality \\
- & With ex-post analysis on the impact of tax policy on gender equality \\
- & With analysis of the impact of specific sectoral policies on gender equality \\
- & With analysis of the impact of individual programs on gender equality
\end{tabular} \\
\hline
\end{tabular}




\begin{tabular}{|c|c|c|}
\hline Indicators & Questions & Applicable responses \\
\hline Parliamentary control & $\begin{array}{l}\text { 31. Has the legislature/Parliament in the last three years } \\
\text { undertaken any of the following activities in relation to } \\
\text { gender equality? } \\
\text { (YES/ NO) }\end{array}$ & $\begin{array}{ll}- & \text { Conduct hearings on gender equality issues } \\
- & \text { Published any reports on gender equality issues } \\
- & \text { Discussed the impact of the budget on gender equality } \\
- & \text { Discussed the impact of tax policies on gender equality } \\
- & \text { Reviewed information on gender equality goals or performance targets } \\
- & \text { Reviewed information in annual reports or financial statements on the performance } \\
& \text { of gender equality initiatives } \\
- & \text { Established a committee on gender issues } \\
- & \text { Other, please specify }\end{array}$ \\
\hline
\end{tabular}

Note: These 23 questions are the core questions of the full GB survey and these questions and the 12 indicators are used to produce the gender budgeting index. 
Appendix 5. Table of Correlations Between GBI Components $(n=21)$

\begin{tabular}{|c|c|c|c|c|c|c|c|c|c|c|c|c|}
\hline & LEGAL & INSTITUTIONAL & DATA & $\begin{array}{c}\text { GENDER } \\
\text { STATEMENTS }\end{array}$ & $\begin{array}{c}\text { BUDGET } \\
\text { CIRCULAR }\end{array}$ & $\begin{array}{c}\text { EX-ANTE } \\
\text { GIA }\end{array}$ & $\begin{array}{c}\text { LINKING GOALS } \\
\& \text { PROGRAMS }\end{array}$ & $\begin{array}{c}\text { BUDGET } \\
\text { CLASSIFICATION }\end{array}$ & $\begin{array}{c}\text { BUDGET } \\
\text { EXECUTION }\end{array}$ & $\begin{array}{c}\text { EX-POST } \\
\text { GIA }\end{array}$ & AUDITS & PARLIAMENTS \\
\hline LEGAL & 1.00 & 0.60 & 0.02 & 0.75 & 0.80 & 0.45 & 0.31 & 0.27 & 0.43 & 0.43 & 0.38 & 0.30 \\
\hline INSTITUTIONAL & 0.60 & 1.00 & 0.15 & 0.55 & 0.65 & 0.46 & 0.64 & 0.69 & 0.32 & 0.27 & 0.07 & 0.27 \\
\hline DATA & 0.02 & 0.15 & 1.00 & 0.11 & 0.01 & 0.51 & 0.11 & 0.00 & 0.01 & -0.06 & -0.25 & 0.47 \\
\hline STATEMENTS & 0.75 & 0.55 & 0.11 & 1.00 & 0.59 & 0.66 & 0.31 & 0.38 & 0.36 & 0.30 & 0.37 & 0.32 \\
\hline CIRCULAR & 0.80 & 0.65 & 0.01 & 0.59 & 1.00 & 0.32 & 0.29 & 0.28 & 0.46 & 0.43 & 0.25 & 0.47 \\
\hline EX-ANTE GIA & 0.45 & 0.46 & 0.51 & 0.66 & 0.32 & 1.00 & 0.25 & 0.19 & 0.08 & 0.24 & 0.28 & 0.55 \\
\hline $\begin{array}{l}\text { LINKING GOALS } \\
\& \text { PROGRAMS }\end{array}$ & 0.31 & 0.64 & 0.11 & 0.31 & 0.29 & 0.25 & 1.00 & 0.60 & 0.16 & 0.11 & 0.05 & 0.35 \\
\hline CLASSIFICATION & 0.27 & 0.69 & 0.00 & 0.38 & 0.28 & 0.19 & 0.60 & 1.00 & 0.31 & -0.03 & -0.06 & -0.03 \\
\hline EXECUTION & 0.43 & 0.32 & 0.01 & 0.36 & 0.46 & 0.08 & 0.16 & 0.31 & 1.00 & 0.34 & 0.35 & 0.27 \\
\hline EX-POST GIA & 0.43 & 0.27 & -0.06 & 0.30 & 0.43 & 0.24 & 0.11 & -0.03 & 0.34 & 1.00 & 0.25 & 0.06 \\
\hline AUDITS & 0.38 & 0.07 & -0.25 & 0.37 & 0.25 & 0.28 & 0.05 & -0.06 & 0.35 & 0.25 & 1.00 & 0.35 \\
\hline
\end{tabular}

Source: IMF Survey and IMF Staff. Note: GB tools and institutions highlighted in red reflect correlations greater than 0.4. Green reflects the correlation of a GB tools and institutions with

themselves showing a score of 1 given they are perfectly correlated with themselves. 


\section{Appendix 6. Methodology for the Gender Budgeting Index}

The IMF's Fiscal Affairs Department (FAD) developed an online gender budgeting survey, to help assess countries' gender budgeting practices. The key purpose of the survey is to obtain comparative data on the current status of GB practices in G20 countries and beyond.

The paper is based on the data generated using responses from the self-assessment survey completed by government officials to a close ended multiple-choice questionnaire. The survey was sent to all G20 governments in 2019. The respondents are government officials, mainly at the ministry of Finance or/and the ministry of women or related entities responsible for gender issues in a given country. The data collection for this study took place in 2019 and 2020 with follow up and quality check of responses taking place in late 2019 and 2020. During the analysis, in order to assure the quality of the data, the team contacted the respondents whenever there was a need for an explanation or to verify responses. For some responses, countries are asked to provide links to relevant documents, which have been verified, and where information is available answers have been scrutinized to detect and remove inconsistencies as much as possible.

The sample understudy comprises of twenty-one (21) countries; nineteen (19) G20 countries (being the $20^{\text {th }}$ the European Union) and two guests G20 countries, namely Austria and Spain. The survey only assesses the gender budgeting practices at central government level.

The study assessed the status of GB practices in G20 countries using twelve (12) indicators comprised of twenty-three (23) questions (see Appendix 4). Each question is scored, ranging from 0-3 based on the level of GB practices in the country. The scores capture not only the existence of the most relevant PFM tools but also the design quality and soundness of GB tools and PFM practices and some aspects of their application. For example, in addition to assessing if governments produce impact assessments, scores are higher for those countries where a common methodology is in place, and the assessment is used in decision making. The quality aspect is determined by awarding higher scores for better practices.

The scores of the twelve indicators have been calculated by taking the arithmetic mean of the scores of the questions under each indicator. Each indicator is ranked based on their level of performance, scores between 2.5 and 3 are considered advanced practices, values between 1.1 and 2.4 are associated with good practices, values between 0.1 and 1 denote limited practices. For the G20 countries these are presented in Table 3 of the paper. Further, the overall country score of the 'Gender Budgeting Survey' is calculated by taking the arithmetic mean of the scores of the twelve indicators. In terms of relative ranking of overall country performance, scores between 1.47 and 2.25 are considered high, 0.75 and 1.46 are medium and scores between 0.03 and 0.74 denote low. The overall GBI score explains the relative position of a country with GB tools, in comparison to other G20 countries. The paper provides countries' comparative overall gender budgeting scores in Figure 7.

\section{Acknowledgement}

Thanks are due to the respondents of the G20 countries and Austria and Spain for taking time to provide quality data for the survey. 


\section{Appendix 7. A Possible Sequencing of GB Reforms}

\section{At a first stage, countries could prioritize establishing supporting frameworks and institutions by:}

- Enshrining gender equality as a principle informing PFM. This may involve legislative amendments, preferably in high-rank laws (at least Organic Budget Laws and PFM laws), which can be subsequently supplemented by changes in technical and sectoral regulations. Legislative changes should clearly define the departments responsible for the mainstreaming of GB reforms and the coordination of gender discussions during budget preparation. Considerable benefits can be drawn from the MOF playing a central or prominent role in these coordination arrangements.

- Ensuring the availability of gender-disaggregated statistics and gender needs diagnoses in critical sectors. The production of comprehensive statistics by gender is a medium-term process that involves line ministries and sectoral agencies, national institutes of statistics and private producers. In a first stage, these statistics can be confined to basic variables, such as employment, education enrollment, access to health services or monthly earnings. Only on the basis of these data, which in some countries can be generated with the support of donors, is it possible to diagnose major gender gaps and develop basic tools to address them. In order to raise social awareness about these gaps and the importance of reducing them, consideration can be given to the publication of an annual report on the status of gender equality and the evolution of the main gaps. This report can be discussed in Parliament. It also can be part of the annual budget execution performance report where they exist.

- Strengthening, where needed, the alignment between national gender equality goals, sectoral strategic objectives and programs targeted to women. Gender equality targets should cascade from national strategies and development plans to specific sectoral plans, adequately broken down and costed by programs and activities. In a first stage, countries can focus on programs specifically targeted at women, the objectives and impact of which are easier to define. A coordinating entity with technical expertise within the government can oversee the broad alignment of these programs with government's priorities. At this stage, a formal exante GIA may not be necessary to underpin program proposals, but only a brief assessment of their intended effects on gender equality in view of their beneficiaries and their linkages with sectoral strategies. Additionally, the MOF should verify the financial viability of these plans and the consistency with resources. Technical capacity and statistics permitting, a few annual performance indicators can be piloted in these programs.

- Ensuring that in-year and annual budget execution reports capture gender equality programs. In the same vein, those ministries managing programs with pilot performance indicators can produce a written assessment, as soon as statistical information is available, on the non-financial performance of these programs, to be circulated at government level. If these analyses are deemed to have some quality, they can be incorporated into the annual report on gender equality.

- Producing and publishing a set of GB guidelines, with clearly defined objectives, processes, responsibilities, and sequenced milestones. Good practice is that these guidelines are produced jointly by the ministry of finance, which has the most comprehensive view of the budget process, and another specialized ministry, such as women or social affairs in consultation with the rest of line ministries. The guidelines can differentiate several levels of practice and set a clear timeline for the application of each of them in view of the starting position of the country and technical capacity of line ministries. As part of the basic level of practice, the guidelines should describe at a minimum: i) the information line ministries are expected to provide to the MOF during the strategic phase of budget preparation, when annual budget priorities are decided; ii) the guidance that budget call circulars will provide to help line ministries to integrate their gender priorities and programs in their budget requests and how to track and report them (decide on the use of gender budget classifiers and gender markers); iii) some technical criteria for the definition of performance indicators, and the content of the assessment reports to be produced by line ministries.

Transitioning to the second stage can be facilitated by the gradual development of ex-ante GIA and an enhanced identification of gender-sensitive programs in the budget. This can be done by:

- Expanding the statistical base of gender-disaggregated statistics to new sectors and improving databases of beneficiaries of expenditure policies by gender. 
- Piloting ex-ante GIAs in a number of line ministries. Ex-ante GIAs could include at this stage those programs not exclusively targeted at women. Starting from a reduced number of pilot ministries and programs, they could be gradually rolled-out to other departments and supported by a training agenda. These efforts should be underpinned by the development of a common methodology eventually annexed to the GB Guidelines. Complementarily, ex-ante GIAs should be accompanied by a two-pronged quality control, involving ministries of women when it comes to their technical content and MOFs regarding its budgetary side. As long as the pilot phase yields satisfactory outcomes, GIAs can begin to be used in bilateral budget discussions between the MOF and line ministries.

- Extending performance indicators to all gender-sensitive programs and sub-programs. These indicators should differentiate between outputs and outcomes, cover the whole life of the sub-program and activity and include numerical targets.

- Developing a system of markers for gender-sensitive programs, in parallel to the implementation of exante GIAs. To be fully effective, these markers could be incorporated in the Chart of Accounts or budget classifiers and the FMIS -in this phase or the third one-, which would ensure a complete monitoring of their financial performance, and budget execution reports. If not possible, they can be reported in other systems.

- Discussing gender gaps and gender-sensitive policies in the annual budget statement, where this exists. This discussion should reflect gender policy priorities and the flagship initiatives of the government in this area. When the statement is published together with the budget proposal rather than as a pre-budget statement, it could also include quantitative and performance information about the proposed appropriations to gender-sensitive programs. The use of budget classifiers or tagging in budget proposals will help the compilation of the gender budget statement making visible the policies objectives and allocations.

- Publishing an annual report compiling and analyzing the financial and non-financial performance of gender-related programs, eventually as part of an annual gender equality report or annual performance report. For the sake of accountability, gender performance information should be discussed in parliament, for instance in a distinct hearing session.

Countries moving to the third stage could consider action in the following areas:

- Expanding statistics by gender to the entirety of sectors and developing tax statistics by gender. Together with expenditure, such as social transfer statistics by gender, tax statistics can be used to analyze combined incentives of fiscal policies on labor supply and human capital accumulation.

- Developing and discussing multi-annual projections of gender-related expenditure in key programmatic and budgetary documents. The latter include sectoral strategies. Medium-Term Budget Frameworks (MTBF) and budget/gender statements. Gender budget classifiers could also be reflected in MTBF, to facilitate the identification of gender-sensitive initiatives among government's strategic priorities. To raise the impact of these projections, the parliament can debate them in a separate session/hearing.

- Gradually rolling-out ex-ante GIA to all ministries. Ex-ante GIA should become an integral part of regulatory impact assessment for all ministries during this phase. The ministry of finance would verify that, material, GIAs are included in all budget submissions and assessments of infrastructure projects, and then used as a tool for framing discussions with line ministries during bilateral hearings.

- Actively using performance information during budget preparation, especially in the course of mediumterm expenditure planning and bilateral hearings subsequent to the submission of budget requests. Budget call circulars can support this approach, by requesting the inclusion of this information in budget requests and clarifying that it will be discussed during bilateral hearings and taken into consideration to determine final expenditure ceilings by department.

- Enriching the qualitative analysis of performance reports. Beyond monitoring quantitative performance indicators, these reports could also dwell on the reasons why some programs may fail to deliver their objectives, or if they have surpassed expectations or produce beneficial effects of an unexpected kind.

- Undertaking non-financial performance audits and ex-post GIA of selected gender-sensitive policies and publishing their results. Then feeding the results of these assessments into new policy decisions. Like performance information, this analysis should be utilized to inform budget preparation and improve gender markers decisions. 
Appendix 8. Q9: Legal Provision for Gender Budgeting in G20 Countries

\begin{tabular}{|c|c|c|c|c|c|c|c|c|}
\hline Country & $\begin{array}{c}\text { In the } \\
\text { Constitution }\end{array}$ & $\begin{array}{c}\text { In an } \\
\text { Organic } \\
\text { Law }\end{array}$ & $\begin{array}{c}\text { In a Public } \\
\text { Finance } \\
\text { Law } \\
\end{array}$ & $\begin{array}{c}\text { In an } \\
\text { Annual } \\
\text { Budget Law } \\
\end{array}$ & $\begin{array}{c}\text { In a } \\
\text { Planning } \\
\text { Law }\end{array}$ & $\begin{array}{c}\text { In } \\
\begin{array}{c}\text { Regulations } \\
\text { only }\end{array} \\
\end{array}$ & $\begin{array}{c}\text { In } \\
\text { Other } \\
\text { Laws } \\
\end{array}$ & No \\
\hline Argentina & & & & & & $X$ & & \\
\hline Australia & & & & & & & & $x$ \\
\hline Austria & $x$ & $x$ & $x$ & $X$ & & & & \\
\hline Brazil & & & & $x$ & $x$ & & & \\
\hline Canada & & & $x$ & & & & & \\
\hline China & & & & & & & & $x$ \\
\hline France & & & & & & $x$ & & \\
\hline Germany & & & & & & & $x$ & \\
\hline India & & & & & $x$ & & & \\
\hline Indonesia & & & & & & & & $x$ \\
\hline Italy & & & $x$ & & & & $x$ & \\
\hline Japan & & $x$ & & & & & & \\
\hline Mexico & & & & $x$ & $x$ & $x$ & & \\
\hline Russian Federation & & & & & & & & $x$ \\
\hline Saudi Arabia & & & & & & & & $x$ \\
\hline South Africa & & & & & & $x$ & & \\
\hline South Korea & & $x$ & $x$ & & & & & \\
\hline Spain & & $x$ & & & & & $x$ & \\
\hline Turkey & & & & & & & & $x$ \\
\hline United Kingdom & & & & & & & & $x$ \\
\hline $\begin{array}{l}\text { United States of } \\
\text { America }\end{array}$ & & & & & & & & $x$ \\
\hline
\end{tabular}




\section{Appendix 9: Gender Budgeting (GB)Practices in G20 and Selected Countries ${ }^{36}$}

This appendix provides summary details on gender budgeting practices in individual G20 countries and Austria and Spain. The write up for each country follows a similar structure, briefly discussing the country's gender equality commitments and policies, its GB legal and institutional framework and the GB public financial management tools. ${ }^{37}$

\section{Gender Budgeting Practices in Argentina}

Gender Equality Commitments and Polices: Over the past few years, Argentina has launched several initiatives which aim to improve equality and inclusion in the areas of health, education, labor force participation and access to justice. The current administration has a renewed focus on tackling gender equality issues, including promoting women's rights and addressing gender violence.

Gender Budgeting Legal and Institutional Frameworks: The 2018-2020 National Plan for Equal Opportunities and Rights' (Plan Nacional de Igualdad de Oportunidades y Derechos, PIOD), coordinated by the National Institute for Women, aims at creating equal conditions and rights for all people, independently of their gender. One of its stated objectives is the formal legal introduction of GB. In 2019, for the first time the budget formulation process and the draft budget bill introduced a gender perspective. ${ }^{38} \mathrm{~A}$ draft law which proposes to give GB a permanent legal basis, has been reviewed by the Parliament's Budgetary Office. $^{39}$

The status of the National Institute for Women was elevated in December 2019 when the President created Argentina's first Ministry of Women, Gender and Diversity, tasked with overseeing the country's public policies on issues affecting women, gender and sexual minorities. ${ }^{40}$ In addition, a new government cabinet committee was created in August 2020 to advance the objective of mainstreaming gender equality into public policies. ${ }^{41}$ Both the Ministry of Economy and the Ministry of Women are leading GB reform. In particular, the Directorate of Economy, Equality and Gender in the Ministry of Economy has played a central role in achieving consensus among stakeholders. Civil society in Argentina has played a successful role in collaboration with these ministries to promote transparency in gender budget allocations. ${ }^{42}$

GB Public Financial Management Tools: Since 2018, Argentina has introduced a number of GB initiatives and tools. Budget circulars have incorporated GB since 2018 and the circular for 2021 budget instructs implementing institutions to identify the budget lines that are relevant for monitoring of gender policies. ${ }^{43}$ In 2019, the Ministry of Economy and Public Finance, introduced a methodology to identify spending programs with a gender impact, in order to estimate the amount of public spending directed towards reducing gender inequalities. ${ }^{44}$ On the basis of this analysis, the Secretariat of Finance, together with the

\footnotetext{
${ }^{36}$ These country write ups have been produced by the authors of this paper, especially Nino Tchelishvili, and by Laura Gores, Lesley Fisher, Lorena Rivero del Paso and Ozlem Aydin.

${ }^{37}$ These country write ups are not intended to be comprehensive but rather to provide a brief overview of the selected GB approaches in $\mathrm{G} 20$ countries. Unless otherwise indicated the data for these write ups reflects the period of the completion of the GB survey.

${ }^{38}$ Proyecto de ley de presupuesto general de la administración nacional 2019, Mensaje (https://www.economia.gob.ar/onp/documentos/presutexto/proy2019/mensaje/mensaje2019.pdf) and 2019 budget circular https://www.minhacienda.gob.ar/onp/documentos/instrutexto/archivos/cir1-18.pdf.

${ }^{39}$ Oficina del Presupuesto del Congreso, Análisis del proyecto de ley de incorporación de la perspectiva de género en los presupuestos públicos (S-0268/2020);

${ }^{40}$ Ley de Ministerios / Decreto 7/2019, Boletín Oficial de la República Argentina, 10 December 2019.

${ }^{41}$ https://www.argentina.gob.ar/noticias/se-creo-el-gabinete-nacional-para-la-transversalizacion-de-las-politicas-de-genero

${ }^{42}$ https://acij.org.ar/wp-content/uploads/2018/02/minuta_genero.pdf

${ }^{43}$ Circular ONP N 1/2018, Formulación del Presupuesto Nacional 2019 y Plurianual 2019-2021; Circular N $1 / 2020$ Instrucciones generales para la formulación del Presupuesto Nacional 2021.

${ }^{44}$ Argentina, Presupuesto ciudadano; Argentina, Ministerio de Hacienda, Presupuesto con perspectiva de género, una propuesta metodológica, Agosto 2019.
} 
Directorate of Economy, Equality and Gender, publishes quarterly budget execution reports and open budget that monitor expenditure linked to gender policies. ${ }^{45}$ The report also presents performance information, with progress measured against predefined performance indicators. Notably, Argentina has integrated gender spending markers into the financial management information system (eSidif), by introducing a tagging methodology and by assigning weightings. This helps to identify which budgetary programs contribute to the achievement of gender-sensitive policies and the size of their contribution. Gender impact assessments are still not widespread and conducted only for a few new proposals.

\section{Gender Budgeting Practices in Australia}

Gender Equality Commitments and Polices: Consistent with commitments made under international treaties Australia protects and promotes the right to equality and the right to be free from discrimination through legislation, policies and programs at the federal, state and territory levels. The 'Commonwealth Sex Discrimination Act 1984 ' is the national legislation that gives effect to Australia's obligations under CEDAW. The Act covers the issues of discrimination in education, partnerships, marital status, sexual harassment and potential pregnancy. The 'Australian Human Rights Commission' is an independent statutory organization responsible for receiving complaints about breaches of the Act. In addition to the 'Fair Work Act 2009' and the 'Workplace Gender Equality Act 2012' further implement CEDAW rights in relation to gender equality and non-discrimination in employment. Although no separate legislation is required by states and territories to ensure Australia's compliance with CEDAW, all Australian states and territories have antidiscrimination laws that also prohibit sex discrimination. These laws are administered by equal opportunity or anti-discrimination bodies in each state.

The Government's priorities for women's gender equality are targeted across three key areas: women economic security including workforce participation; supporting more women into leadership positions; and ensuring that women are safe from violence. ${ }^{46}$

GB Legal and Institutional Frameworks: Australia is a pioneer in global GB having first initiated GB in 1984. The key pillar of Australia's efforts has been the publication of a gender budget statement which was published from 1984 until 2013. ${ }^{47}$ Requirements for governments to undertake GB are not established within the legal framework. As a result, support for GB PFM initiatives, including the form and substance of associated gender budget statements, are determined by the governing political party (Sharp, 2013). Therefore "the processes by which the assessments of the gender impact of the budget are undertaken, the quality of the gender analysis, the lines of accountability and the budget status of gender budget statements changes over time". ${ }^{48}$

Institutional arrangements as of 2019 included a Minister for Women, who is supported by the Office for Women, a functional unit within the Department of the Prime Minister and Cabinet. The Office for Women is responsible for coordinating gender work across government and providing advice to both the Minister for Women, and the Prime Minister, to deliver policies and programs to advance gender equality and improve the lives of Australian women. Under different governments, the placement of the Office for Women within the machinery of government has varied, sometimes within central agencies and at other times under the purview of the relevant line ministry with responsibility for family and community issues. Given its role in the budget process, the Ministry of Finance helps to coordinate the implementation of GB budget circulars as necessary, that set out annual budget process requirements for GB. These requirements change from year to year depending on the priority placed on GB by the incumbent government.

\footnotetext{
${ }^{45}$ https://www.presupuestoabierto.gob.ar/sici/listado-informes-genero (Informe de seguimiento del gasto vinculado con políticas de género en el Presupuesto).

${ }^{46}$ Office for Women, Department of the Prime Minister and Cabinet (pmc.gov.au).

${ }^{47} 2013$ Sharp and Broomhill: A Case Study of Gender Responsive Budgeting in Australia.

48 Ibid.
} 
Across the Australian government, disaggregated gender data and statistics are produced in relation to the labor force, including gender composition of the private sector and educational attainment (particularly STEM). More specifically, the Australian Bureau of Statistics (ABS) produces regular releases that include breakdowns by gender, (including monthly labor force outcomes that detail rates of employment by gender and workforce participation with gender segregation by occupation and industry). The Department of Industry, Science, Energy and Resources also prepares the annual 'STEM Equity Monitor' ${ }^{\prime 49}$, a national data report on girls' and women's participation in STEM.

While Australia does not have a National Strategy or Action Plan for gender equality ${ }^{50}$, there are strategies and activities for achieving each of these goals including: the Fourth Action Plan to Reduce Violence against Women and their Children ${ }^{51}$, the Women's Workforce Participation Strategy ${ }^{52}$ and the BoardLinks ${ }^{53}$ program. Internationally, the Department of Foreign Affairs and Trade's 'Gender equality and women's empowerment ${ }^{\prime 54}$ strategy, aligned with SDG 5, guides gender equality initiatives within Australia's diplomatic, development and regional security efforts. Funding for these strategies and activities is provided in the budget, among relevant programs across the five years of the medium-term budget framework. In addition, each Australian state and territory has strategic action plans for women's advancement or strategies for gender equality.

GB Public Financial Management Tools: The Australian government does not explicitly track the proportion of the national budget that is invested in the promotion of gender equality and the empowerment of women however, outcome and program-based budgeting is a long-established practice in Australia. ${ }^{55}$

At the time the survey was conducted, a GB statement was not produced and published by the government. The last prepared women's budget was the May 2013 'Women's Budget Highlights 2013-14' prepared when the Office for Women was located within a line ministry with responsibility for family and social issues. However, the opposition party has published a Women's Budget Statement ${ }^{56}$ since 2014 and independent not-for-profit entities such as the National Foundation for Australian Women (NFAW) ${ }^{57}$ have published a set of position papers to apply a gender lens over the budget for the last five years, since 2016. The position papers prepared by the NFAW summarize the importance of announced budget measures to women in Australia. They also provide recommendations and modelling on the impacts on women of increased government expenditure in certain sectors.

In 2018, the Minister for Women issued a 'Women's Budget 2018-19 Snapshot'58 which is a short glossy document to highlight the new spending measures that benefit women in the budget. In the 2020 Budget (October 2020) the Australian Government produced a second 'Women's Economic Security Statement'59, building on the inaugural statement in 2018. The Statement highlights new spending decisions and policy changes announced in the budget that are designed to improve workforce participation and improve women's financial security.

Gender impact assessments are reported to occasionally influence decisions of future spending. For example, as a result of the high proportion of women that work part-time, the 'Time Use Survey' will be reestablished to learn more information about how men and women use their time; and how it impedes on

\footnotetext{
${ }^{49} \mathrm{https}$ ///www.industry.gov.au/data-and-publications/stem-equity-monitor.

${ }^{50}$ Australia's National Review- Beijing+25.

${ }^{51}$ https://www.dss.gov.au/women-publications-articles-reducing-violence/fourth-action-plan.

${ }^{52}$ https://womensworkforceparticipation.pmc.gov.au/.

${ }^{53}$ https://www.boardlinks.gov.au/.

${ }^{54}$ https://www.dfat.gov.au/about-us/publications/Pages/gender-equality-and-womens-empowerment-strategy.

${ }^{55}$ Australia's National Review- Beijing +25 .

${ }^{56}$ https://alp.org.au/media/2212/2020-womens-budget-statement.pdf.

${ }^{57}$ https://nfaw.org/projects/gender-lens-on-the-budget/.

${ }^{58}$ https://www.pmc.gov.au/news-centre/office-women/womens-budget-2018-19-snapshot.

${ }^{59}$ https://www.pmc.gov.au/office-women/economic-security/wess.
} 
the ability to work full-time hours. Individual line ministries, who are responsible for developing policy proposals for consideration in the budget process, prepare ex-ante gender impact assessments for some new proposals.

In-year budget execution reports issued by the government do not include information on gender related expenditure. Year-end budget execution reports or Annual Reports are produced at a decentralized level. Each agency is responsible for reporting against their performance in delivering on relevant gender equality goals and targets. Under the outcome-based performance reporting model in place in Australia, agencies provide performance measures and targets in Annual Corporate plans and program performance criteria in Portfolio Budget Statements. Annual performance statements that report progress against targets and criteria are included in agency annual reports.

In addition, the Australian Bureau of Statistics (ABS) produces the annual 'Gender Indicators' ${ }^{60}$ publication bringing together existing data from $A B S$ and other official data partners to compare outcomes for women and men in one publication. The release identifies outcomes for men and women across six domains including: economic security, education, health, work and family balance, safety and justice, and democracy, governance and citizenship. Further, the 'Gender Balance on Australian Government Boards Report'61 is prepared annually by the Australian Government Office for Women, and reports on the Government's performance against its gender diversity target. For the public sector there is a gender diversity target for women to hold 50 percent of Australian Government board positions overall, and women and men each holding at least 40 percent of positions at the individual board level.

For the private sector, the Workplace Gender Equality Agency (WGEA) produces an annual 'Australia's Gender Equality Scorecard'62 based on the mandatory reporting requirements for non-public sector employers with 100 or more employees, who must report annually against six gender equality indicators (including gender composition of the workforce and boards; flexible work arrangements and sex-based harassment). This covers more than 40 percent of employees in Australia. Non-compliant employers may not be eligible to tender for contracts under the Commonwealth and some state procurement frameworks and may not be eligible for some Commonwealth grants or other financial assistance. Names of employers that do not comply with WGEA reporting obligations are published on the agency website and presented to the Minister.

Australia does not conduct gender audits. The Parliament has published reports on gender equality issues, discussed the impact of the budget on gender equality and reviewed information on gender equality goals and targets. The Australian Parliamentary Budget Office (PBO) can conduct costings of the gender impact of policy proposals at the request of Senators and Members of Parliament. For example, at the time of a major tax policy change a senator requested that the PBO cost and publish the financial implications of the tax policy change over a ten-year period, disaggregating the financial implications by gender. ${ }^{63}$

\section{Gender Budgeting Practices in Brazil}

Gender Equality Commitments and Polices: Brazil includes gender equality in the Constitution and gender equality policies are incorporated into national development, strategic and sectoral plans. The most recent multi-annual four-year national plan (PPA 2020-2023) establishes an umbrella program for implementing ministerial policies that aims to promote the rights of women, the elderly and people with disabilities. ${ }^{64}$ In 2018, a National System of Policies for Women (Sinapom) and a National Plan to Combat

\footnotetext{
${ }^{60} \mathrm{https} / /$ www.abs.gov.au/statistics/people/people-and-communities/gender-indicators-australia/nov-2019.

${ }^{61} \mathrm{https} / / /$ www.pmc.gov.au/sites/default/files/publications/2019-2020-gender-balance-report-aust-govt-boards_0.pdf.

62 https://www.wgea.gov.au/data/wgea-research/australias-gender-equality-scorecard/2018-19-gender-equality-scorecard.

${ }^{63}$ https://www.aph.gov.au/About_Parliament/Parliamentary_Departments/Parliamentary_Budget_Office/Publications/Costings.

${ }^{64}$ Law No. 13,971/2019, of December 27, 2019. http://www.planalto.gov.br/ccivil 03/ ato2019-2022/2019/lei/L13971.htm

Program 5034: Protection of Life, Strengthening the Family, Promotion and Defence of Human Rights for All.
} 
Domestic Violence (PNaViD) were established. ${ }^{65}$ Sinapom is managed by the 'National Secretariat of Policies for Women' within the Ministry of Women, Family and Human Rights. The secretariat aims to expand and strengthen the formulation and implementation of public policies for women's rights, to confront all types of violence and to promote the inclusion of women in the country's social, economic, political and cultural development processes. Among its competencies, the 'National Secretariat of Policies for Women' formulates and coordinates the implementation of the National Policy for Women; updates and strengthens the National Plan for Women (together with the states, the municipalities, the Federal District and civil society) and finances, with other federal entities, the implementation of public policies for women.

GB Legal and Institutional Frameworks: Since 2004, the Pluriannual Plan approved by law and the budget laws have considered a gender perspective in government programs. This includes specific antiviolence laws and laws for the advancement of women and equal access and opportunities in health and education. ${ }^{66}$ The Ministry of Women and the Ministry of Finance have a coordinating role and there is an inter-ministerial committee on gender.

GB Public Financial Management Tools: For several years, the national budget has included expenditure lines earmarked for gender-related programs. Currently, it is possible to identify specific budget allocations related to policies supporting women across four categories: 1) Policies for Equality and Confronting Violence against Women; 2) Brazilian Women's House; 3) Dial 180-Women's Service Centre; and 4) Operation of the Women's Rights Council. ${ }^{67}$ The Legislature has played an important role increasing budget allocations for these policies during discussions on the budget proposal. ${ }^{68}$ Performance indicators related to achieving gender equality goals are used in some programs. However, ex-ante impact assessments are not conducted, and ex post impact assessment are used but do not influence decisions in practice. Additionally, in Brazil civil society plays a significant role in the analysis of gender budget allocations as well as helping to define policy priorities. At the national level, the Feminist Center for Research and Advice (CFEMEA), a civil organization, has since 1995 analyzed the impact of the budget on women, primarily on health and reproductive rights. ${ }^{69}$ They also produced an annual analysis of the budget until 2012, which was called the Women's Budget. ${ }^{70}$ Their findings, along with those of other civil society organizations, have impacted budget allocations made to women's polices by the Congress. Some municipalities of Brazil have also mainstreamed gender equality through their budgeting practices.

\section{Gender Budgeting Practices in Canada}

Gender Equality Commitments and Policies: Since the 1995 Beijing declaration, gender equality has been a key government priority. Political support for achieving gender equality has been strongly elevated under the current administration, with successive Canadian Ministers of Finance, committing to ensuring rigorous GB practices to help support greater gender equality and inclusion.

\footnotetext{
${ }^{65}$ Decree No. 9,586 / 2018. http://www.planalto.gov.br/ccivil 03/ ato2015-2018/2018/decreto/D9586.htm

${ }^{66}$ Economic Commission for Latin America and the Caribbean (ECLAC), 2017. Gender equality plans in Latin America and the Caribbean: Road Maps for Development. United Nations, Santiago, Chile.

${ }^{67}$ Marinho Rodrigues, J. 2020. Execução Orçamentária de Ações de Combate à Violência contra as Mulheres: Estudo Técnico $n^{\circ}$ 16/2020 - Consultancy for the Chamber of Deputies. https://www2.camara.leg.br/orcamento-dauniao/estudos/2020/ET16 Violncia MUlher.pdf.

${ }^{68}$ Marinho Rodrigues, J. 2020. Execução Orçamentária de Ações de Combate à Violência contra as Mulheres: Estudo Técnico $n^{\circ}$ 16/2020 - Consultancy for the Chamber of Deputies. https://www2.camara.leg.br/orcamento-dauniao/estudos/2020/ET16 Violncia MUlher.pdf.

${ }^{69}$ Network of Women Parlamentarians of the Americas. Gender Budgets: Summary of the Main Concepts and of Certain Initiatives in the Americas https://www.feminamericas.net/en/themes/ThemResumeBudgeta.5.pdf.

${ }^{70}$ IMF Working Paper. 2016. Western Hemisphere: A Survey of Gender Budgeting Efforts. https://www.imf.org/external/pubs/ft/wp/2016/wp16153.pdf.
} 
GB Legal and Institutional Frameworks: Canada has been a long-standing practitioner of GB. After the 1995 Beijing declaration, the government committed to conducting gender-based analysis (GBA) of legislation, policies, and programs to assess their potential impact on men and women. GBA as an analytical tool has evolved overtime and expanded to GBA Plus, which takes a broader view to include other identity factors beyond gender (e.g., race, sexual orientation, age, religion, age, and disability). Since 2016, the government made a public commitment to complete and publish a GBA Plus of budgetary measures. Previously, GBA Plus was part of the internal budget briefing process, with little-to-no public exposure. ${ }^{71}$

The '2018 Gender Budgeting Act' enacted in legislation many existing practices surrounding GBA Plus and required the government to include with the annual budget a report on the impact of new budget measures on gender and diversity. In addition, it requires the government to produce annually a report on the impact of tax expenditure on gender and diversity and also to publish annually impact analyses of existing expenditure programs

In terms of institutional arrangements, 'The Status of Women Canada', an agency created in 1976 had primary responsibility to coordinate gender equality policies across all levels of government, federal and provincial. Since its inception, the role and authority of the 'Status of Women Canada' has evolved and has recently been elevated into the 'Department for Women and Gender Equality' whose responsibility extends to advancing equality for all Canadians with different identity factors. The agency also provides government-wide leadership and expertise on GBA Plus and supports gender focal points in department and agencies.

GB Public Financial Management Tools: In recent years, major steps have been taken towards the integration of GB practices across all stages of the PFM cycle, most particularly in the planning and budget preparation stages. Key initiatives include implementing gender budgeting statements and integrating gender impact assessments into the budget process. As a result, an annual gender statement was introduced in 2017, as a chapter of the proposed budget. It was tabled in the House of Commons and published online. The 2017 Gender statement was the first public assessment of the budget from a gender perspective and reflected the government's efforts in understanding the differential outcomes of policy choices for people and aimed to promote a transparent discussion on equality challenges.

The 2018 budget included a gender equality chapter and focused on results. It introduced the Gender Results Framework (GRF), which outlines the government's six main gender equality priorities. The GRF is a whole-of-government tool to help guide future policy decisions and to track developments in gender equality and diversity across the identified priorities. All priorities have associated goals objectives and indicators to benchmark progress. Some associated objectives include addressing the gender wage gap, promoting more equal parenting roles, greater representation of women in senior management positions, eliminating gender-based violence and harassment and, reducing poverty and improving health outcomes.

The Government launched a public website for the GRF, which provides information on each goal, it's primary objectives and indicators for tracking progress, and initiatives and policies that support each goal. With the Budget 2019, GBA Plus was performed and published in the budget documentation for all budget measures. The Gender Equality Chapter summarizes efforts undertaken to advance gender equality and diversity and assesses the progress in GB efforts, including in implementing the GRF. Two important new publicly accessible resources were also introduced in the course of 2018-2019 (i) the Gender, Diversity and Inclusion Statistics hub, launched by the Statistics Canada to track the progress on the GRF indicators and (ii) the Gender Results Framework Portal, launched by the Department for Women and Gender Equality, that provides an up-to-date information on each gender equality goal.

\footnotetext{
${ }^{71}$ Government of Canada, 2016 A Plan for Middle Class progress, Fall Economic Statement 2016; https://www.budget.gc.ca/feseea/2016/docs/statement-enonce/fes-eea-2016-eng.pdf.
} 
In terms of oversight, the Canadian Parliament has a House of Commons, Standing Committee on the Status of Women. This committee has parliamentary oversight of the government's gender policy, programs and expenditure decisions. The Committee on Public Accounts also plays a role and every year it reviews the main and supplementary budget estimates of the Department for Women and Gender Equality. It also requires all federal departments and agencies to report on their use of gender analysis in the development of policy and legislation. It produces reports on the implementation of gender-based programs at the federal level. The Office of the Auditor General reviews the Government's performance in gender mainstreaming, however gender budget audits are not performed.

Since the conclusion of the IMF GB survey, Canadian authorities have taken further actions to strengthen their approach to GB in the context of the COVID-19 crisis. For example, the gender and diversity impacts of COVID-19 were taken into consideration in developing Canada's COVID-19 Economic Response and

Recovery Plan. The Government published summaries of the gender-based analyses plus (GBA Plus) for all measures in its COVID-19 Economic Response Plan, in Annex 1 of the July 2020 Economic and Fiscal Snapshot and Annex 3 of the 2020 Fall Economic Statement and most recently in Budget 2021's Impacts Report (Annex 5) (along with all other new budget measures).

Canada's GRF was also used to examine the impacts of COVID-19 on diverse groups, helping it to map response measures based on how specific communities and priority groups have been impacted by the pandemic, in support of decision-making. For example, the Gender Results Framework includes a pillar on "Poverty Reduction, Health and Wellbeing." Analysis found that in May 2020 women, youth and indigenous peoples were more likely to report poorer mental health. As a result, the Government included support for virtual care and mental health tools in its response measures. Consistent with the '2018 Gender Budgeting Act's' reporting requirements in terms of gender and diversity of the existing Government of Canada expenditure programs, it is also intended for annual Departmental Results Reports to include ongoing observed impacts on gender and diversity of COVID programs.

\section{Gender Budgeting Practices in China}

Gender Equality Commitments and Policies: The Chinese 1954 constitution guaranteed equal rights for women. The 1982 constitution of the People's Republic of China (PRC) further reiterated the commitment to gender equality by stating that "Women in the PRC enjoy equal rights with men in all spheres of life, in political, economic, cultural, social and family life. The State protects the rights and interests of women, applies the principle of equal pay for equal work to men and women." More recent laws and regulations reaffirm that the state guarantees women's equal rights and opportunities. The government has launched national programs for gender equality and mainstreamed gender across sectors. The 'National Human Rights Action Plan 2012-2015' included a section on women's rights addressing issues such as maternal mortality, gender-based violence, gender-based discrimination in employment, women's participation in political life, and equal access to resources, providing an opportunity for targeted initiatives in certain sectors. The 'National Program for the Development of Chinese Women for 2011-2020' (the national program) is also designed to coordinate inter-sectoral efforts for women's development.

GB Legal and Institutional Frameworks: A GB framework has not been introduced in China at a national level. However, the National Working Committee on Women and Children, coordinates the implementation of the national program for the development of Chinese women. The Ministries of Finance, Education, Civil Affairs, Health Development and Foreign Affairs, the National Planning Commission and 30 other departments are required to participate in the implementation of the program. Relevant departments have set up action plans to implement the program. Along with the national-level agencies, the state governments and local governments are also required to implement the national program.

GB Public Financial Management Tools: GB has not been initiated the national level and experience has been limited to training programs. At the subnational level, a few subnational governments have 
introduced a gender responsive approach in their local planning and budgetary processes, mostly without any directive from the national government. Some of these initiatives include: In 2005, a Gender Budget was piloted in Zhangjiakou City, Hebei Province. In 2009, Jiaozuo City in Henan province, for the first time produced a multi-volume publication presenting gender analysis of key allocations in education, employment, public health, cultural activities, family planning and poverty alleviation. In 2013, Shenzhen, Guangdong Province, implemented a local regulation on promoting gender equality, requiring establishment of systems for gender statistics, gender analysis and assessments and gender responsive budgeting. Several provinces and cities have set up gender assessment mechanisms to analyze budgets of projects against social indicators, including gender.

\section{Gender Budgeting Practices in France}

Gender Equality Commitments and Policies: In France, gender equality is enshrined in the Constitution. More recently, under the '2014 Law on Gender Equality', it is mandated that a gender perspective is integrated into each policy developed by government Ministries. ${ }^{72}$ In 2017, the French President declared gender equality a "grand national cause" of his five-year mandate. Three priority areas have been defined: fighting gender-based and sexual violence, promoting professional equality in all its dimensions; a significant reduction of the pay gap by 2022 ; and disseminating a culture of equality. ${ }^{73}$ In line with this goal, line ministries have signed roadmaps defining specific gender equality objectives. These cover a variety of domains, such as guaranteeing gender equality in higher education, educating children about the importance of gender equality from the earliest age, including gender aspects in foreign diplomacy and ensuring equal employment in the public administration. In addition, the High Council for Equality between Women and Men, an independent consultative body established since 2013, monitors gender-based violence, stereotyping, parity, health issues and rights in the international context.

GB Legal and Institutional Frameworks: The government presents each year a transversal policy document on the policies for promoting equality between women and men. This is supported by the Organic law 2009-403, that requires the government to transmit to the Council of State and then to Parliament, a gender impact assessment with each bill that is submitted. This was reinforced in 2012 with a Prime Ministerial circular that requires all new laws to include a gender impact assessment. On the institutional side, the current government created the State Secretariat for Equality between Women and Men (SEEFH), to coordinate inter-ministerial actions on gender equality and was subsequently elevated it to an Alternate Ministry (ministère délégué). The Ministry of Finance is mainly responsible for $G B$, in partnership with the Alternate Ministry, supported by an inter-ministerial committee on gender. Gender units established within the line ministries check the quality of gender assessments within budget proposals.

GB Public Financial Management Tools: GB practices in France for been around for many years, the most recent incarnation is based on the use of three main tools along the budget cycle and complemented by others. These tools are the ex-ante gender impact assessment of all new legislative proposals; the integration of a gender perspective into the already well-established program and performance budgeting framework; and the development of a specific annex accompanying the budget law that assesses its impact on gender equality. The latter 'specific annex' constitutes a 'Gender Budget Statement' that assesses fiscal policies from a gender perspective. It covers all governmental agencies and identifies the key programs

\footnotetext{
${ }^{72}$ Loi 2014-873 pour l'égalité réelle entre les femmes et les hommes.

${ }^{73}$ Document de politique transversale en annexe du projet de loi de finances pour 2020, Politique de l'égalité entre les femmes et les hommes, p. 10. https://www.performancepublique.budget.gouv.fr/sites/performance publique/files/farandole/ressources/2020/pap/pdf/DPT/DPT2020 egalite femmes hommes.pdf https://www.budget.gouv.fr/documentation/documents-budgetaires/exercice-2021/le-projet-de-loi-de-financeset-les-documents-annexes-pour-2021/documents-de-politique-transversale-2021.
} 
that contribute to addressing gender equality, alongside the resources allocated and key performance indicators.

Budget circulars support GB implementation and provide guidance to the ministries regarding how to prepare performance information and construct gender impact assessments. ${ }^{74}$ In addition, the authorities report that ex-post gender impact assessments are being used to guide new decisions. ${ }^{75}$ More recently, the Government has launched a pilot program aimed at deploying a gender-sensitive budgeting methodology to each state budget program. This began with the GB pilot project measuring the gender impact of programs in four-line ministries. ${ }^{76}$ The 2020 budget circular draws lesson from the pilot and instructs all ministries to integrate a gender dimension when defining or revising the performance indicators included in the Specific Annex of the Budget Law. These will eventually be the basis for monitoring progress in the annual performance reports. ${ }^{77}$

\section{Gender Budgeting Practices in Germany}

Gender Equality Commitments and Policies: Germany's constitution, the Basic Law, enshrines a commitment to an active and effective gender equality policy. Article 3(2) of the Basic Law states that 'men and women are equal', and furthermore explicitly obliges the State to enforce equal rights for women and men and to work towards eliminating existing disadvantages. ${ }^{78}$ Despite a long-standing commitment to gender equality enshrined in the constitution, Germany has only recently formulated a national strategy in this area. In July 2020, the German government presented its strategy 'Towards a Stronger Future', making it the first federal government to define objectives and policy measures for gender equality across ministries. The strategy has nine goals including ensuring economic independence for everyone, bringing more women into economic leadership positions, eliminating stereotypes in culture and science and strengthening gender equality in public administration. ${ }^{79}$ In the federal government, the realization of equal rights is a task which is mainstreamed. ${ }^{80}$

The '2006 General Equal Treatment Act' covers all forms of discrimination on various grounds, including gender, in the workplace, in certain business transactions, in labor laws and other areas of law. ${ }^{81}$ Germany has taken measures to strengthen its services for support of women afflicted by domestic violence and to combat human trafficking. Equal pay for women, childcare and parental leave are enhanced through legislation. Legislation on transparency is aimed at ensuring accurate reporting of pay and reducing gender pay gaps by large corporations.

GB Legal and Institutional Frameworks: Since 2000, gender equality has been a guiding principle in the 'Joint Rules of Procedure of the Federal Ministries', stating that all federal ministries are to promote it in

\footnotetext{
${ }^{74}$ https://www.performance-publique.budget.gouv.fr/sites/performance_publique/files/files/circulaires/circulaires/2019/2PERF19-3083/2PERF-19-3083.pdf.

${ }^{75}$ IMF GB Survey 2019.

${ }^{76}$ Circulaire de la direction du budget $n^{\circ}$ DF6-2PERF-19-3083 du 18 avril 2019 relative à la préparation des volets performance des projets annuels de performance (PAP) du PLF 2020 et élaboration des documents de politique transversale (DPT).

${ }_{77}$ Circulaire de la direction du budget n D DF-2PERF-20-3099 du 10 avril 2020 relative à la préparation des volets performance des projets annuels de performance (PAP) du PLF 2021 et des documents de politique transversale (DPT).

${ }^{78}$ Germany, Basic Law, Article 3(2). (Grundgesetz für die Bundesrepublik Deutschland).

79 The others are: (i) establishing care professions as attractive career paths; (ii) setting standards for the digital world; (iii) making paid work and unpaid care work reconcilable; (iv) establishing equal participation in democracy and (v) making gender equality a task for the entire government. (Germany, Towards a stronger future, The federal government's gender equality strategy, July 2020); https://www.gleichstellungsstrategie.de/.

${ }^{80}$ Germany, Federal Republic of, Permanent Mission to the United Nations, New York, 2014, Response of the Government of the Federal Republic of Germany to the UNECE Questionnaire on the Implementation of the Beijing Declaration and Platform for Action (1995) and the Outcome Document of the 23rd Special Session of the General Assembly (2000) (Berlin). (Quote from G7 Paper).

${ }^{81}$ Combined Seventh and Eighth Report of the Federal Republic of Germany on the United Nations Convention on the Elimination of All Forms of Discrimination against Women (CEDAW), 2015.
} 
their political, regulatory and administrative acts ('gender mainstreaming'). ${ }^{82} \mathrm{New}$ laws are accompanied by an ex-ante gender impact assessment. ${ }^{83}$ The main responsibility for the development of strategies, laws and federal programs rests with the Federal Ministry for Family Affairs, Senior Citizens, Women and Youth. It publishes an annual gender equality index and, since 2011, a gender equality report per a parliamentary term, produced by an independent expert commission and accompanied by a statement of the government. The latest 2017 report focused on how to restructure paid work and (unpaid) care work.

All the government departments at the regional level, in the Laender, have gender equality policy units. These gender equality policy units meet to exchange their views. Further, the Laender have enacted corresponding Gender Equality Acts and regulations.

GB Public Financial Management Tools: Germany has not formally adopted GB at the national level. In 2005 , the federal government had commissioned a feasibility study, but abandoned the process in 2007, arguing that the federal budgeting process in its present form - with a limited performance orientation did not lend itself to GB. ${ }^{84}$ Subsequent governments have reaffirmed this position. ${ }^{85}$

Germany does however use a few components of GB. Each line ministry is in charge of ensuring gender equality when designing policies within its respective remit ('gender mainstreaming'). In 2015, Germany introduced annual spending reviews to assess the performance of the budget across ministries. They complement the top-down method of preparing the federal budget. So far, the Federal Ministry of Finance has carried out nine spending reviews on different topics. The 2019-20 spending review analyzed selected funding programs in the areas of further education, labor market re-entry and business start-ups. For the first time, gender aspects were also taken into account within the spending review. In addition, the Federal Ministry for Family Affairs, Senior Citizens, Women and Youth has revised its "Guidance for conducting gender-sensitive regulatory impact assessments" as a result of improvements that were identified in gender mainstreaming for non-statutory funding programs. Some Laender, and some municipalities such as Berlin or Bremen have well established GB initiatives. ${ }^{86}$

\section{Gender Budgeting Practices in India}

Gender Equality Commitments and Policies: The principle of gender equality is enshrined in the Indian Constitution. The Indian Constitution grants gender equality and empowers the State to adopt positive discrimination measures in favor of women. The 'National Policy for the Empowerment of Women' $(2001)^{87}$ has a goal to bring about the advancement, development and empowerment of women. Specifically, the objectives of this policy includes; enjoyment of human rights and fundamental freedom by women on equal basis; elimination of discrimination and all forms of violence against women and the girls; creating an environment through positive economic and social policies for full development of women to enable them

\footnotetext{
82 Gemeinsame Geschäftsordnung der Bundesministerien (GGO), paragraph 2.

${ }^{83}$ Deutscher Bundestag, Wissenschaftliche Dienste, Sachstand Gender Budgeting, WD 4 - 3000 - 030/16, 2016, p. 11.

${ }^{84}$ Germany, Bundesministeriums für Familie, Senioren, Frauen und Jugend, Machbarkeitsstudie Gender Budgeting auf Bundesebene, March 2006 - Anmerkungen der Bundesregierung zur Machbarkeitsstudie Gender Budgeting, June 2007.

${ }^{85}$ Germany, Deutscher Bundestag, Einzelfragen zum parlamentarischen Verfahren der Haushaltskontrolle, WD 4 - 3000 $\underline{025 / 19}$, p. 12.; Antwort der Bundesregierung auf die Kleine Anfrage, Geschlechtersensible Haushaltspolitik (Gender Budgeting), Drucksache 17/11124, p. 3; Unterrichtung der Bundesregierung, Kombinierter siebter und achter Bericht der Bundesrepublik Deutschland zum Übereinkommen der Vereinten Nationen zur Beseitigung jeder Form von Diskriminierung der Frau (CE-DAW), BT-Drs. 18/5100, p. 11

${ }^{86}$ Germany, Permanent Mission to UN; Quinn, Sheila, 2016, "Europe: A Survey of Gender Budgeting Efforts," IMF Working Paper 16/155 (Washington, DC: IMF). (Quote from G7 Paper); Gender Büro, Gender Budgeting in Deutschland: Ein (nicht vollständiger) Überblick, 2014.

${ }^{87}$ National Policy for The Empowerment of Women (2001).
} 
to realize their full potential; providing equal access to participation and women empowerment; and mainstreaming a gender perspective in the development process.

The Minister of Finance in her 2019 Budget speech highlighted the importance of empowering women, especially in rural areas ${ }^{88} \mathrm{An}$ inter-governmental committee is to be established to encourage and facilitate women's participation in the country's development.

GB Legal and Institutional Frameworks: Legal requirements for GB in India are enshrined in planning laws. While the Ministry of Finance has been leading work to institutionalize GB processes, the Ministry of Women and Child Development, as the portfolio agency for women, has supported the process by strengthening internal and external capacities. This includes building the expertise of GB units within ministries in order to better deliver and manage gender policies, schemes and programs.

GB Public Financial Management Tools: The first national GB initiative appeared in India in 2001 with the National Institute of Public Cooperation and Child Development, an Indian government agency under the Ministry of Women and Children Development, undertaking several studies of gender related economic policies and analysis of the gender impact of budgets in selected States. This became the first step toward Gender Budget Analysis.

In 2003, the Cabinet Secretary of the Government of India, suggested that Ministries and Departments should include a chapter on gender issues in their Annual Reports. This was followed by instructions to ministries and departments to establish gender budget units. Gender budget units were envisaged as the focal points for mainstreaming gender. Since 2005, GB processes have been included as part of the budget circular. The budget circular for the budget 2018-2019 calls on all ministries to prepare a gender statement with the budget estimates highlighting the quantity of public expenditure earmarked for (a) women specific programs with $100 \%$ allocation for women and (b) pro-women allocations - at least 30\% - for gender neutral programs. The Ministry of Finance combines these agency inputs to produce a Ministerial Gender Budget Statement at the whole of government level. Many State Governments like Rajasthan, Gujarat, Madhya Pradesh, Karnataka, Orissa, Kerala, Assam, Bihar, Chhattisgarh, Tripura, Nagaland, Uttar Pradesh and Uttarakhand have adopted elements of $\mathrm{GB}$.

In summary, governments have deployed various tools in the budget preparation phase of the budget cycle to support GB, including a budget circular and production of a GB statement. The government report that neither ex-ante not ex-post gender impact analysis are currently performed. In addition, a gender lens is not incorporated into the chart of accounts to allow the tracking of gender-related spending and as a result annual budget execution reports on gender initiatives are not yet available.

\section{Gender Budgeting Practices in Indonesia}

Gender Equality Commitments: Indonesia's commitment to achieving gender equality is reflected in the 1945 Constitution and in a number of laws that ratify Indonesia's commitments to international treaties. In 2000, Indonesia issued a gender mainstreaming policy, which made it mandatory for all government agencies to mainstream gender issues into the national development program. Gender mainstreaming has been included in the Long-Term National Development Plan 2005-2025 with the emphasis on progressing women's empowerment through (1) Improving of quality of life and the role of women in various development sectors; (2) Decreasing violence, exploitation and discrimination against women; (3) Strengthening the institutionalization and networks for gender mainstreaming.

Realizing the great potential of Indonesian women, the government designed various women's economic empowerment programs, such as Mekaar and UMi, providing various types of small business loans to women.

${ }^{88}$ https://www.indiabudget.gov.in/budgetspeech.php. 
The government expanded the target of recipients of the Family Hope Program (PKH) so that every child from an underprivileged families continue to have access to education. In addition, the early childhood education program has been launched for boys and girls to have equal opportunities to learn. The government has a goal to achieve 30 percent female representation in the Parliament.

GB Legal and Institutional Framework: The legal framework in Indonesia strongly supports gender mainstreaming. Concrete actions include: (i) Presidential instruction 9/2000 on gender mainstreaming in planning and development for national and sub-national governments; (ii) the Ministry of Finance Decree, on Guidance for the Annual Working Plan on Implementation Gender Mainstreaming via gender based budgeting; (iii) Law 17/2003 on National Public Finance, governing performance budgeting procedures; (iv) Law 32/2004 on Regional Governance making woman empowerment as one of obligatory functions for sub-national governments and (v) Decree No.15/2008 (latest No.67/2011) on General Instructions for Gender Mainstreaming at a Local Level.

Four agencies, the National Planning and Development Agency, the Ministry of Women Empowerment and Child Protection, the Ministry of Finance and the Ministry of Home Affairs are coordinating their efforts to drive the gender mainstreaming agenda and promote gender responsive budgeting. At the subnational level, the Ministry of Home Affairs acts as an advisor for the local government. Gender mainstreaming has been implemented in several regions with varying success.

GB Public Financial Management Tools: Gender budget implementation started with the pilot exercise in 2009 in seven government agencies who were asked to prepare Gender Budget Statements covering four key areas: (a) Outcomes and outputs of the largest-sub-programs and their implications for gender equality; (b) Outcomes and outputs which specifically target women and girls; (c) Outcomes and outputs which will benefit both men and women and promote gender equality; $(d)$ Outcomes and outputs which will strengthen gender mainstreaming institutions (gender focal points, working groups etc.). Following on from the pilot, gender responsive planning and budgeting at the Ministry of Finance follows the national planning and budgeting cycle. Indonesia's gender mainstreaming policy integrates planning and budgeting by identifying fiscal policies objectives, indicators to measure the achievement of such objectives and gender-based targets. Situation analysis / gender needs analysis is carried out to inform both strategic and operational policies for both men and women. Gender related goals are formulated and incorporated into program planning. The authorities report that they are not taking an integrated approach to GB across the budget cycle. A holistic Gender Budget Statement is not yet produced at the national level. In addition, the budget circular does not yet guide the development of a gender perspective into the resource allocation process and ex-ante and ex-post gender impact analysis is not performed. They do not monitor GB budget execution nor engage in gender audits or have in place mechanisms that facilitate strong parliamentary oversight.

\section{Gender Budgeting Practices in Italy}

Gender Equality Commitments: The Gender Equality principles enshrined in the Constitution (1948) of the Italian Republic focus on social protection of mothers, children, and the young and equal pay for women. The Code for Equal Opportunities (Legislative Decree 198/2006) provides the legal framework for integrating the objective of gender equality in all policies and to fight against discrimination, including in access to the labor market. Since 1996, the Department of Equal Opportunities, under the Italian Presidency of the Council of Ministers, oversees promoting and coordinating gender responsive policies and government actions to support women's rights.

GB Legal and Institutional Framework: At the central level a general framework for GB was introduced in the Italian Public Finance and Accounting Law (Law 196/2009) and amended in 2016 (Art. 38-septies) introducing the first gender budget pilot (Bilancio di Genere) that analyzed the final accounts from a 
gender perspective. The first pilot Gender Budget Report was the 2016 end-year gender budget final accounts. The Legislative Decree 116/2018 provided further instructions on the role and scope of the gender budget and launched collaboration between the Ministry of Economy and Finance with representatives of the Ministry, Presidency of the Council of Ministers, the National Statistics Institute and academia or research institution. The reform aimed not only at assessing the impact of past policies on gender but at reallocating resources based on sustainable and well-being indicators (BES), some of them broken down by gender. Additional provisions are part of the performance management framework (Legislative Decree 150/2009) and Decree of 2017 that includes GB in the annual performance management report that all public administrations are required to prepare.

At the local level, some initiatives of GB were already carried out in the 2000s, especially in provinces and municipalities, then in the regions. Following a bottom-up approach, a number of pilot projects were launched, and many local administrations committed themselves to GB. ${ }^{89}$

GB Public Financial Management Tools: The GB framework is focused on the analysis of budget execution and reporting in the final accounts that are submitted to Parliament. Since 2017, the Gender Budget Report aims to evaluate the impact of budgetary policies (revenue and expenditure) on men and women in terms of money, services, time, and unpaid work with reference to the State budget final accounts..$^{90}$ Notably, the report includes a reclassification of the previous year's expenditures of the State budget according to a gender classifier: "neutral" expenditures with no effect on gender, neither direct nor indirect; "sensitive to gender" expenditures which may have a different impact on men and women though indirectly; and expenditures "directly aimed at reducing gender inequalities", measures directly aimed at reducing gender inequalities or promoting equal opportunities. Ministries classify their spending according to these categories, based on their assumptions of gender impact and they are asked to explain such assumptions based on the Ministry of Economy and Finance's annual guidelines. ${ }^{91}$ Also, the Gender Budget Report includes a repository of legislation since 1948, an appendix with Ministries' answers to questionnaires on gender impact, personnel and sectoral policies and a statistical appendix on indicators to monitor gender gaps. In addition, the main results are disseminated through the government Open Budget app. ${ }^{92}$

$\mathrm{GB}$ is incorporated in the performance management framework and operationalized through the programbased structure of the budget. The budget circular requires that government bodies submit performance budgeting documentation (so-called "Notes to the budget") setting out the objectives and appropriate indicators for monitoring the gender impact of national policies. These notes are presented as an annex to the draft budget law and final accounts statement.

Some regional governments have passed laws to introduce pilot projects or to make GB part of the annual budget approval process. Gender Responsive Budgeting initiatives are conducted by the National Social Security Institute (INPS), by some public universities and local administrations (Comuni). However, practices are fragmentary and often discontinuous. ${ }^{93}$

\footnotetext{
${ }^{89}$ See Badalassi and Addabbo speeches in Federal Ministry of Family Affairs, Senior Citizens, Women and Youth, The European conference of German EU Presidency, 4/5 June 2007 https://www.bmfsfj.de/resource/blob/93530/3d7b5981c92e3a108533dee32e258887/die-verteilung-machts-dokumentationenglisch-data.pdf.

90 The report can be found here: https://www.rgs.mef.gov.it/ Documenti/VERSIONE-I/Attivit--i/Rendiconto/Bilancio-digenere/2019/Bilancio-di-genere-2019 Relazione-al-Parlamento.pdf.

${ }_{91}$ IMF GB Survey 2019 and the circular https://www.rgs.mef.gov.it/VERSIONE-I/circolari/2020/circolare_n_07_2020/

${ }^{92}$ http://bilancioaperto.mef.gov.it/landing.html.

93 IMF GB Survey 2019.
} 


\section{Gender Budgeting Practices in Japan}

Gender Equality Commitments and Policies: The principle of gender equality in Japan is established through the '1999 Basic Act for Gender Equal Society'. The 'Basic Act' also provides the legal basis for the 'Basic Plan for Gender Equality', formulated every five years, it sets out the government's main policy measures to support gender equality. ${ }^{94}$ Generally it includes a variety of initiatives across a wide range of fields to encourage the active participation women in labor force. For example, the 'Fifth Basic Plan for Gender Equality' approved by Cabinet in $2020^{95}$ focuses on increasing the recruitment of women throughout different disciplines and promoting women's labor force participation in both public and private sectors. The Basic Plan sets out 11 key fields, with outcome targets to be achieved by 2025, and called for the use of gender-disaggregated data to assess progress. The Act also established the Council for Gender Equality in the Cabinet Office, headed by the Prime Minister. ${ }^{96}$

In addition to the 'Basic Act', the '2016 Act on the Promotion of Women's Participation and Career Advancement in the Workplace' requires national government, local governments and employers with over 300 regularly employed workers (100 from April 2022) to establish an action plan to support women's participation and to disclose information. Based on the 2016 Act, certain corporations that promote worklife balance are to receive additional evaluation points in the government procurements conducted under the overall-greatest-value evaluation method and the competitive proposal evaluation method. The 'Act on the Prevention of Spousal Violence and the Protection of Victims' is also in place to prevent spousal violence against women and protect victims of spousal violence.

GB Legal and Institutional Frameworks: To help address gender inequality issues, in 2015 the Japanese government adopted a GB approach at the central government level. ${ }^{97}$ The 'Fifth Basic Plan for Gender Equality ${ }^{\prime 98}$ is a national plan for gender equality that stipulates specific measures to be implemented by looking ahead FY 2025, while including measures to be tackled in the current year for example 2021. The Plan sets out performance objectives and targets for improving gender equality, outlining 89 outcomes targets which is aiming to achieve. The Plan stipulates that each June, based on the opinion of the 'Council for Gender Equality', the government will formulate intensive policies to accelerate the empowerment of women and reflect these in budget requests by line ministries.

GB Public Financial Management Tools: GB in Japan is coordinated by an inter-ministerial committee known as the 'Council for Gender Equality'. One of the roles of the council is to provide general guidance to the line ministries during the budget preparation process, even though this is not done formally by issuing a budget circular. The Council for Gender Equality provides guidance at the beginning of the budgetary cycle and afterwards coordinates the budgetary discussions on gender-related issues. The government reported that gender equality goals are linked to programs and costed on an annual basis.

The government also produces and publish a gender budget statement. The 'Intensive Policy to Accelerate the Empowerment of Women' was formulated with the purpose of incorporating the perspective of women's empowerment into the annual requests for budgetary appropriations of government ministries

\footnotetext{
${ }^{94}$ Second meeting of the ASEAN+3 Committee on Women, Country Paper Japan, Gender Mainstreaming and Gender Budgeting: Achievements, Gaps and Challenges, 2015.

95 These fields include increasing women's participation in policymaking and employment, improving work-life balance, promotion of gender equality in rural areas, gender equality in science and technology including active participation by women in STEM fields, supporting women's lifelong health, elimination of all forms of violence against women, support for low income women, gender-related tax and social security reforms, and gender-responsive foreign aid and cooperation. (IMF G7 paper)

${ }_{96}$ This discussion is based on Japan (2014), Chakraborty (2016), and OECD (2016). (IMF G7 paper); Japan, Gender Equality Bureau, Women and Men in Japan 2020, Section 3.1, Framework for Promotion of Gender Equality.

${ }_{97}$ Japan, Gender Equality Bureau, Women and Men in Japan 2020, Section 3.4, Intensive Policy to accelerate the Empowerment of Women 2019.

${ }^{98}$ https://www.gender.go.jp/english contents/about danjo/whitepaper/pdf/5th bpg.pdf.
} 
and agencies. The English version sets out policy measures taken to improve gender equality across three key areas - economic participation, safety, and empowerment. While the gender budget statement includes the policy measures, it does not disclose the resources allocated to support each of the measures. GB efforts in Japan are primarily concentrated in the planning and budget preparation phase and GB PFM tools have yet to integrated across the budget cycle. For instance, there are no tools or practices in place as yet to support GB in budget execution and monitoring nor parliamentary oversight or audit activities.

\section{Gender Budgeting Practices in the Republic of Korea}

Gender Equality Commitments and Policies: The Constitution of Korea upholds the principle of equal rights and opportunities for men and women. The 'Organic Law of Gender Equality' requires all government agencies to consider gender equality perspective in all policy areas and to pursue a well-coordinated strategy. 'The Framework Act on Women's Development' was approved in 1995 to promote equality between men and women in all the areas of politics, economy, society and culture and to facilitate women's development. The Act was revised in 2014, a given the new name of the "Framework Act on Gender Equality" to emphasize importance of following practical and measurable ways to achieve gender equality. For example, this included the introduction of a quota (to be reevaluated every 5 years) for women in executive and senior positions in the public sector aimed at enhancing female representation. Since the mid-1990s, Korea has actively made efforts to enhance gender equality and women's empowerment through gender mainstreaming and introduction of gender sensitive policies in different sectors.

In 2014, in a medium-term plan for economic innovation, the government set the major goal to increase female employment rate. To do so the government implemented a number of measures to encourage female workers to remain in the workforce, by providing affordable, good-quality childcare, and expanding paid parental leave. Gender equality objectives and the challenges associated with an aging population are key drivers of policy formulation in Korea. Economic policies announced annually by the Ministry of Strategy and Finance which aim to promote female labor participation and to reduce the gender pay gap, include policies for enhancing labor market flexibility, creating jobs for women, providing quality vocational trainings for women who are economically inactive due to childcare and other household responsibilities and boosting public assistance for childcare.

GB Legal and Institutional Framework: The requirement to undertake GB is set out in the legal framework. The 'National Finance Act' (2006 revision) requires for the government to (i) evaluate the national budget's differential impacts on men and women, (ii) draw up gender budget statements which analyze the impact of the budget expenditure on women and men in advance, and (iii) prepare gender sensitive balance sheets, which assesses whether the budget benefits women and men equally and remedies gender discrimination.

Institutionalization of GB initiatives in Korea was driven by civil society. In 1998, the Korean Federation of Women's Association (KFWA), undertook the gender-based analysis of the national budget focusing on the share of government expenditure allocated to gender equality through women-specific programs. Later, the KFWA submitted a petition calling on the National Assembly to implement GB. The Congressional Committee for Gender Equality and Family passed a resolution on GB and gender mainstreaming as one of the national government's policy priorities in 2002. National gender machinery functions through the Ministry of Gender Equality (created in 1998) and Family and Women's Focal Points established in key ministries of government.

GB Public Financial Management Tools: Korea adopted a gender impact assessment system in 2002, to establish and enforce the gender analysis of policies. This was reinforced in 2012 by the law for 'Gender Impact Analysis Assessment' (GIAA) and revised in 2018 with the approval of the law for 'Gender Impact Assessment'. Under the law, central and local governments should analyze and assess the impact of the 
policies which influence the rights, interests, and social participation of women. In addition, the law requires that the gender impact assessment should inform policy outcomes. As such a report on the gender impact of the policy is required to be submitted to the Minister of Gender Equality and Family every year.

The 'National Finance Act' mandates that from 2010, all ministries are required to submit a gender budget statement and balance sheet to the National Assembly. To establish this practice, a pilot project started in 2008 initially involving sixteen government departments, who conducted gender budget analysis and prepared gender budget statements. The Ministry of Strategy and Finance led the reforms, providing a format for the GB statements, which included information on budget allocation, and gender-related performance goals and indicators to measure whether performance goals have been met. This process has continued, with the Ministry of Strategy and Finance driving the process, collecting the gender budget statements of each ministry and submitting them to the National Assembly. Gender Budget Statements are directly linked to the prior year's 'Gender-Sensitive Balance Sheet' that evaluates whether males and females have equally benefited from the budget. It contains information about the previous years' budget execution and an evaluation as to whether the previous year's gender goals have been met.

The Korean Women's Development Institute (a specialized gender equality research body and affiliated with the Ministry of Gender Equality and Family) in association with the Ministry of Strategy and Finance developed manuals for the construction and use of GB performance indicators. Indicators are embedded in the Self-Assessment Budgetary Program (SABP), that requires all line ministries to undertake in-depth performance evaluation of all budgetary programs. Performance evaluations are to be submitted to the National Assembly. In addition, under the 'National Finance Act' the government has to prepare an annual report that evaluates whether women and men receive equal benefits of public funds and whether this has contributed to reduce gender inequality.

\section{Gender Budgeting Practices in Mexico}

Gender Equality Commitments and Policies: Mexico's legal and institutional framework for gender equality has a long tradition, going back to the 1974 constitutional reform that enshrined gender equality. In 2006, a law on equality between women and men was enacted. In 2007 a law to combat gender violence was enacted. ${ }^{99}$ The 2011 Planning Law guarantees equality of opportunity between women and men and stipulates that the National Development Plan must be formulated with a cross-cutting gender perspective. Mexico has also included in the 2018 reform of the Planning Law a reference to the Sustainable Development Goals, including Gender Equality Goal 5, and has set up a Council for the 2030 Agenda in which all ministries are represented. Mexico has developed comprehensive tagging of the budget to SDGs and linked this to budget performance information.

The General Law for Equality between Women and Men establishes that the federal executive is in charge of the application of the National System for Equality between Women and Men and the development of a national program for women and men equality (PROIGUALDAD). ${ }^{100}$

GB Legal and Institutional Frameworks: Mexico is the country with one of the most complete GB legal frameworks and is a pioneer for GB in Latin America. In 2006, the Budget and Financial Responsibility Federal Law was enacted, which stipulates that the administration of public resources should be based on a criterion of gender equality, amongst others. This law provides guidelines on how gender considerations should be incorporated into all aspects of the budget process and establishes cross-cutting annexes including one on gender equality. This annex incorporates the information on resources allocated to women and gender equality. Article 27 states that it is necessary to ensure that budget planning

\footnotetext{
${ }^{99}$ The law on equality was enacted in 2006 and reformed in 2018. http://www.diputados.gob.mx/LeyesBiblio/pdf/LGIMH 140618.pdf ${ }^{100}$ PROIGUALDAD, Programa Nacional para la Igualdad entre Mujeres y Hombres 2020-2024. Oficial Gazette, 12/22/2020.
} 
incorporates a gender perspective and supports a cross cutting perspective, and that the budget complies with programs, projects, and actions promoting equality between women and men. ${ }^{101}$ Article 41 stipulates that the gender-related cross-cutting annex in the annual budget proposal must consider, at least, the same proportion of the programmable expenditure compared to the preceding fiscal year. The 2012 revision to the Budget and Fiscal Responsibility Law further introduced a gender perspective into the program structure, and gender-related indicators into the performance evaluation system. ${ }^{102}$

On the institutional side, since 2001, the National Institute for Women (INMUJERES) was established as the government's entity for the coordination and promotion of the national gender equality policy and the fight against gender violence. It plays a key role in the development of $G B$, importantly in gender analysis coordination. The Ministry of Finance also plays a key role in GB implementation through budget preparation, review of gender assessments and monitoring of the cross-cutting annexes. ${ }^{103}$

GB Public Financial Management Tools: Mexico has one of the most completed GB frameworks incorporating $\mathrm{GB}$ tools both in upstream and downstream budget processes, that is from planning and budget preparation to execution, reporting and external control. It has also developed a transparent system with progress being measured and published by the Ministry of Finance in the Budget Transparency Portal. ${ }^{104}$ Among the GB tools being used in Mexico we can highlight the following: (i) budget specific guidelines on gender objectives and on identifying gender-related budget allocations; (ii) budget classification that incorporate a gender perspective with specific gender related programs linked to policies and the abovementioned gender-related cross-cutting annex; (iii) a budget statement that includes the gender-related budget information for the next budget year; (iv) ex post gender impact assessments to assess the impact of executed programs on gender equality objectives; $(v)$ quarterly and annual budget execution reports incorporating financial and performance monitoring information on gender-related programs; (vi) financial and performance audits by the Supreme Audit Institution; (vii) parliamentary oversight plays a crucial role in the promotion of GB with a special Commission for gender equality; also the parliament has conducted hearings and reviewed information on gender equality targets.

The gender-related cross-cutting annex of the annual budget decree lists the budget allocations dedicated to gender equality by implementing line ministries and institutions ${ }^{105}$, dividing the resources by specific gender objectives. For instance, for 2020, these affected 33 sectors and 107 spending programs, managed by 112 execution units. The existing performance evaluation system has helped GB implementation in Mexico. Performance evaluation must incorporate specific indicators to evaluate the impact of budgetary programs on gender equality, the eradication of gender-based violence, and any form of gender discrimination. Implementing institutions periodically report to INMUJERES and the Ministry of Finance on their progress via an electronic platform.

\section{Gender Budgeting Practices in Russia}

Gender Equality Commitments and Policies: To implement the Beijing Declaration and the Platform for action, Russia adopted a guideline on improving the status of women in the Russian Federation in 1996. The following areas were identified as strategically important by the government: observance of women's rights, women's empowerment, equal rights for female participation in labor market, women healthcare, and addressing violence against women. Specific measures are set out in the 'National Action Plan for the Advancement of Women' the first of which was adopted for the period 1997-2000. Currently the

\footnotetext{
101 http://www.diputados.gob.mx/LeyesBiblio/pdf/LFPRH_061120.pdf.

${ }^{102}$ Ley federal de presupuesto y responsabilidad hacendaria, marzo de 2006, última reforma DOF 6-11-2020.

103 https://www.gob.mx/inmujeres.

${ }^{104}$ Mexico Ministry of Finance. Budget Transparency Portal. https://www.transparenciapresupuestaria.gob.mx/en/PTP/programas.

105 Annex 13: http://www.diputados.gob.mx/LeyesBiblio/pdf/PEF 2020 111219.pdf.
} 
government is implementing the National Action Strategy for Women for 2017-2022 (Government decree No. 410-p, March 8, 2017), that has set out two main goals: (i) improve the economic status of women, and (ii) increase the participation of women in public and political life. To achieve these objectives the government has put in place policies and programs including equal pay legislation, providing opportunities for employment in highly paid jobs, increasing women's competitiveness in the labor market, supporting women in the SME sector, as well as policies to promote women's education, including vocational education in advanced areas of economy, and women specific healthcare and social policies and programs. GB Legal and Institutional Framework: GB has gained attention in recent years, but institutional mechanisms and comprehensive framework for mainstreaming gender perspective in the budget process have not been developed to date.

GB Public Financial Management Tools: Some of the advanced features of the PFM system in Russia has encouraged the application of certain GB tools although the overall approach to GB is limited. The federal government has developed a comprehensive performance monitoring framework with performance targets which are defined, measured and monitored. Relevant executive authorities carry out monitoring of the implementation of measures identified within the framework of the National Strategy for Action on Women for 2017-2022. Gender disaggregated data is also produced and publicly available. Parliamentary oversight is exercised through the committee on gender issues.

\section{Gender Budgeting Practices in Saudi Arabia}

Gender Equality Commitments and Policies: As ratified by royal decree in 2000, the Kingdom of Saudi Arabia (KSA) is a signatory to the UN Convention on the Elimination of All Forms of Discrimination against Women (CEDAW). The KSA has also committed to making progress against the SDG's, including SDG 5 on Gender Equality. The World Bank report "Women, Business, and the Law 2020" recognized Saudi Arabia as one of the economies that has enacted the most reforms to enhance the legal gender equality since 2017, reflecting the large number of reforms to the legal framework that KSA has implemented in the two-year period. These measures removed restrictions on women's ability to leave the house and equalized women's right to choose a place of residency. They prohibited discrimination based on gender in employment, the dismissal of pregnant women and discrimination based on gender in accessing to credit and financial services. The decrees also introduced pension equality by equalizing the retirement ages for men and women and mandating pension care credits for maternity leave. These more recent reforms build on other changes in Saudi Arabia, which in 2015 for the first time allowed women to vote and run as candidates in municipal elections and in 2017 gave women the right to drive.

These reforms are spurred by Saudi Arabia's "Vision 2030" adopted in 2016. Vision 2030 outlines the Kingdom's general objectives, goals, and targets to become a world-class model of a successful and pioneering nation. Saudi Arabia aims to achieve its "Vision 2030" objectives through three main pillars: 1) A Vibrant Society, 2) A Thriving Economy, 3) An Ambitious Nation. Pillar two sets out a specific objective for Women focusing on 'Providing Equal Opportunities'. The goal is to increase women's participation in the workforce. The Saudi Arabian authorities have set a target to increase women's participation in the workforce from 22 percent to 30 percent by 2030. This goal is planned to be realized through a number of government programs including the national transformation program, the human capital development program and specific programs in the health and education sectors. Specific initiatives have been developed as a part of the national transformation program including promoting flexible work, providing childcare services for working women, providing leadership training and mentorship to women, supporting and facilitating transportation of women, and initiatives to protect against domestic violence. Funding allocated to each of these programs in the budget is not yet visible.

GB Legal and Institutional Framework: A legal framework for GB has not been developed however, the government has signaled its commitment towards gender equality by establishing the Family Affairs Council in 2016, which unites the efforts made by all government sectors towards the wellbeing of the 
family, proposes regulations and awareness programs, and monitors international recommendations and conventions ratified by the KSA. The Family Affairs Council works along with the Ministry of Finance, the Ministry of Labor and Social Development, the Ministry of Health and the Ministry of Education towards gender equality and women's welfare. The role of the Ministry of Finance includes developing gender performance indicators and raising awareness of GB within government agencies.

GB Public Financial Management Tools: While a comprehensive GB framework is yet to be adopted by the Saudi authorities, some elements to aid implementation of GB exist. This includes the development of disaggregated gender fiscal statistics and a program and performance-based approach to budgeting, although funding allocated to individual programs cannot yet be observed in budget documentation.

The General Authority for Statistics has begun collecting disaggregated gender statistics across a range of sectors, although they are not yet published. In addition, since 2018 an annual 'Statistical Report on the Current Status of Progress against the SDGs' has been prepared and published. The report identifies statistical indicators to track progress against SDG goals, aiming to construct a timeline for each indicator, and enable monitoring of the progress achieved. For SDG 5 this includes measuring and tracking progress made against six indicators including: age of marriage, percentage of seats occupied by women in national parliaments and local governments, percentage of women in upper and middle management positions, percentage of women who can make informed decisions about reproductive health care, who own land and who own a mobile phone. The authorities report that increasingly this disaggregated data is being used to inform policy decisions and allocate resources through the budget process. As set out above a number of polices have been developed by Saudi Authorities to support women's development, particularly to increase women's workforce participation. These policies or initiatives are linked to national strategies (Vision 2030) and operationalized by national and sectoral programs and plans. Plans have set objectives with measurable targets (at least at a high-level) and list specific initiatives that are planned to help achieve the identified objectives.

\section{Gender Budgeting Practices in South Africa}

Gender Equality Commitments and Policies: South Africa's commitment to gender equality is firmly established in the Constitution (1994). The Bill of Rights guarantees full and equal enjoyment of all rights by all genders and the protection of people against any form of discrimination on account of their gender. In addition, South Africa is a signatory to a number of international and regional commitments to gender equality and women empowerment, including the CEDAW and more recently the Southern African Development Community Protocol on Gender and Development (2012). The South African Parliament has also passed legislation that furthers the goals of gender equality, including the 'Employment Equity Act, 1998', and the 'Promotion of Equality and Prevention of Unfair Discrimination Act, 2000'.

The Commission for Gender Equality promotes gender equality through relevant legislation and monitors South Africa's compliance with regional and international conventions and standards. The Commission is accountable to the Ministry of Women and subject to the 'Public Finance Management Act 1999' as amended (PFMA) for its fiscal operations. It follows the legal framework on budgeting, reporting and transparency required by the PFMA.

Policies to enhance gender equality are embedded in ministerial and sectorial plans. The government's national development plan for gender equality is translated into the five-year strategic plan by the Ministry of Women. The Department of Monitoring and Evaluation tracks government's performance against the national development plan and the SDGs to ensure that targets are met.

GB Legal and Institutional Framework: In 2018, the Cabinet approved a comprehensive approach to GB, launching the Gender Responsive Planning, Budgeting, Monitoring, Evaluation and Auditing Framework (GRPBMEAF). The framework has strong political support and is seen as a key component to ensuring 
better outcomes for women and girls and more tangible gender impacts in South Africa. Importantly, the framework aims to integrate gender policy priorities within existing planning and medium-term budgeting frameworks at both the national and subnational level.

GB Public Financial Management Tools: In 1995, the South African Women's Budget Initiative started working on plans to promote gender budgeting as part of the work to orientate the post-apartheid resource allocation. ${ }^{106}$ The first women's budget was launched as a joint effort between civil society and Parliament in 1996. The aim of the initiative was to insert gender references into published government budgets as part of gender mainstreaming efforts. Unfortunately, the initiative did not continue after 1999.

The launch of the GRPBMEAF, has led to a gender tagging initiative, introduced in 2020, whereby departments were asked to disaggregate their spending according to gender in the Medium-Term Expenditure Framework (MTEF) budget database. This requires the relevant departments to track spending on women's economic inclusion in agricultural and economic sectors; eradication of gender-based violence in the criminal justice sector; social transformation in health and education; and monitoring of gender policies at the subnational level during budget formulation. This reform has been introduced with the 2020 budget and its success has yet to be evaluated.

South Africa has a strong tradition of Program Based Budgeting (PBB) that helps to support and identify multi-year funding allocations (including new spending programs) related to women. More detailed allocations by economic classification are provided in the Estimates of National Expenditure (ENE)—an annual publication outlining allocations per program. It also includes the requirement to report against key performance targets.

The government reported that it does not yet produce a gender budget statement and budget call circulars are not sufficiently specific when it comes to driving GB reforms. While the National Treasury issues annual guidelines requiring budgeting by program, the instructions on GB are very general and do not provide sufficient guidance to enable all gender-related spending to be captured through the chart of accounts. ${ }^{107}$ In addition, the government does not perform an ex-ante gender impact assessment during budget preparation. There is no publicly available report on in-year spending against gender related programs. Although the National Treasury publishes a monthly spending reporting per department, the spending information is at the aggregate level per department and not per program. There is no narrative explaining the deviations from budgets or the reasons for non-achievement of targets.

All departments, including the Department of Women and the Gender Commission, are subject to an annual audit including an assessment against selected performance indicators including gender targets. The Auditor-General's report is public but there are no performance reports on gender issues to date. South Africa does not perform ex-post gender impact assessments, but the Department of Women publishes reports on gender equality goals and performance targets on its website.

\section{Gender Budgeting Practices in Turkey}

Gender Equality Commitments and Policies: During the 1980s, a strong women's movement raised public awareness of violations of women's rights, especially violence against women. ${ }^{108}$ Following the ratification of international treaties, Turkey passed laws to eliminate discrimination against women in the 1990s. A law to protect survivors of domestic violence was enacted in 1998. Starting in 2000, amendments were made to the Constitution to reinforce the gender equality principle (2001, 2004 and 2010) and

\footnotetext{
${ }^{106}$ Government's Gender Responsive Budgeting Framework - Commission for Gender Equality Review of Implementation Report, Commission for Gender Equality, 2021.

107 Speech by President Ramaphosa on High level virtual G7 Partnership for African Women's Financial Inclusion - September 2020.

108 UN Women: Turkey, https://eca.unwomen.org/en/where-we-are/turkey.
} 
number of other laws were adopted and/or amended to reflect the government's commitment to the gender equality. (e.g. Civil Code (2001), Penal Code (2004), Labor Law (2003), the Law on the Establishment of the Committee on the Equality of Opportunity for Women and Men (2009). ${ }^{109}$

GB Legal and Institutional Frameworks: Turkey made a commitment to undertake GB initiatives in its 10th Development Plan. The Ministry of Women and Social Policies and focused NGOs have organized a number of activities to raise awareness of GB practices. The Turkish Grand National Assembly, with support from the UN Women, has been actively engaged in these awareness campaigns. In order to further understanding, several trainings and workshops on GB have been delivered to the senior administration of the assembly and to budgeting experts in the line ministries and public institutions.

GB Public Financial Management Tools: The Turkish Grand National Assembly has been championing gender mainstreaming and encouraging gender perspectives to be incorporated into plans, policies and budgets. The National Assembly is leading by example and the budget circular instructs departments of the Assembly to incorporate activities and projects to promote gender equality into budget proposals. Gender related performance indicators have also been incorporated into the Eleventh Development Plan 20192023. The 11th Development Plan continues GB initiatives such as awareness-raising and encourages activities that will be carried out to ensure further involvement of women in management and decisionmaking bodies in the public and private sector. The assembly conducts hearings on gender related issues and discusses the impact of the budget and tax policies on gender equality.

The Turkish budget documentation includes information on the resources allocated for women and the policies for women under the relevant public administrations. "Annual Public Investment Preparation Guide" for the period 2019-2021 requires that public investment projects should be planned and implemented in a manner that will contribute to gender-responsiveness and women's empowerment.

\section{Gender Budgeting Practices in the United Kingdom}

Gender Equality Commitments and Policies: At the national level, the Government Equalities Office (GEO) is responsible for promoting social equality and is working with the Cabinet Office to promote equality policies for people of nine protected characteristics, of which gender is one. In 2017, the GEO launched a portal, where employers that have 250 or more employees are required to submit a report on the gender pay gap of the organization. Based on the submitted data, the GEO produces a report "Reducing the gender pay gap and improving gender equality in organizations: Evidence-based actions for employers."

The UK government has further developed gender equality policies in response to the UN SDG 5, including the support for equal pay, female labor force participation, paid leave and childcare. The Equality and Human Rights Commission (EHRC), non-departmental public body established by the 'Equality Act 2006' and sponsored by the Government Equalities Office, has a mandate to protect people against discriminatory treatment and holds business and government organizations accountable for promoting and upholding equality and human rights. UK government departments are required to ensure compliance with the Public Sector Equality Duty (PSED) set out in the 'UK Government Equality Act 2010'. The Act protects people against discrimination, harassment or victimization in employment.

GB Legal and Institutional Frameworks: The United Kingdom does not have a GB initiative in place. Civil society have played a role to advocate for GB. The UK Women's Budget Group (WBG), established in 1989 as an independent UK organization, has brought together feminist activists, academics and experts, and formed a civil society platform for responding to budget statements and economic policy proposals of the government for promoting gender equality.

\footnotetext{
${ }^{109}$ Gender Budgeting Survey 2018, IMF.
} 
GB Public Financial Management Tools: Despite there being no GB initiative in place, some small elements are beginning to emerge. For example, the 2018 Budget contained some gender equality impact assessments. In 2019, a Treasury Committee of the Parliament published a 2018 budget report finding that there has been some improvement in gender impact assessments, but these assessments were not considered robust enough. The report suggested that the UK Treasury should produce and publish robust impact assessments of future budgets, including the individual tax and welfare measures contained within them.

\section{Gender Budgeting Practices in the United States}

Gender Equality Commitments and Policies: Internationally, the United States remains one of the few countries that has not endorsed the UN treaty CEDAW. However, domestically at the Federal level there is legislation and policies which include measures to promote women's political and economic leadership, healthcare and to attract women and girls to STEM fields and measures to fight violence against women and human trafficking. These policies both directly and indirectly impact gender equality. For instance, policies on equal pay for women, paid leave initiatives, policies to eliminate violence against women and support female-owned businesses aim to have an explicit impact on promoting gender equality. Policies targeted towards ensuring affordable health care, high-quality college education and securing part-time workers have implicit impacts on gender equality.

Federal laws such as the Equal Pay Act of 1963, Title VII of the Civil Rights Act of 1964, the Age Discrimination in Employment Act of 1967, the Pregnancy Discrimination Act (PDA) 1978, and Title I of the Americans with Disabilities Act of 1990 (ADA) introduced by US Equal Employment Opportunity Commission provide legal protection to the employees against discrimination at work. It is the responsibility of the US Equal Employment Opportunity Commission (EEOC) to enforce federal laws to safeguard employees from discrimination based on their gender, pregnancy, age, race and religious beliefs. At the state level, there are laws to protect against workforce discrimination in the instance of gender, age, marital status, religion, similar to the 'Federal Civil Rights Law'. These state laws are applicable to both the public and private sector. Minnesota ${ }^{110}$ is the first state to provide equal pay for state government employees and also the first to require an equal pay for all local government employees.

In June 2020, some Federal agencies including the United States Departments of Defense, Homeland Security, State, and the United States Agency for International Development (USAID) released their plans to advance the 2019 United States Strategy on Women, Peace, and Security (WPS). These plans outline steps the Federal Government is taking to enhance women's role in preventing, resolving, and recovering from conflict.

GB Legal and Institutional Frameworks: GB is not conducted at the federal level and as such there is no GB framework or supporting legal provisions. The information presented in the budget does not incorporate a gender perspective. As necessary, during the budget preparation process, discussions around gender issues are coordinated by the White House Domestic Policy Council. However, there is not currently an institution at the federal level that has taken on primary responsibility for GB reforms.

At the state/county level, the City of San Francisco is a good example of where GB has been implemented, following the CEDAW ordinance. Seven City and San Francisco have undergone a rigorous analytical process to submit gender analysis reports to the CEDAW Taskforce. The Taskforce helps to identify the potential areas to improve. Many states (40 states including DC) have an office for women's affairs, often referred to as a Women's Commission or Women's Council. Some of these committees act in an advisory

\footnotetext{
${ }^{110}$ Pay Equity: Minnesota Experience (2016) by the Legislative Office on the Economic Status of Women, Minnesota.
} 
capacity for the governor or legislature especially in areas such as the gender pay gap. These committees have no independent standing and as a result are unable to intervene in budget development.

GB Public Financial Management Tools: The United States does not have a federal GB initiative. The GPRA 2010 Modernization Act requires federal agencies to report annually on progress in meeting their strategic targets. To that end, a number of useful indicators have been developed some of which refer to gender policies, whereby there is an indicative set of data in the most relevant areas. Apart from this, the Senate has been active in discussing topics connected with the budgetary dimension of gender policies.

As noted above, there are a few instances where GB has been implemented at the subnational level, either at the State or county level. The most notable is the City of San Francisco who are applying a gender lens to budget spending but are yet to develop key performance indicators for gender related outcomes or spending.

\section{Gender Budgeting Practices in Austria}

Gender Equality Commitments and Policies: The Austrian Constitution commits of the Federation, the Lander and the municipalities to the equal standing of men and women and enshrines the advancement of equality between men and women as a key policy objective. In this vein, efforts to enhance gender equality have been taking place over many decades. An important legislative initiative was the '1979 Equal Treatment Act', that pursued the elimination of all discriminations against women working in the private sector. Numerous sectoral measures and plans have sought to eliminate specific inequalities in employment, access to qualifications, income or unpaid work. One of the most significant was the National Action Plan for Gender Equality in the Labor Market, which ended in 2018 with no follow-up strategy. Gender equality plans have predominantly been scattered across sectors, with no overarching national strategy which covers all sectors and harnesses synergies between line ministries. Looking to the future, Austria is committed to implementing the 2030 Agenda and the 17 Sustainable Development Goals, both nationally and at a global level.

GB Legal and Institutional Frameworks: GB was introduced in Austria as part of a broader fiscal reform implemented between 2009 and 2013, structured around two pillars: a medium-term budget framework and a performance management framework. Reforms in the legislative framework (articles 13 and 51(8) of the Constitution) enshrined gender equality as one integral element of budgeting and performance management respectively. For its part, the 'Federal Budget Act' enshrines gender impact assessments as part of regulatory impact assessment, and a directive specifies the content of such assessments and their materiality thresholds.

GB Public Financial Management Tools: As part of the performance management reforms all ministries and supreme organs (e.g. the constitutional court, the court of audit) define a multi-annual strategic plan and define at least one and a maximum five medium-term gender-related outcome objectives as part of the outcome and output statements. Additionally, all of these objectives include accompanying indicators and performance measures to track progress against the goals set.

The evaluation of outputs and outcomes of gender equality policies is the final and most important step of closing the policy loop of performance management in Austria. The ministries and supreme organs have to undergo a self-evaluation, which entails monitoring the performance indicators and results and describing the causal effects of implemented activities of a certain policy. The Federal Performance Management Office oversees quality of outcomes and compiles a standardized report which is submitted to Parliament and published. ${ }^{111}$

\footnotetext{
111 inwww.wirkungsmonitoring.gv.at.
} 
Regulatory impact assessments for new policies include short to medium-term outcome objectives, measures, indicators, an ex-ante assessment and ex-post evaluation of possible impacts in specific impact dimensions. The following impact dimensions are currently analyzed: Gender equality, economy as a whole, companies, environment, consumer protection policies, administrative costs for citizens and companies, social impact and children and youth. The Ministry of Finance and the Federal Ministry for Arts, Culture, Civil Service and Sport provide continued technical assistance. The evaluation of the impacts on gender equality is part of the evaluation report on regulatory impact assessments which is submitted to parliament annually.

In terms of external ex-post control, the Court of Audits is committed to undertaking gender audits according to the constitutional principles; however, there is no formal obligation to do so and the inclusion of gender aspects in audit reports is somewhat discretionary. In the last years, 55 reports had a gender component (i.e. around one fourth of total annual reports).

The accountability of the Austrian government in the area of gender is reinforced by the oversight of the national Parliament. Several committees carry out this task: (i) The Budget Committee, discusses strategic objectives and ex-post GIAs as integral part of annual budget and MTEF discussion; (ii) Sectoral committees review ex-ante GIAs of new legislation; (iii) The Gender Equality Committee reviews GIA of new legislation primarily aimed at improving gender equality, and discusses the PFMO's annual report; (iv) The Court of Audit Committee discusses audit reports with gender aspects. Further the Parliamentary Budget Office issues analyses of the annual budgets, with special emphasis on the consistency of gender objectives and indicators, and ad-hoc reports or proposals for improvement on gender-related topics, such as the comprehensiveness of gender-related documents or gender-disaggregated statistics within budget documentation.

\section{Gender Budgeting Practices in Spain}

Gender Equality Commitments and Policies: Gender equality is enshrined in the 1978 Constitution. The first plans promoting equal opportunities were produced in 1988 and the Institute for Women was created 1983, however the inflexion point in institutionalizing gender equality policies came in 2007 . The Ministry of Equality was created in 2008 and the Organic Law 3/2007 112 for the Effective Equality of Women and Men adopted an integral and modern approach. It sets the requirement for government to periodically produce a Strategic Plan on Equal Opportunities that will include cross cutting policies to achieve the objective of equality between women and men and eliminate gender discrimination (article 17) and the need to produce gender impact assessment reports for all draft regulations (article 19). According to Royal Decree $1729 / 2007$, the strategic plans are to be produced every two years and are the reference framework for all stakeholders. The plans are required to be monitored and evaluated. The current plan period is 2019-2022 and it is developed by the Ministry of Equality, mainly in collaboration with the other ministries through their Equality Units (created also by Organic Law 3/2007). Sectoral plans are also published under this reference framework. Royal Decree 1370/2007 creates the inter-ministerial commission for equality of women and men. The Parliament has a Commission on Equality in the Congress and the Senate. Spain has also committed to international treaties and conventions against any form of discrimination.

Policies that had relevant impact in the social debate include the 2004 Organic Law on integral protection against gender violence and its successive plans and policies against stereotypes. In addition, the public sector plans for gender equality in the central government served as a model for other sectors policies. Revenue policies also have a gender perspective, for instance, income tax can be declared individually (with an option of a family-based), and tax credits applied for working mothers. Expenditure policies also have played an important role in promoting women's participation in the workforce such as free education for

112 https://www.boe.es/buscar/act.php?id=BOE-A-2007-6115, https://www.boe.es/buscar/pdf/2008/BOE-A-2008-517consolidado.pdf. 
children starting at 3 years and subsidized childcare for 0-3 years and reforms in pensions and parental leave.

GB Legal and Institutional Frameworks: The above-mentioned Law 3/2007 requires that all draft regulations submitted for the approval of the Council of Ministers must incorporate a report on gender impact assessment. ${ }^{113}$ The annual Draft Budget Law is accompanied by a 'Gender Impact Report' and specific instructions for gender impact evaluations are provided in the budget circular (ministerial order of the Ministry of Finance). The Ministry of Finance coordinates the process with the Ministry of Equality and line ministries Equality Units.

GB Public Financial Management Tools: Since 2009 the annual Draft Budget Law for central government has been accompanied by a 'Gender Impact Report' (Informe de Impacto de Género). ${ }^{174}$ This report is part of the budget documents analyzed by Congress. This is the equivalent of a Gender Budget Statement and incorporates a summary of the gender impact assessments (GIA) carried out during the budget preparation process. The report explains how the budget programs contribute to the objectives of gender equality and are generally linked to the strategic plan on equal opportunities. The ex-ante GIA have to be conducted for all draft bills during the year and for the budget proposals to be included in the budget bill, to capture not only the intentional effect on gender but also the unintentional. This process relies on an institutional framework coordinated by the Ministry of Finance's state secretariat for budget, and the close collaboration of the Ministry for Women with the line ministries elaborating the GIAs for their proposed measures. The gender impact assessments and the final report are based on instructions provided by the Ministry of Finance that coordinates the process, by annual Ministerial Order, that is equivalent to a budget circular.

In Spain, the collection of data on gender-related issues is the responsibility of the National Institute of Statistics, the Institute for Women and Equal Opportunities, and also the Institute for Fiscal Studies that conducts economic studies on gender impact. Indicators and available statistics are used in the abovementioned gender impact reports. Finally, the regional and local governments can develop gender-related policy initiatives and approve their own budgets considering GB approaches. Andalusia, for example, adopted the $\mathrm{G}+$ methodology in 2007 to identify the fiscal policies with the greatest impact on improving gender equality, and introduced gender audits since 2013 (IMF 2017). ${ }^{115}$

Since the conclusion of the IMF GB survey, the Spanish authorities are taking further actions to strengthen their approach to GB. Notably the recent Ministry of Finance Order 669/2021, requires a revision to the Gender Impact Report that accompanies the General State Budget. It will going ahead include three chapters on "Reality" the current situation of women and men in Spanish society; "Representation" with the employment situation of the Spanish Public Sector according to the sex of the employees; and "Resources - Results" where the budgetary programs have been catalogued in terms of gender relevance. With the data obtained from the Ministerial Departments and Constitutional Bodies, a brief description of each program is given in terms of equality, the main lines of action envisaged in the program related to gender equality are explained, and the specific objectives and indicators in terms of equality that have been defined for the program are included. The program categorization methodology has been improved. A weighting is introduced for each of the questions that serves for the categorization of the budget program in terms of gender and a software application has been developed for data entry of the report.

\footnotetext{
${ }^{113}$ Royal Decree 931/2017 regulates the gender impact assessment report, that has to be done with the economic and budgetary impact report (memoria de análisis de impacto normativo).

${ }^{114}$ https://www.sepg.pap.hacienda.gob.es/sitios/sepg/enGB/Presupuestos/Informes/mpacto/Paginas/InformelmpactoGenero.aspx.

${ }^{115}$ Gender Budgeting in G7 Countries, IMF 2017.
} 